\title{
Peripheral Biomarkers in Repeated Ketamine Infusions Trial
}

\section{Amanda Van Geel}

A thesis submitted to the Faculty of Graduate and Post-Doctoral Affairs in partial fulfillment of the requirements for the degree of:

Master of Science

in

Neuroscience

Carleton University

Ottawa, ON

2021

(C) Amanda Van Geel, Ottawa, Canada, 2021 


\section{ABSTRACT}

Major depressive disorder (MDD) has a high prevalence among Canadians and places extensive burden on the health care system. Due to the heterogeneity of the disorder, adequate treatment is difficult, highlighting a need for new therapeutic strategies to provide symptomatic relief in individuals with treatment-resistant depression. Importantly, the novel antidepressant strategy, ketamine, has been shown to reduce depressive symptoms in a significant proportion of individuals with treatment-resistant depression. Abnormalities in the endocrine and immune systems are well documented in patients with MDD, however, the mechanisms by which repeated ketamine infusions influence these physiological systems are unclear. This study examined the effects of repeated ketamine infusions on the endocrine and immune systems using the peripheral biomarkers C-reactive protein (CRP) and cortisol. Plasma CRP and salivary cortisol were measured from biological specimens collected from participants at various time points during a repeated ketamine infusions clinical trial conducted at the Royal's Institute of Mental Health Research (IMHR) from January 2013 to December 2017. Neither plasma CRP nor salivary cortisol predicted antidepressant treatment response to ketamine. Pre-treatment plasma CRP was correlated with pre-treatment severity of depressive symptom severity and suicidal ideation severity. While both depressive symptoms and suicidal ideation were reduced with repeated ketamine treatment, there was no significant change in plasma CRP levels throughout the clinical trial. Morning salivary cortisol did change throughout the clinical trial in a sexspecific way. At baseline, males exhibited a blunted cortisol awakening response (CAR) compared to females. After ketamine treatment, males exhibited an increase in cortisol upon awakening indicating a reversal (normalization) of their blunted CAR. In contrast, females' morning cortisol output was reduced after repeated ketamine infusions. Further sex-specific 
investigation into ketamine's effect on glucocorticoid expression is needed to advance the knowledge of the underlying mechanisms of ketamine's rapid antidepressant effects to more effectively treat patients with depression. 


\section{TABLE OF CONTENTS}

ABSTRACT ii

LIST OF TABLES vi

LIST OF FIGURES vii

LIST OF ABBREVIATIONS viii

ACKNOWLEDGEMENTS

INTRODUCTION

Major Depressive Disorder 2

Common Treatment Strategies for MDD 4

Treatment-Resistant Depression 6

$\begin{array}{ll}\text { Ketamine } & 8\end{array}$

Pharmacology 8

History 9

Ketamine for Depression $\quad 10$

Ketamine Administration 12

Tolerability and Safety 13

Ketamine’s Mechanism of Antidepressant Action 15

$\begin{array}{ll}\text { Inflammation } & \mathbf{1 7}\end{array}$

Ketamine and Inflammatory Markers 18

C-reactive protein (CRP) 20

Hypothalamic-Pituitary-Adrenal (HPA) Axis 21

Cortisol and Ketamine 23

STUDY RATIONALE, RESEARCH OBJECTIVES AND HYPOTHESIS 23

Statement of Research Objectives $\quad 24$

Statement of Hypotheses $\quad 25$

METHODOLOGY $\quad 25$

Participants $\quad 25$

Inclusion and Exclusion Criteria $\quad 25$

$\begin{array}{ll}\text { Study Design } & 27\end{array}$

Drug Administration $\quad 29$

Clinical Measures $\quad 29$

Mini-International Neuropsychiatric Interview (M.I.N.I.) 29

Montgomery-Asberg Depression Rating Scale (MADRS) 30

Montgomery-Åsberg Depression Rating Scale-Suicidal Ideation (MADRS-SI) 31 
Quick Inventory of Depressive Symptomology: Self Report (QIDS-SR) 31

Biological Specimen Collection and Analysis $\quad 32$

Blood Collection $\quad 32$

Plasma CRP Analysis $\quad 32$

Saliva Collection 33

Salivary Cortisol Analysis $\quad 34$

Statistical Analysis $\quad 35$

$\begin{array}{ll}\text { RESULTS } & 37\end{array}$

Demographic and Clinical Characteristics at Baseline 37

Clinical Results $\quad 39$

Plasma C-Reactive Protein Results $\quad 40$

Baseline Plasma C-Reactive Protein $\quad 40$

Plasma C-Reactive Protein with Repeated Ketamine Infusions Treatment 45

Salivary Cortisol Results $\quad 48$

Baseline Salivary Cortisol 48

Salivary Cortisol with Repeated Ketamine Infusions Treatment 52

Biological Variables and Treatment Response 59

DISCUSSION

Summary of findings $\quad 62$

$\begin{array}{ll}\text { C-reactive Protein } & 63\end{array}$

$\begin{array}{ll}\text { Cortisol } & \mathbf{6 5}\end{array}$

Proposed mechanism for sex-specific changes in cortisol after ketamine treatment

Strengths and Limitations $\quad 71$

Strengths 71

Limitations $\quad 72$

Clinical Implications and Future Directions

$\begin{array}{ll}\text { CONCLUSION } & 75\end{array}$

REFERENCES 


\section{LIST OF TABLES}

Table 1: Demographic and clinical characteristics of study participants 38

Table 2: Plasma C-Reactive Protein (CRP) at baseline (pre-treatment) 41

Table 3: Correlation between pre-treatment demographic and clinical characteristics and $\log \mathrm{CRP}$

42

Table 4: Salivary cortisol awakening response at baseline 50

Table 5: Correlations between pre-treatment demographic and clinical characteristics and salivary cortisol awakening response $\quad 51$

Table 6: Regression coefficients ( $(3)$ for baseline biological measures predicting change in clinical variables 


\section{LIST OF FIGURES}

$\begin{array}{ll}\text { Figure 1: Study design. } & 28\end{array}$

Figure 2: Correlation between body mass index $(\mathrm{kg} / \mathrm{m} 2)$ and pre-treatment $\operatorname{logCRP}$ values 43

Figure 3: Correlation between baseline total MADRS score and pre-treatment logCRP values 44

Figure 4: Change in plasma CRP values with repeated and maintenance infusions 46

Figure 5: Change in plasma logCRP values with repeated and maintenance infusions 47

Figure 6: Baseline salivary cortisol awakening response in males $(n=12)$ and females $(n=17) 50$

Figure 7: Salivary cortisol area under the curve with respect to the ground (AUCG) throughout the clinical trial

Figure 8: Salivary cortisol area under the curve with respect to increase (AUCI) throughout the clinical trial

Figure 9: Change in salivary cortisol awakening response throughout clinical trial

Figure 10: Changes in salivary cortisol area under the curve with respect to ground (AUCG) by sex throughout the clinical trial

Figure 11: Changes in salivary cortisol area under the curve with respect to increase (AUCI) by sex throughout the clinical trial

Figure 12: Panel A. Pre-treatment $\log C R P$ values by response status (mean \pm SEM). Panel B.

Pre-treatment salivary cortisol awakening response in responders $(n=19)$ and nonresponders $(\mathrm{n}=10 ;$ mean \pm SEM) 


\section{LIST OF ABBREVIATIONS}

ACTH Adrenocorticotropic Hormone

ACPS 1-aminocylopropanecarboxylic acid

AMPA $\quad \alpha$-amino-3-hydroxy-5-methyl-4-isoxazolepropionic

ANOVA Analysis of Variance

AP-7 2-amino-7-phophonoheptanoic acid

$\mathrm{AUC}_{\mathrm{I}} \quad$ Area Under the Curve with respect to the Increase

$\mathrm{AUC}_{\mathrm{G}} \quad$ Area Under the Curve with respect to the Ground

BDNF Brain-derived Neurotrophic Factor

BMI Body Mass Index

CANMAT Canadian Network for Mood and Anxiety Treatments

CAR Cortisol Awakening Response

CBT Cognitive Behavioural Therapy

$\mathrm{CRH} \quad$ Corticotropin Releasing Hormone

CRP C-Reactive Protein

DBS Deep Brain Stimulation

DSM-IV Diagnosis and Statistical Manual of Mental Disorders, $4^{\text {th }}$ edition

DSM-5 Diagnosis and Statistical Manual of Mental Disorders, $5^{\text {th }}$ edition

DST Dexamethasone Suppression Test

ECT Electroconvulsive therapy

EDTA Ethylenediamine Tetraacetic Acid

eEF2 Eukaryotic Elongation Factor 2

ELISA Enzyme-Linked Immunosorbent Assay

FDA Food and Drug Administration

GABA Gamma Aminobutyric Acid

HPA Hypothalamic-Pituitary-Adrenal

HPG Hypothalamic-Pituitary-Gonadal

ICD-10 International Statistical Classification of Diseases and Related Health Problems-10

IFN Interferon

IL Interleukin

IMHR Institute of Mental Health Research 
MADRS Montgomery-Åsberg Depression Rating Scale

MADRS-SI Montgomery-Åsberg Depression Rating Scale-Suicidal Ideation

MAOIs Monoamine Oxidase Inhibitors

MDD Major Depressive Disorder

M.I.N.I. Mini-International Neuropsychiatric Interview

MK-801 dizolcipine

MST Magnetic Seizure Therapy

mTOR Mammalian Target of Rapamycin

NMDA N-methyl-D-aspartate

NOC Notice of Compliance

OCD Obsessive Compulsive Disorder

PCP Phencyclidine

PFC Prefrontal Cortex

PTSD Post-Traumatic Stress Disorder

QIDS-SR Quick Inventory of Depressive Symptomology: Self Report

RIA Radioimmunoassay

rTMS Repetitive Transcranial Magnetic Stimulation

SNRI Serotonin Norepinephrine Reuptake Inhibitors

SSRI Selective Serotonin Reuptake Inhibitors

TCA Tricyclic Antidepressants

tDCS Transcranial Direct Current Stimulation

TNF- $\alpha$ Tumor Necrosis Factor- $\alpha$

TRD Treatment-Resistant Depression

VNS Vagus Nerve Stimulation 


\section{ACKNOWLEDGEMENTS}

First and foremost, I would like to express my utmost gratitude to both my supervisors. Thank you to Dr. Jennifer Phillips for providing me with numerous opportunities and for spending countless hours guiding me every step of the way. Thank you to Dr. Natalina Salmaso for her continued support and encouragement over the last 4 years and for always challenging me to be a better scientist. I am incredibly fortunate to have such inspiring women as role models.

Thank you to all members of the Phillips and Salmaso lab for sharing their knowledge, providing feedback, and being a listening ear. I would like to thank Gareth Rurak and Patricia Burhunduli for acting as mentors along this journey as well as Katie Vandeloo who taught me the ropes of clinical research with unending patience. I would like to acknowledge the many people who have contributed to this project including Dr. Pierre Blier, Maria Da Silva and both past and present members of the MDRU team.

Thank you to my thesis advisory committee, Dr. Alfonzo Abizaid and Dr. Argel AguilarValles, and my internal examiner, Dr. Robert Coplan, for taking the time to read and critically examine my thesis. I would also like to thank Dr. Zachary Patterson for acting as chair of my examination board and who I have had the pleasure to work for as a teaching assistant. Thank you all for your support and flexibility in adapting to this virtual pandemic world.

Finally, I would like to thank my friends and family for their encouragement, patience and the countless hours of their lives they have spent listening to me speak about my thesis. In particular, thank you to my Dad for inspiring me to pursue academia and emulating the kind of researcher I strive to be. 


\section{INTRODUCTION}

\section{Major Depressive Disorder}

Major depressive disorder (MDD) is a common mental disorder that is both prevalent and debilitating. More than 264 million people suffer from this disorder worldwide, making it one of the leading causes of disability (James et al., 2018; World Health Organization, 2020). It affects 4.7\% of Canadians every year and $11.3 \%$ of the Canadian population have met MDD criteria at some point in their lifetime (Pearson et al., 2013). Despite advances in treatment strategies, the prevalence in Canada has not significantly changed over the last couple of decades (Patten, Williams, Lavorato, Fiest, et al., 2015). However, there is variation in reported depression prevalence between countries from $0.4 \%$ in Vietnam to $15.7 \%$ in Morocco (Rai, Zitko, Jones, Lynch, \& Araya, 2013). Taking this variance into consideration, the global prevalence is estimated to be approximately 5\% with higher rates found in Africa, the Middle East and South Asia (Ferrari et al., 2013).

Furthermore, there is a well-documented difference in prevalence of MDD between males and females. In Canada, the annual rate of depression in females is $5.8 \%$ and only $3.6 \%$ in males (Pearson et al., 2013). The disparity in prevalence between males and females is reported globally with females being 1.7 times more likely to experience MDD than males (Ferrari et al., 2013). This difference is consistent across different cultures and countries of varied socioeconomic status suggesting a biological component to the disorder (Rai et al., 2013). Accordingly, females are more vulnerable to depression during periods of sex hormone fluctuations including puberty, prior to menstruation, postpartum and perimenopause (Albert, 2015). In fact, the difference in prevalence first appears in adolescence, while preadolescent boys and girls report similar rates of depression (Cyranowski, Frank, Young, \& Shear, 2000; Nolen- 
Hoeksema \& Girgus, 1994). The sex difference is the greatest during adolescence and early adulthood and decreases with age (Patten, Williams, Lavorato, Wang, et al., 2015; Pearson et al., 2013).

The Diagnostic and Statistical Manual of Mental disorders, $5^{\text {th }}$ edition, (DSM-5) defines the diagnostic criteria for MDD (American Psychiatric Association, 2013). The symptoms include: depressed mood; diminished interest or pleasure; significant change in weight or appetite; insomnia or hypersomnia; psychomotor agitation or retardation; fatigue or loss of energy; feelings of worthlessness or excessive or inappropriate guilt; diminished ability to think or concentrate or indecisiveness; and recurrent thoughts of death or suicide. To be diagnosed with MDD one must experience at least 5 symptoms, including either depressed mood or anhedonia for a two-week period that causes significant distress or impairment (American Psychiatric Association, 2013). Using these criteria, it is possible for two people to share an MDD diagnosis without sharing a single symptom. Additionally, some symptoms are seemingly opposite: weight loss and weight gain; insomnia and hypersomnia; as well as restlessness and lethargy. A study by Fried \& Nesse (2015) found there were over a thousand unique symptom profiles in a sample of 3703 patients with depression. The heterogeneous presentations of MDD illuminate a need to examine biological correlates to better understand this multifaceted disorder. Within the symptoms of MDD, suicidal ideation is among the most concerning. Suicidal ideation is a common symptom of MDD and it can progress to suicidal plans, attempts, and death by suicide. Approximately half of Canadians with MDD experience suicidal ideation in their lifetime and 23\% report developing a suicide plan (Patten, Williams, Lavorato, Wang, et al., 2015). Comparatively, the lifetime prevalence in suicidal ideation and plans in the general Canadian population is $12 \%$ and $4 \%$ respectively (Government of Canada, 2020). Furthermore, 
people with MDD have a five times greater risk of suicide attempt with reported rates ranging from $2-71 \%$ depending on numerous factors including setting (inpatient or outpatient), income, and region (Dong et al., 2019; Nock, Hwang, Sampson, \& Kessler, 2010). In Canada, 17\% people with MDD report attempting suicide in their lifetime which is six times greater than the rate for the general Canadian population (Government of Canada, 2020; Patten, Williams, Lavorato, Wang, et al., 2015). Consequently, patients with depression are also more likely to die by suicide, with rates ranging from $2.2 \%$ in outpatient populations to $8.6 \%$ in patients with a history of hospitalization for suicide risk (Bostwick \& Pankratz, 2000).

As is the case for depression rates, there are sex differences in suicide-related outcomes as well. Death by suicide is more prevalent in males than females (Navaneelan, 2017; Nock et al., 2008) whereas suicidal ideation and behaviours including plans and attempts are more prevalent in females (Nock, Borges, Bromet, Alonso, et al., 2008; Nock, Borges, Bromet, Cha, et al., 2008). An estimated 800,000 people die by suicide every year, (World Health Organization, 2019) including 4,000 Canadians (Government of Canada, 2020) with people meeting criteria for mood disorders making up approximately half of all suicide deaths (Arsenault-Lapierre, Kim, \& Turecki, 2004; Conwell et al., 1996; Harwood, Hawton, Hope, \& Jacoby, 2001; Henriksson et al., 1993). Given the potential fatal consequences of MDD, improvement in treatment strategies to alleviate both depression and accompanying suicidal ideation are necessary to reduce the lives lost.

Common Treatment Strategies for MDD

Currently, there are diverse treatment strategies for depression including pharmacological, psychological, and neurostimulatory therapies (Gelenberg et al., 2010). The 
majority of pharmacological treatments for depression target the monoamine systems: serotonin, norepinephrine, and dopamine. This is based on the monoamine hypothesis of depression which posits that impairments in serotonin, norepinephrine, and dopamine systems contribute to the pathology of depression (Hirschfeld, 2000). This hypothesis was articulated more than 50 years ago, supported by the discovery of the antidepressant properties of agents that enhance the monoamine systems including monoamine oxidase inhibitors (MAOIs) and tricyclic antidepressants (TCAs) (Hillhouse \& Porter, 2015). Presently, MAOIs and TCAs are recommended less frequently due to their potential for serious side effects and drug interactions (Kennedy et al., 2016). Instead, the Canadian Network for Mood and Anxiety Treatments (CANMAT) recommends the use of selective serotonin reuptake inhibitors (SSRIs), serotonin norepinephrine reuptake inhibitors (SNRIs), agomelatine, bupropion, mirtazapine, and vortioxetine as first line pharmacological treatments for depression (Kennedy et al., 2016). These agents all modulate the monoamine systems in different ways: SSRIs and SNRIs increase the amount of serotonin, or serotonin and norepinephrine respectively, by blocking their reuptake (Owens, Morgan, Plott, \& Nemeroff, 1997; Wong, Horng, Bymaster, Hauser, \& Molloy, 1974); agomelatine is a serotonin antagonist that enhances norepinephrine and dopamine signalling (Millan et al., 2003); bupropion inhibits the reuptake of norepinephrine and dopamine (Stahl et al., 2004); mirtazapine acts on norepinephrine and serotonin receptors to enhance their release (Anttila \& Leinonen, 2001); and vortioxetine is a serotonin agonist, antagonist and transporter inhibitor (Bang-Andersen et al., 2011; Sanchez, Asin, \& Artigas, 2015). Additionally, psychological therapies including cognitive behavioural therapy (CBT), interpersonal therapy, and behavioural psychotherapies are recommended both on their own to treat mild depression or in adjunct to pharmacological therapies (Kennedy et al., 2016; Parikh et al., 2016). Lastly, 
electroconvulsive therapy (ECT) and repetitive transcranial magnetic stimulation (rTMS) have shown to be effective at reducing depression symptomology (Berlim, Van Den Eynde, TovarPerdomo, \& Daskalakis, 2014; Kellner et al., 2010) but are rarely recommended before pharmacological avenues have been explored (Milev et al., 2016). Despite multiple treatment options, both pharmacological and nonpharmacological, MDD remains a difficult disorder to treat due to low remission rates, high rates of relapse, and residual symptoms in treatment responders (Warden, Rush, Trivedi, Fava, \& Wisniewski, 2007).

\section{Treatment-Resistant Depression}

While treatment-resistant depression (TRD) has varying definitions, the most common definition is: failure to respond to at least two medications for depression from different pharmacological classes administered at adequate dose and duration (Gaynes et al., 2020; Souery et al., 1999). Using this definition, Rizvi et al. (2014) found that 21.7\% of MDD patients are treatment-resistant in Canada. The literature is inconclusive on the presence of sex differences in TRD. Rizvi et al. (2014) reported no difference in TRD prevalence between males and females. Contrarily, Kubitz et al. (2013) found TRD was more common among females. Oppositely, Trivedi et al. (2006) reported females having higher remission rates implying they are more treatment-responsive. In any case, there is evidence that TRD patients report lower quality of life (Johnston, Powell, Anderson, Szabo, \& Cline, 2019; Mrazek, Hornberger, Altar, \& Degtiar, 2014), longer episode duration (Kubitz et al., 2013; Rizvi et al., 2014), and more comorbid mental health disorders, specifically anxiety and personality disorders as well as comorbid chronic pain, fibromyalgia, and migraines (Ivanova et al., 2010; Souery et al., 2007). Furthermore, TRD patients are at increased risk of suicide (Souery et al., 2007) with 30\% 
reporting suicide attempt history compared to $8.4 \%$ of their non-resistant counterparts (Bernal et al., 2007; Hantouche, Angst, \& Azorin, 2010; Nelsen \& Dunner, 1995). TRD patients therefore pose an increased economic burden due to disability and increased healthcare costs (Ivanova et al., 2010; Johnston et al., 2019).

The prevalence and poor prognosis of TRD illuminates a need for novel treatment strategies for TRD. Currently, patients that do not respond to first line pharmacotherapy have several options. Firstly, they can switch to another medication for depression or add an adjunctive medication such as lithium, triiodothyronine, serotonin-dopamine antagonists, or stimulants to augment response (Gelenberg et al., 2010; Kennedy et al., 2016). This trial and error process can take many months as each medication trial is recommended to last 4-8 weeks before switching to another strategy (Gelenberg et al., 2010). Furthermore, the likelihood of remission decreases as the number of failed treatment strategies increases (Rush et al., 2006). Secondly, neurostimulatory therapies including ECT and rTMS are recommended for MDD patients that do not respond to pharmacotherapy (Milev et al., 2016). ECT has been used to effectively treat depression for decades but has many common adverse side effects including headaches, disorientation and memory loss (Geddes et al., 2003; Milev et al., 2016). While not as effective as ECT, rTMS is a novel therapy that does not cause cognitive side effects and therefore is better tolerated than ECT (Chen, Zhao, Liu, Fan, \& Xie, 2017; Serafini et al., 2015). Other neurostimulation techniques that have shown some efficacy for TRD include transcranial direct current stimulation (tDCS) (Sharafi, Taghva, Arbabi, Dadarkhah, \& Ghaderi, 2019); vagus nerve stimulation (VNS) (Berry et al., 2013); deep brain stimulation (DBS) (Berlim, McGirr, Van Den Eynde, Fleck, \& Giacobbe, 2014); and magnetic seizure therapy (MST) (Kayser et al., 2015). However, these treatments are not commonly used because more evidence into their 
efficacy and tolerability is necessary before they become recommended and widely available treatments (Milev et al., 2016). Despite existing treatment strategies, there still remains an unmet need for rapid, efficient and well-tolerated treatments for TRD. Leading to the investigation into the therapeutic agent, ketamine, whose rapid antidepressant effects in TRD patients (Berman et al., 2000; Kryst et al., 2020) have been described as the most significant discovery in the treatment of depression in the last 50 years (Duman \& Aghajanian, 2012).

\section{Ketamine}

Pharmacology

Ketamine is referred to as an NMDA receptor antagonist because its primary mechanism of action is binding to the phencyclidine (PCP) binding site on the N-methyl-D-aspartate (NMDA) glutamate receptor and blocking ion influx (Black et al., 1996; Vincent, Kartalovski, Geneste, Kamenka, \& Lazdunski, 1979; Zukin \& Zukin, 1979). Ketamine has also been shown to have effects on muscarinic and nicotinic acetylcholine receptors (Coates \& Flood, 2001; Hirota, Hashimoto, \& Lambert, 2002); cholinesterase (Schuh, 1975); opioid receptors (Hustveit, Maurset, \& Øye, 1995); dopamine receptors (Kapur \& Seeman, 2002); serotonin receptors (Kapur \& Seeman, 2002); and monoamine transporters (Nishimura et al., 1998). Due to its chiral center, ketamine has two enantiomers: $\mathrm{S}(+)$ and $\mathrm{R}(-)$ 2-(2-chlorophenyl)-2-(methylamino) cyclohexanone (Calvey, 1995). While ketamine is commonly used as a racemic mixture, some studies have investigated $\mathrm{S}$ and $\mathrm{R}$ ketamine separately and revealed differences in pharmacokinetics, pharmacodynamics and clinical effects between the two enantiomers (Muller, Pentyala, Dilger, \& Pentyala, 2016; Vollenweider, Leenders, Øye, Hell, \& Angst, 1997). Furthermore, ketamine generates multiple metabolites which are found in the bloodstream after 
an infusion, some of which have been shown to be psychoactive (Hashimoto, 2019; Zarate et al., 2012). Thus, ketamine's effects on multiple neurotransmitter systems, differences between its enantiomers and potential effects of its metabolites must be investigated to understand the full spectrum of ketamine's pharmacological effects on the brain and rest of the body.

\section{History}

Ketamine, a PCP derivative, was first discovered in the 1960's for its dissociative anesthetic properties (Domino, 2010; Domino, Chodoff, \& Corssen, 1965). In 1970, it was approved by the Food and Drug Administration (FDA) for use as an anesthetic and analgesic and remains a commonly used anesthetic for emergency procedures (Green, Roback, Kennedy, \& Krauss, 2011; U.S. Food \& Drug Administration, 1970). Shortly after its approval for clinical use, there were reports of illicit use of ketamine for its dissociative and psychedelic properties (Ahmed \& Petchkovsky, 1980; Siegel, 1978). Consequently, ketamine was classified as a controlled substance in 1999 (Drug Enforcement Agency, 1999) and remains a schedule 1 controlled drug presently in Canada meaning that it is illegal to manufacture, possess, or distribute ketamine without the proper authorization (Government of Canada, 2019). While it is speculated that some recreational users of ketamine were aware of its antidepressant properties in the 1970s and 1980s (Domino, 2010), it was not until 2000 when the first clinical trial reported the antidepressant effects of ketamine (Berman et al., 2000). Six years later, Zarate et al. (2006) replicated these initial findings, followed by numerous others: Murrough et al. (2013); Sos et al. (2013); Lapidus et al. (2014); Lenze et al. (2016); Li et al. (2016); and Singh et al. 2016. In 2019, Spravato ${ }^{\circledR}$ a nasal spray of esketamine, the s-enantiomer of ketamine, was approved by the FDA to be used in the treatment of TRD in conjunction with an oral medication for depression such as 
an SSRI or SNRI (U.S. Food \& Drug Administration, 2019). In July 2020, Spravato® became available to Canadians with TRD, following Health Canada's Notice of Compliance (NOC) indicating that it has met safety, efficacy, and quality requirements (Health Canada, 2020; Janssen, 2020).

\section{Ketamine for Depression}

Ketamine is a novel treatment strategy for depression that provides two benefits compared to traditional treatment strategies: rapid onset of antidepressant effects and higher rates of response and remission in TRD. Since the first study conducted by Berman et al. (2000), numerous trials have demonstrated ketamine's rapid antidepressant effects (Kryst et al., 2020). Meta-analyses have found that a single administration of a subanesthetic dose of ketamine causes a significant reduction of depressive symptoms that appears as early as 40-60 minutes after administration, peaks at 24 hours post-administration, and lasts approximately one week (Kishimoto et al., 2016; Kryst et al., 2020). These effects occur much faster than traditional pharmacotherapies used to treat depression which often take several weeks to be effective (Rush et al., 2006). Furthermore, the average response and remission rates 24 hours after a single administration of ketamine are approximately 54\% and 34\% respectively (Kishimoto et al., 2016). In comparison, the largest pharmacotherapy trial for depression to date, STAR*D, had a response rate of $47 \%$ and a remission rate of $27.5 \%$ with an SSRI (Trivedi et al., 2006). Since multiple studies have included patients with unipolar and bipolar depression, meta-analyses have used subgroup analysis to determine efficacy and found that a single administration of ketamine was effective at reducing depressive symptoms in both psychiatric disorders (Kryst et al., 2020; Newport et al., 2015). 
Furthermore, ketamine has a beneficial effect on suicidal ideation that is partially independent from its decrease in depressive symptoms (Wilkinson, Ballard, et al., 2018). Ketamine significantly reduces suicidal ideation 24 hours to 1 week after treatment and a significant proportion of participants were free of suicidal ideation on days 1-3 after administration (Wilkinson, Ballard, et al., 2018). Ketamine's beneficial and rapid effect on suicidal ideation holds promise for treatment of acutely suicidal patients. Similarly, ketamine is very promising for the treatment of TRD. Kryst et al. (2020) found that ketamine's antidepressant effects were more pronounced in TRD whereas the response rate for traditional pharmacotherapies for depression, generally decrease in treatment-resistant populations (Sinyor, Schaffer, \& Levitt, 2010). Another advantage of ketamine is that it's effective when used as both a monotherapy and as an adjunctive therapy (Kryst et al., 2020). This is a further benefit to patients with TRD as they are able to use ketamine as adjunctive therapy to treat residual symptoms if they are experiencing some symptom relief from their current medication. Unfortunately, the antidepressant effects of a single administration of ketamine are transient lasting only about a week with no significant benefit compared to control after 10 days postadministration (Kishimoto et al., 2016).

In order to maintain antidepressant effects, repeated administration of subanesthetic doses of ketamine can be used. The first study to report that repeated administrations of ketamine can sustain antidepressant effects was conducted by Murrough et al. (2013b). Murrough et al. (2013b) administered 6 infusions of ketamine over a 12-day period and found that not only did the repeated infusions sustain the antidepressant effects, they also delayed relapse with the median time to relapse after the last infusion being 18 days. Since then, multiple studies have replicated the finding that repeated administrations of ketamine both sustain antidepressant 
effects and extend duration of response after administration (Diamond et al., 2014; Rasmussen et al., 2013; Shiroma et al., 2014). Using the same protocol as Murrough et al. (2013b), 6 infusions over 12 days, Shiroma et al. (2014) and Zheng et al. (2018) found that repeated infusions increased participants' rates of response and remission compared to previous studies using single infusions (Kryst et al., 2020) indicating that ketamine may have cumulative antidepressant effects with repeated administrations. This has since been confirmed by the direct comparison of single and repeated infusions administered in the same patients in the current clinical trial conducted in our lab (Phillips et al., 2019). While it is evident that repeated ketamine administrations can sustain antidepressant response for 2-3 weeks (Kryst et al., 2020), more research is needed to determine how ketamine's antidepressant effects can be maintained in the long-term (Papakostas, 2020). Thus far, there is evidence that ketamine treatment at a reduced frequency (weekly or biweekly) after repeated administrations can maintain ketamine's antidepressant effects and decrease risk of relapse (Daly et al., 2019; Phillips et al., 2019).

\section{Ketamine Administration}

Varied dose, rates, and routes of drug administration of ketamine have been used for the purpose of treating depression. The most commonly administered subanaesthetic dose for the treatment of depression is $0.5 \mathrm{mg} / \mathrm{kg}$ (Andrade, 2017), although doses ranging from $0.1 \mathrm{mg} / \mathrm{kg}$ $0.75 \mathrm{mg} / \mathrm{kg}$ have been examined (Cusin et al., 2017; Lai et al., 2014; Loo et al., 2016). This dose range is still lower than the average dose used for anesthesia which is approximately $2 \mathrm{mg} / \mathrm{kg}$ (JHP Pharmaceuticals LLC, 2012; Lanning \& Harmel, 1975) and common recreational doses of 100-200mg (Weiner, Vieira, McKay, \& Bayer, 2000). Furthermore, in most clinical trials examining ketamine for the treatment of depression, intravenous ketamine is generally infused 
over a 40 minute period, thus with a slow rate of administration (Andrade, 2017). A longer duration of 100 minutes has also been used and this rate was both tolerable and effective at reducing depressive symptoms (Rasmussen et al., 2013; Vande Voort et al., 2016). On the other hand, shorter administration durations of 2-5 minutes, while effective, can cause significant adverse psychotomimetic effects (Lai et al., 2014). It follows that a faster administration rate is often used to obtain the desired dissociative and anesthetic effects for recreational or anesthetic purposes (JHP Pharmaceuticals LLC, 2012; Sassano-Higgins, Baron, Juarez, Esmaili, \& Gold, 2016). Lastly, multiple routes of ketamine administration have been explored for the treatment of depression including intranasal (Lapidus et al., 2014), oral (Irwin \& Iglewicz, 2010), sublingual (Lara, Bisol, \& Munari, 2013), subcutaneous (Loo et al., 2016), intramuscular (Chilukuri et al., 2014; Loo et al., 2016), and most commonly intravenous (Andrade, 2017). Despite these variations in dose, rate, and route of administration, many studies replicate the methodology first used by Berman and colleagues (2000): a $0.5 \mathrm{mg} / \mathrm{kg}$ dose of racemic ketamine administered intravenously for 40 minutes (Aan Het Rot et al., 2010; Murrough, Iosifescu, et al., 2013; Zarate et al., 2006).

\section{Tolerability and Safety}

While ketamine is considered safe and well-tolerated, it is not without side effects (Wan et al., 2015). The most common side effects of ketamine at subanaesthetic doses include drowsiness, dissociation, dizziness, confusion, visual disturbances, nausea, and vomiting (Berlim et al., 2014) . However, these effects are transient and often resolve within a couple hours (Aan Het Rot et al., 2010; Murrough, Iosifescu, et al., 2013; Zarate et al., 2006). Interestingly, dissociative side effects have been correlated with increased clinical efficacy after a single 
administration of ketamine (Newport et al., 2015; Sos et al., 2013; Zarate et al., 2006). Yet, these side effects decrease with repeated ketamine administrations while clinical efficacy increases (Phillips et al., 2019). Other commonly reported side effects during ketamine administration include hemodynamic changes such as elevations in blood pressure and heart rate but they also resolve within a few hours (Lapidus et al., 2014; Murrough, Iosifescu, et al., 2013; Newport et al., 2015; Zarate et al., 2006). Therefore, although there are common side effects associated with ketamine administration, they are relatively benign and transient (Fond et al., 2014; Wan et al., 2015).

Ketamine's history of abuse does raise concerns about its potential addictive properties. Thus far, there have been no reports of increased substance use in clinical trials of ketamine for depression (Wan et al., 2015). Although, there have been two case studies reporting ketamine abuse after its use for antidepressant purposes (Bonnet, 2015; Schak et al., 2016). One anesthetic nurse self-administered ketamine to cope with her depression which escalated to a ketamine addiction and one man with a history of alcohol use disorder who was prescribed ketamine for his depression used higher doses than prescribed causing significant impairment in his home and work life (Bonnet, 2015; Schak et al., 2016). These case studies highlight the importance of ketamine treatment being used as prescribed and administered under the care of a health care professional. Given ketamine's potential for abuse and dependence, the risk of addiction should be considered when administering ketamine as a treatment for depression, in particular in patients with a history of substance use disorder (Strong \& Kabbaj, 2018).

Lastly, the effects of long-term ketamine treatment for depression on health remain unknown. Evidence from chronic recreational ketamine users indicate that long-term ketamine use can adversely affect the urinary and gastrointestinal system and cognitive function (Bokor \& 
Anderson, 2014; Morgan, Muetzelfeldt, \& Curran, 2010; Sassano-Higgins et al., 2016).

However, chronic recreational ketamine users consume ketamine at much higher doses than those used to treat depression (Sassano-Higgins et al., 2016; Weiner et al., 2000), therefore it is unclear whether prolonged administration of ketamine at the clinically relevant dose for depression will induce these effects. Multiple clinical studies using subanaesthetic dose ketamine to treat depression have reported no cognitive deficits and conversely, have even found increased cognitive function correlated with the alleviation of depressive symptoms (Basso et al., 2020; Chen et al., 2018a; Zheng et al., 2019). Due to the novelty of ketamine as a treatment for depression, studies on the long-term effects of ketamine treatment are limited. Thus far, a study of over 200 participants that received ketamine treatment for over a year found that there were no additional side effects than those identified with short term use (Daly et al., 2019). Similar findings were demonstrated in a smaller sample receiving ketamine treatment for two years (Wilkinson, Katz, et al., 2018) and in a case report of a patient receiving ketamine treatment for five years (Chan et al., 2018). Thus, while current evidence indicates that the use of ketamine for depression is safe and well-tolerated, larger and longer-term studies are needed to confirm the lack of long-term adverse effects.

\section{Ketamine's Mechanism of Antidepressant Action}

In the last few decades, focus has shifted away from the monoamine hypothesis of depression as more preclinical and clinical evidence emerges implicating the glutamatergic system in the pathophysiology of depression (Mitchell \& Baker, 2010; Sanacora, Treccani, \& Popoli, 2012). Importantly, preclinical work conducted by Skolnick and colleagues in the 1990's was pivotal in discovering the role of the NMDA glutamate receptor in depressive pathology. In 
1990, Trullas and Skolnick found that NMDA receptor antagonists (2-amino-7-

phophonoheptanoic acid [AP-7], dizolcipine [MK-801], and 1-aminocylopropanecarboxylic acid [ACPS]) reduced depressive-like symptoms in mice on tests of antidepressant efficacy including the forced swim test and tail suspension test. Additionally, they found that chronic use of many of the most common treatment strategies for depression affected NMDA receptor binding, implicating the NMDA receptor as a common pathway for the therapeutic effects of depression treatment strategies (Paul, Nowak, Layer, Popik, \& Skolnick, 1994; Skolnick et al., 1996). Given this preclinical evidence, Skolnick (1999) proposed that NMDA receptor antagonists had the potential to be novel and faster-acting medications for depression which was supported one year later when Berman et al., (2000) demonstrated the rapid antidepressant effects of the NMDA receptor antagonist, ketamine.

Since the pivotal findings of the rapid antidepressive effects of ketamine and other NMDA receptor antagonists, there have been numerous studies investigating their potential mechanism of action. While the mechanism of action has not been completely elucidated, there are a couple theories explaining how NMDA receptor antagonism could induce antidepressant effects (Hermes \& Sanacora, 2016). The first theory stipulates that the antidepressant effects of NMDA antagonists are dependent on an increase in $\alpha$-amino-3-hydroxy-5-methyl-4isoxazolepropionic (AMPA) receptor activity (Aleksandrova, Phillips, \& Wang, 2017) which is supported by the finding that AMPA antagonists attenuate these effects (Maeng et al., 2008). This theory postulates that the increased AMPA receptor activity occurs as a result of NMDA receptor antagonism on inhibitory gamma aminobutyric acid (GABA) interneurons inducing an increase in glutamatergic signalling in the prefrontal cortex (PFC) (Moghaddam, Adams, Verma, \& Daly, 1997) and consequently increased AMPA receptor activity (Björkholm, Jardemark, 
Schilström, \& Svensson, 2015). Alternatively, another theory hypothesizes that the antidepressant effects are dependent on the deactivation of eukaryotic elongation factor 2 (eEF2), an enzyme that regulates protein translation, induced by NMDA receptor antagonism (Autry et al., 2011; Monteggia, Gideons, \& Kavalali, 2013). However, both theories posit that the antidepressant effects of NMDA receptor antagonists are caused by the downstream effects (either increased AMPA receptor activity or the deactivation of eEF2) on brain-derived neurotrophic factor (BDNF), mammalian target of rapamycin (mTOR) signalling pathways and the consequent increase in synaptogenesis and spine density in the PFC (Duman, Li, Liu, Duric, \& Aghajanian, 2012; N. Li et al., 2010; Monteggia et al., 2013; Naughton, Clarke, Oleary, Cryan, \& Dinan, 2014). Furthermore, recent work has highlighted the importance of eukaryotic initiation factor 4E-binding proteins (part of mTOR signalling) in ketamine's antidepressant action (Aguilar-Valles et al., 2021). However, other NMDA receptor antagonists are not as effective as ketamine at reducing depressive pathology (Newport et al., 2015), indicating a need to explore additional potential mechanisms of antidepressant action for ketamine involving other biological systems (Sanacora \& Schatzberg, 2015).

\section{Inflammation}

There is extensive data implicating inflammation in depressive pathology (Miller \& Raison, 2016). Inflammation is one of the body's immune responses to injury or infection (Lackie, 2019). While beneficial in the short-term, inflammation can become detrimental to the body if it becomes chronic (Blakemore \& Jennett, 2001). Some cytokines including interleukin-6 (IL-6), interleukin-1 $\beta$ (IL-1 $\beta$ ) and tumor necrosis factor- $\alpha$ (TNF- $\alpha$ ), promote inflammation and therefore are often used as markers of inflammation (Monastero \& Pentyala, 2017). Patients with 
MDD have been found to have elevated levels of proinflammatory cytokines (Howren, Lamkin, \& Suls, 2009; Valkanova, Ebmeier, \& Allan, 2013) indicating the presence of low-grade inflammation thought to contribute to depression (Miller, Maletic, \& Raison, 2009). Correspondingly, depression treatment strategies often reduce pro-inflammatory markers (Strawbridge et al., 2015; Więdłocha et al., 2018). Additionally, inducing inflammation in nondepressed individuals induces depressive symptoms (Bonaccorso et al., 2002; Capuron et al., 2002; Eisenberger, Inagaki, Mashal, \& Irwin, 2010; Harrison et al., 2009; Reichenberg et al., 2001) whereas anti-inflammatory treatments can reduce depressive symptoms (Köhler et al., 2014), particularly in MDD patients with elevated baseline inflammation (Raison et al., 2013). This suggests the use of inflammatory biomarkers as potential predictors of treatment response in depression (Audet \& Anisman, 2013; Lopresti, Maker, Hood, \& Drummond, 2014). Generally, higher levels of inflammatory markers are associated with non-responsiveness to pharmacotherapies for depression (Lanquillon, Krieg, Bening-Abu-Shach, \& Vedder, 2000; Strawbridge et al., 2015). However, for treatment strategies with anti-inflammatory properties elevated inflammation holds promise as a biomarker for treatment response (Hashimoto, 2015; Raison et al., 2013; Yang, Wardenaar, Bosker, Li, \& Schoevers, 2019).

\section{Ketamine and Inflammatory Markers}

Ketamine has been shown to affect multiple aspects of the immune system to prevent inflammation (Loix, De Kock, \& Henin, 2011). Interestingly, ketamine only has antiinflammatory effects when there is an inflammatory stimulus and therefore it is considered immunomodulatory, not immunosuppressive (De Kock, Loix, \& Lavand'homme, 2013). However, this information is derived from preclinical data and clinical data using anesthetic 
doses of ketamine. Thus far, clinical studies that administered single subanesthetic doses of ketamine have inconsistently found changes in inflammatory markers. Both Chen et al. (2018) and Yang et al. (2015) found that IL-6 decreased after ketamine treatment and that higher baseline IL-6 was associated with greater treatment response to ketamine. In contrast, Park et al. (2017) found that IL-6 increased after ketamine treatment and Kiraly et al. (2017) did not find baseline IL-6 to be a reliable marker for predicting treatment response. Yang et al. (2015) also found that elevated IL-1 $\beta$ and TNF- $\alpha$ predicted treatment response but again these findings were not replicated by Park et al. (2017) or Kiraly et al. (2017). Therefore, current knowledge is inconclusive on the effects of a single subanesthetic dose of ketamine on inflammatory markers and larger studies with replicated results are needed to draw conclusions (Cui et al., 2019).

There have been two studies to date that have investigated inflammatory markers after repeated ketamine infusions with conflicting results. The first study conducted by Allen et al., (2018) found that the inflammatory markers IL-6, interleukin-8 (IL-8), interleukin-10 (IL-10) and interferon- $\gamma(\mathrm{IFN}-\gamma)$ did not change with ketamine treatment and were not predictive of treatment response. Contrarily, a more recent study conducted by Zhan et al., (2020) found that IFN- $\gamma$, TNF- $\alpha$, and various interleukins including IL- 6 and IL-10 were decreased after repeated ketamine infusions. This discrepancy may be attributed to differences in pre-treatment inflammatory markers. Allen et al. (2018) found that depressed participants did not have significantly higher inflammatory markers than healthy controls prior to treatment initiation (Allen et al., 2018) whereas Zhan et al., (2020) found that inflammatory markers were correlated with depressive symptom severity. Further investigation into changes in inflammatory markers with repeated ketamine infusions is warranted with consideration of potential influence of pretreatment levels of inflammation. 
C-reactive protein (CRP)

C-reactive protein (CRP), a plasma protein produced by the liver and adipocytes in response to IL-6, TNF- $\alpha$, and IL-1 $\beta$ (Nagasawa, 2008), is widely used as a clinical marker of systemic inflammation (Aguiar et al., 2013). There is a robust association between elevated levels of CRP and MDD confirmed by a meta-analysis of 20 studies ( $p<0.0001$; Haapakoski et al., 2015). Often measured peripherally, plasma CRP is strongly correlated with CRP in the cerebrospinal fluid (CSF) in patients with MDD (Felger et al., 2020)

There is also some evidence that that ketamine may affect CRP. The addition of subanesthetic doses of ketamine was shown to decrease CRP compared to controls in patients undergoing anesthesia for cardiac surgery and emergency caesarean section (Hudetz et al., 2009; Jaya et al., 2016). Therefore, it is hypothesized that low dose ketamine treatment for depression will cause a reduction in CRP levels. Furthermore, some studies have shown that elevated CRP is predictive of treatment response for depression treatment strategies with anti-inflammatory properties (Kruse et al., 2018; Papakostas et al., 2014; Raison et al., 2013). Given the antiinflammatory properties of ketamine (Loix et al., 2011), it is hypothesized that elevated pretreatment CRP levels will also predict antidepressant response to ketamine. Thus far however, two studies have investigated the effects of a single ketamine infusion on CRP and found that there was no significant change in CRP after treatment and that CRP was not predictive of treatment response (Chen et al., 2018b; Kruse et al., 2021). However, these studies were limited as CRP levels were only examined for up to 7 days after a single ketamine infusion. Therefore, the effects of repeated ketamine infusions on CRP remain unknown. 


\section{Hypothalamic-Pituitary-Adrenal (HPA) Axis}

Chronic stress has been linked to depression in both clinical (McGonagle \& Kessler, 1990) and preclinical studies (Antoniuk, Bijata, Ponimaskin, \& Wlodarczyk, 2019). This link between chronic stress and depression has prompted investigation of the hypothalamic-pituitaryadrenal (HPA) axis. The HPA axis responds to stressors by releasing glucocorticoids (Bellavance \& Rivest, 2014). This is achieved first by the secretion of corticotropin releasing hormone (CRH) from the hypothalamus into the median eminence; consequently CRH stimulates the pituitary to secrete adrenocorticotropic hormone (ACTH); and lastly, $\mathrm{ACTH}$ stimulates the adrenal cortex to release cortisol which has widespread effects throughout the body (Ulrich-Lai and Herman, 2009). Decades of research have documented dysregulation of the HPA axis in MDD patients (Stetler \& Miller, 2011). It is hypothesized that in a subset of patients with depression, specifically melancholic depression, the HPA axis is hyperactive causing elevated levels of ACTH and cortisol (Juruena, Bocharova, Agustini, \& Young, 2018; Karlović, Serretti, Vrkić, Martinac, \& Marčinko, 2012; Pariante \& Lightman, 2008; Stetler \& Miller, 2011; M. L. Wong et al., 2000). HPA axis hyperactivity is thought to be, in part, promoted by reduced glucocorticoidmediated feedback inhibition demonstrated by non-suppression on the dexamethasone suppression test (DST; in healthy individuals dexamethasone results in a suppression of cortisol secretion) (Carson, Halbreich, Yeh, Asnis, \& Goldstein, 1988; Pariante \& Lightman, 2008).

Given the extensive effects of glucocorticoids in the body, the dysregulation of the HPA axis in depression affects other systems, including the immune system. Glucocorticoids act on almost all immune cells and exhibit both anti-inflammatory and pro-inflammatory properties (Cruz-Topete \& Cidlowski, 2014). However with chronic stress, a risk factor for MDD, the proinflammatory effects of glucocorticoids prevail resulting in low grade inflammation (Dantzer, 
2018). It is hypothesized that the lack of the anti-inflammatory effects of glucocorticoids in depression can be attributed to the loss of glucocorticoid receptor (GR) density and thus desensitization of glucocorticoid mediated feedback (Pariante \& Lightman, 2008). In summary, reduced glucocorticoid mediated feedback may promote both HPA axis hyperactivity and inflammation resulting in patients with MDD presenting with both elevated glucocorticoids and elevated inflammatory factors (Troubat et al., 2021). Furthermore, the interaction between the HPA axis and inflammatory processes is bidirectional such that inflammatory factors promote activation of the HPA axis and glucocorticoid release (Anisman, 2009; Rivest, 2010). Thus, the HPA axis and inflammatory processes both upregulate and sensitize the other which is thought to contribute depressive pathology.

The literature is inconsistent on the effects of depression treatment on the HPA axis (Schüle, 2007; McKay and Zakzanis, 2010). While some studies have shown normalization of the HPA axis with depression treatment (Nickel et al., 2003; Nikisch et al., 2005; Rota et al., 2005; Schüle et al., 2009), a review by McKay and Zakzanis (2010) found that only $46 \%$ of studies report a significant decrease in cortisol, $49 \%$ find no change, and 5\% report a significant increase. Furthermore, they found over half of depressed participants had no differences in cortisol pre-post treatment and that type of treatment and response did not significantly impact change in pre-post cortisol levels (McKay \& Zakzanis, 2010). While it is not evident that cortisol changes with antidepressant treatment, cortisol has shown value as a biomarker for treatment response in some depression treatment strategies including cortisol synthesis inhibitors and psychological therapy (Fischer, Strawbridge, Vives, \& Cleare, 2017; Lombardo et al., 2019). 


\section{Cortisol and Ketamine}

Thus far, the literature on ketamine's effects on cortisol secretion is limited. In healthy volunteers, single subanesthetic doses of ketamine significantly increased cortisol levels from 40 to 200 minutes post-infusion (Khalili-Mahani, Martini, Olofsen, Dahan, \& Niesters, 2015; Krystal et al., 1994). In another study in participants with depression, ketamine did not significantly affect cortisol awaking response one week post-infusion (Allen et al., 2018). However, in both of these studies, the participants' pre-ketamine cortisol levels were not elevated. Preclinical studies have found that ketamine normalized corticosterone (the rodent equivalent to cortisol) elevations in chronically stressed animals and had no effect on corticosterone levels of control animals (Wang et al., 2019; Zhou, Gao, Zhang, Kosten, \& Li, 2018). Therefore, it is hypothesized that ketamine treatment can normalise cortisol levels in patients with depression and HPA axis hyperactivity. This hypothesis is supported by a case study of a patient with TRD for whom ketamine treatment normalized their response to the dexamethasone suppression test (Ostroff \& Kothari, 2015). This hypothesis of reduction in cortisol levels solely in cases of pre-treatment elevation has been proposed for other treatment strategies for depression. A meta-analysis found that the change in cortisol with treatment was significantly greater in melancholic depression, a subtype of depression associated with elevated cortisol compared to other depression subtypes (Karlović et al., 2012; McKay \& Zakzanis, 2010).

\section{STUDY RATIONALE, RESEARCH OBJECTIVES AND HYPOTHESIS}

Despite numerous studies demonstrating ketamine's rapid antidepressant effects, its central mechanism of action is only partially understood. Specifically, current research is 
inconclusive on ketamine's effect on inflammatory markers and cortisol, both of which are dysregulated in depressive pathophysiology. Thus, the primary aim of this study is to investigate the effects of ketamine on peripheral biomarkers plasma CRP and salivary cortisol. Since CRP and cortisol have been shown to be elevated in patients with depression (Haapakoski et al., 2015; Stetler \& Miller, 2011), we hypothesize that repeated ketamine infusions will normalize (i.e. reduce) levels of CRP and cortisol.

Furthermore, the above review illustrated the challenges of treatment for MDD due to the heterogeneity of the disorder and low treatment response rates to treatment. Given the potential fatal consequences of MDD, it is crucial to provide rapid and effective treatment, illuminating a need for biomarkers that can predict treatment response. Thus, the secondary aim of this study is to determine if baseline levels of the peripheral biomarkers plasma CRP and salivary cortisol can predict response to repeated ketamine treatment.

Lastly, given the differences in inflammation and cortisol reported in patients with MDD described above, the tertiary aim of this study is to examine the relationship between pretreatment peripheral biomarkers and depressive symptom severity (including suicidal ideation severity).

\section{Statement of Research Objectives}

Research objective 1: Determine whether repeated ketamine infusions elicit changes in the peripheral biomarkers.

Research objective 2: Investigate if pre-treatment peripheral biomarkers predict treatment response to ketamine. 
Research objective 3: Examine the relationship between pre-treatment peripheral biomarkers and clinical symptom severity.

\section{Statement of Hypotheses}

Research hypothesis 1: Repeated ketamine treatment will decrease levels of peripheral biomarkers, plasma CRP and salivary cortisol.

Research hypothesis 2: Pre-treatment peripheral biomarkers will predict antidepressant response to repeated ketamine infusions.

Research hypothesis: Pre-treatment peripheral biomarkers will positively correlate with pretreatment depressive symptom severity and suicidal ideation severity.

\section{METHODOLOGY}

\section{Participants}

Male and female participants with treatment-resistant depression were recruited from physician referrals and media advertisements for a single center randomized controlled trial of ketamine at the Royal's Institute of Mental Health Research (IMHR), affiliated with the University of Ottawa from January 2013 to December 2017. The study protocol was approved by the Royal Ottawa Mental Health Centre Research Ethics Board.

\section{Inclusion and Exclusion Criteria}

Participants were required to meet the following inclusion criteria:

(1) Males and females between the ages of 18 and 65 years old; 
(2) Primary Axis 1 clinical diagnosis of MDD based on criteria in DSM-IV (American Psychiatric Association, 2000) and confirmed by the Mini-International Neuropsychiatric Interview (Sheehan et al., 1998);

(3) A total score of $\geq 25$ on the Montgomery-Åsberg Depression Rating Scale (MADRS) at screening and randomization with $\leq 20 \%$ improvement between two visits;

(4) Criteria met for TRD, defined as the failure to respond adequately to at least two antidepressant medication trials of different classes and two augmentation strategies at effective doses for at least 6 weeks within the current depressive episode (Sackeim, 2001) (5) Willing to remain on stable doses of concomitant psychotropic medication with no changes to treatment regimen for at least 6 weeks prior to trial and throughout trial duration

(6) Females of childbearing age must not have been pregnant (confirmed with urine pregnancy test at enrollment) and were willing to use a reliable method of birth control during the study

(7) Provision of written informed consent prior to initiation of any study-related procedures

(8) Ability to understand and comply with the requirements of the study, as judged by the investigator(s)

Participants were excluded if they met any of the following criteria:

(1) History of drug abuse or dependence as defined by DSM-IV (American Psychiatric Association, 2000) or a positive urine toxicology screen;

(2) History of mania or hypomania; 
(3) Diagnosis of DSM-IV Axis II disorder that had a major impact on subject's psychiatric status at the time of the study

(4) Depression secondary to cancer, stroke or other severe illness

(5) A body mass index (BMI) $\geq 35$

(6) Known history of intolerance or hypersensitivity to ketamine or midazolam

(7) Unwilling to maintain current antidepressant regimen at stable doses for at least 6 weeks preceding the clinical trial

(8) Unwilling to discontinue use of any narcotic for at least 5 drug half-lives prior to infusions

(9) Unwilling or unable to abstain from benzodiazepines on the day prior to the infusions (10) Females of childbearing age who were pregnant, lactating or were not willing to use a reliable method of birth control throughout study

(11) An unstable medical condition detected by physical examination, ECG, standard blood test, urinalysis or measurement of vitals

\section{Study Design}

Participants completed a three-phase clinical trial to investigate the effects of single, repeated, and maintenance ketamine infusions (Figure 1). Phase 1 of the trial consisted of a randomized, double-blind, crossover comparison of single infusions of ketamine and midazolam, a short-acting benzodiazepine serving as an active placebo control (Murrough et al., 2013). During phase 2, participants received three open-label ketamine infusions per week for two weeks (a total of 6 open-label repeated infusions). A subset of participants who met treatment response criteria ( $\geq 50 \%$ decrease in MADRS) at the end of phase 2 underwent phase 3 , 
maintenance infusions administered once weekly for four weeks (a total of 4 open-label maintenance infusions). To limit carry over of antidepressant effects, participants were required to have a relapse in their depressive symptoms (defined as a return to at least $80 \%$ of their baseline MADRS score) and to wait a minimum of 7 days between the first and second phase 1 infusions and between the final (second) phase 1 infusion and the first infusion of phase 2 .

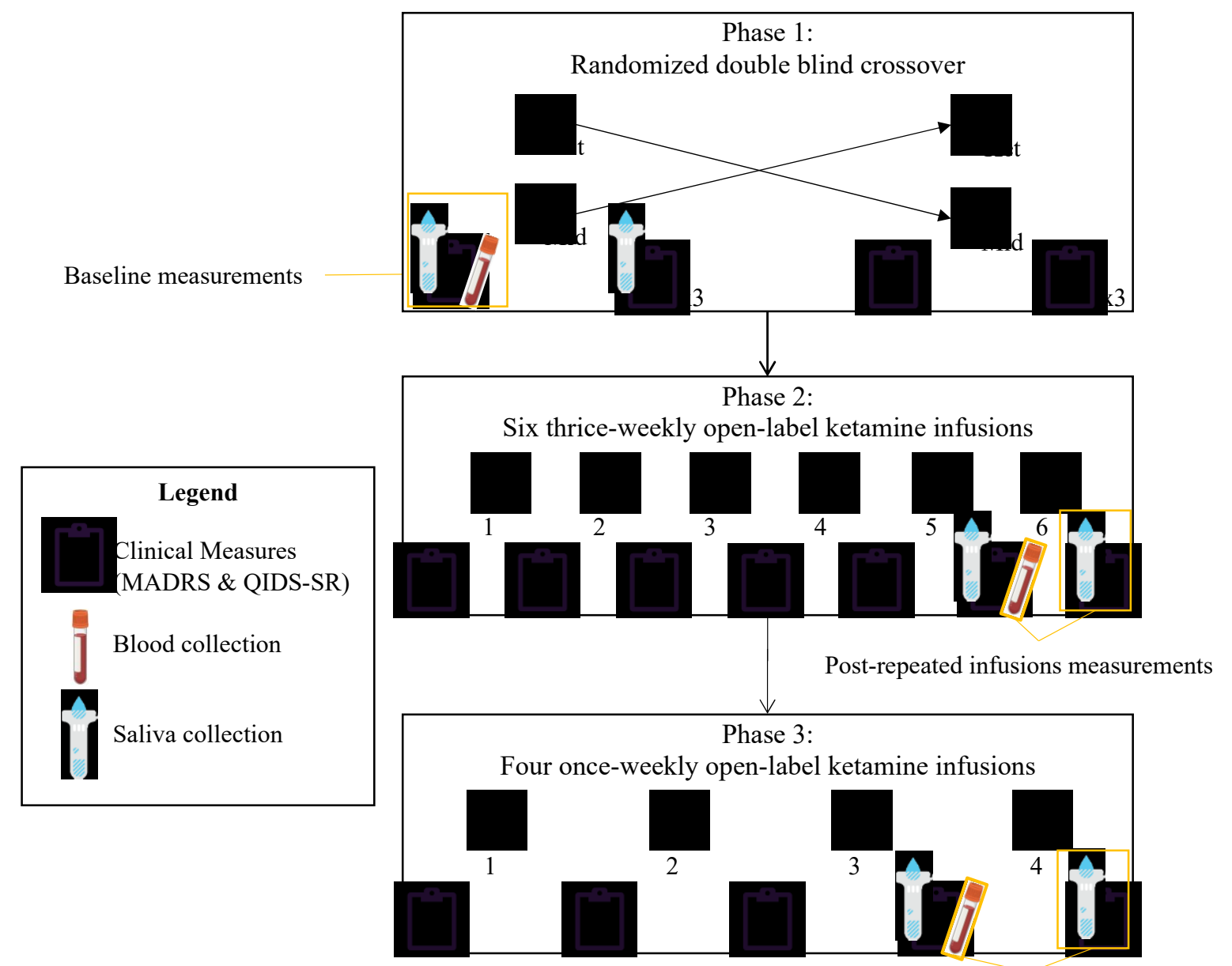

Post-maintenance infusions measurements

Figure 1: Study design. The MADRS and the Quick Inventory of Depressive Symptomology: Self Report (QIDS-SR) were completed at screening, prior to each phase 1 infusion (ketamine and midazolam), at the post-phase 2 follow-up visit ( 3 days after final phase 2 infusion) and at the post-phase 3 follow-up visit ( 3 days after final phase 3 infusion). After both phase 1 
infusions, the MADRS was administered at 2 hours, 24 hours and 7 days post-infusion and the QIDS-SR was completed 1 day, 4 days and 7 days post-infusion. Blood was collected immediately prior to the administration of the first infusion in phase 1 , the final $\left(6^{\text {th }}\right)$ infusion in phase 2 , and the final $\left(4^{\text {th }}\right)$ infusion in phase 3 . Saliva was collected the morning of and the morning after the first infusion in phase 1 , the final $\left(6^{\text {th }}\right)$ infusion in phase 2 , and the final $\left(4^{\text {th }}\right)$ infusion in phase 3.

\section{Drug Administration}

Participants avoided taking benzodiazepines for a day prior to their infusions as they attenuate ketamine response (Frye et al., 2015) and abstained from consuming grapefruit juice on infusions days as it can slow the rate of elimination of both ketamine and midazolam (Peltoniemi et al., 2012). Both ketamine and midazolam infusions were administered by a research nurse and a study physician in an outpatient setting. During phase 1, participants were randomized to receive either $0.5 \mathrm{mg} / \mathrm{kg}$ of ketamine hydrochloride or $30 \mu \mathrm{g} / \mathrm{kg}$ of midazolam, both diluted in $0.9 \%$ saline solution and administered intravenously over a 40 -minute time period by intravenous pump. Participants' blood pressure and pulse were monitored at 5-minute intervals throughout each infusion and continued until vitals returned to pre-infusion levels. During phases 2 and 3, participants received open-label ketamine treatment administered as described above.

\section{Clinical Measures}

\section{Mini-International Neuropsychiatric Interview (M.I.N.I.)}

The Mini-International Neuropsychiatric Interview (M.I.N.I.) is a short, structured diagnostic interview for DSM-IV (American Psychiatric Association, 2000) and International Statistical Classification of Diseases and Related Health Problems-10, ICD-10 (International 
Statistical Classification of Diseases and Related Health Problems-10; World Health Organization, 2004) psychiatric disorders including: MDD, mania and hypomania, panic disorder, agoraphobia, social phobia, obsessive-compulsive disorder (OCD), post-traumatic stress disorder (PTSD), alcohol dependence or abuse, substance dependence or abuse, psychotic disorders, anorexia nervosa, bulimia nervosa, generalized anxiety disorder, and antisocial personality disorder (Sheehan et al., 1998). The M.I.N.I. was administered at the screening visit by a trained mental health professional to confirm MDD diagnosis and to screen out individuals with excluding comorbid diagnoses (mania, hypomania, and history of substance abuse or dependence). In addition to measuring comorbid psychiatric conditions, the M.I.N.I. was used to assess the participants' total number of major depressive episodes and suicide attempt history.

\section{Montgomery-Åsberg Depression Rating Scale (MADRS)}

Throughout the study, the primary clinical measure for depression severity was the 10item clinician-administered Montgomery-Åsberg Depression Rating Scale (MADRS) (Montgomery \& Asberg, 1979). The MADRS contains 10 questions which assess apparent sadness, reported sadness, inner tension, reduced sleep, reduced appetite, concentration difficulties, lassitude, inability to feel, pessimistic thoughts, and suicidal thoughts. Each item is rated on a 7-point (0-6) ordinal scale where elevated scores indicate increased depressive symptoms. Scores on all 10 items are summed to determine a total MADRS score. A total MADRS score between 0-6 corresponds to absence of depressive symptoms; 7-19 corresponds to mild depressive symptoms; 20-34 corresponds to moderate depression, and $>34$ corresponds to severe depression. The MADRS has demonstrated high inter-rater reliability, validity, and sensitivity to change (Montgomery \& Asberg, 1979). Furthermore, it has been used to measure 
depressive symptom severity in previous ketamine trials for treatment-resistant depression (Lapidus et al., 2014; Murrough, Iosifescu, et al., 2013; Singh et al., 2016; Sos et al., 2013).

\section{Montgomery-Åsberg Depression Rating Scale-Suicidal Ideation (MADRS-SI)}

Item 10 on the MADRS (MADRS-SI) was used to measure suicidal ideation in this study (Montgomery \& Asberg, 1979). Using this item, the clinicians determined the participants' level of suicidal ideation and suicide plans. This item is ranked on an ordinal scale from 0-6 with the following anchor points: 0 corresponding to no suicidal ideation; 2 corresponding to fleeting suicidal thoughts; 4 corresponding to common suicidal thoughts and suicide considered a possible solution; and 6 corresponding to explicit plans and active preparations for suicide. Thus, a score $\geq 4$ on MADRS-SI is considered marked suicidal ideation as suicidal thoughts are common and/or there are specific plans.

\section{Quick Inventory of Depressive Symptomology: Self Report (QIDS-SR)}

The Quick Inventory of Depressive Symptomology: Self Report (QIDS-SR) is a 16-item self-report questionnaire used to measure depressive symptom severity (Rush et al., 2003). The 16 items addressed in this questionnaire are latency to fall asleep; sleep during the night; waking up too early; excessive sleeping; feelings of sadness; increased or decreased appetite; increased or decreased weight; concentration and decision making; self-view; thoughts of death or suicide; interest level; energy level; lethargy and restlessness. Each item is rated on an ordinal scale from 0-3 with higher scores indicating increased depressive symptoms. 


\section{Biological Specimen Collection and Analysis}

\section{Blood Collection}

Participants did not fast prior to blood collection. Blood was collected in EDTA (ethylenediamine tetraacetic acid) tubes and then set on ice. Within 30 minutes, EDTA tubes were centrifuged at $1,000 \mathrm{x}$ g for 10 minutes. Plasma from EDTA tubes were transferred into 10 aliquots of $0.5 \mathrm{ml}$. Plasma aliquots were then frozen in a $-80^{\circ} \mathrm{C}$ freezer until analysis.

\section{Plasma CRP Analysis}

Plasma concentrations of C-reactive protein were determined using commercial enzymelinked immunosorbent assay (ELISA) kits for human CRP (Invitrogen). Plasma samples were thawed immediately prior to processing. All samples were first processed as per the manufacturer's protocol (Invitrogen). Plasma samples were diluted with standard diluent buffer $(0.1 \%$ sodium azide; Invitrogen) to a dilution of $1: 3000$. Diluted samples were added to antibody coated wells (Invitrogen) for the antigen (CRP) to bind. Human CRP biotin conjugate secondary antibody (Invitrogen) was added to bind to the bound CRP. Then, streptavidin-HRP (horseradish peroxidase) was added to bind to the biotin conjugate. Tetramethylbenzidine (TMB) stabilized chromogen was added to react with the horseradish peroxidase enzyme resulting in a change in colour (450nm wavelength) that is in proportion to the bound CRP. Therefore, the amount of CRP was calculated from the intensity of the 450 wavelength measured by microtiter plate reader (FluoStar Galaxy). At the dilution in the manufacturer's protocol (1:3000; Invitrogen), the range of CRP levels that can be measured from the standard curve is $0.05 \mathrm{mg} / \mathrm{L}-3.6 \mathrm{mg} / \mathrm{L}$. However, approximately $40 \%$ of samples were above this range and samples were therefore rerun at a dilution of 1:8000 to measure CRP levels between $0.15 \mathrm{mg} / \mathrm{L}-10 \mathrm{mg} / \mathrm{L}$. Approximately $50 \%$ of the 
rerun samples (thus, $20 \%$ of the total samples) were above this range and were included in the analysis at a maximum CRP value of $10 \mathrm{mg} / \mathrm{L}$.

Samples were run in duplicates in a batch after completion of trial. Due to limited space on assay plates, multiple ELISAs were run. However, each sample from a single individual (from all time points) were run on the same plate. Mean intra-assay coefficient of variation (CV) was $6 \%$ and the mean inter-assay $\mathrm{CV}$ was $12 \%$ which is within the acceptable range (Salimetrics, 2021).

\section{Saliva Collection}

Cortisol levels vary throughout the day in a predictable circadian rhythm that includes a large cortisol increase upon awakening (Kalsbeek et al., 2012). Therefore, to encapsulate the circadian rhythm of cortisol, each day that saliva was requested participants were asked to provide 2 samples at each of the following timepoints: 1) upon waking; 2) 30 minutes after waking; and 3) 1 hour after waking. Participants were given tubes containing 1 swab labelled with each timepoint. At each timepoint, participants removed swab from the tube, chewed on swab until saturated with saliva (approximately $0.5 \mathrm{ml}$ ) and then replaced swab into tube. Participants recorded time of saliva sample collection and then brought saliva samples to the next study visit. Participants were requested not to brush their teeth, exercise and eat or drink anything (besides water) for 30 minutes prior to providing a saliva sample. Participants were required to abstain from consuming alcohol or smoking cigarettes for 12 hours prior to their sample collection. Participants were asked to avoid (or take in moderation) sugar, citric acid, and xanathine (found in caffeinated drinks and chocolate) for 24 hours prior to providing saliva sample. Saliva samples were initially stored in a $-20^{\circ} \mathrm{C}$ freezer and later transferred to a $-80^{\circ} \mathrm{C}$ freezer for long-term storage. 


\section{Salivary Cortisol Analysis}

Salivary cortisol was measured using a commercial radioimmunoassay (RIA) kit for cortisol (MP Biomedicals). Samples were thawed immediately prior to the RIA. Samples were processed as per manufacturer's protocol for saliva (MP Biomedicals). Participants' saliva and radioactive cortisol- ${ }^{125}$ I (Iodine-125) were transferred into a pre-labelled antibody-coated tubes for the antigen, cortisol (MP Biomedicals). The tubes were incubated at $37^{\circ} \mathrm{C}$ to allow the cortisol within the saliva and the cortisol- ${ }^{125}$ I to bind to the antibody. The tubes were then aspirated and the level of radiation was read by the gamma counter (Wallac Wizard 1470 automatic gamma counter by Perkin Elmer). Since the cortisol within the saliva and the cortisol${ }^{125}$ I competitively bind to the antibody, there is an inverse relationship between radioactivity and levels of salivary cortisol allowing for the calculation of salivary cortisol from the amount of radioactivity.

Due to limited space, two RIAs were run on different days after completion of the clinical trial. However, each sample from a single individual (from all time points) was run on the same day. Standard curves were run in triplicates and participants' samples were run in duplicates. The mean inter-assay CV was 5\% which is within acceptable range (Salimetrics, 2021). However, mean intra-assay $\mathrm{CV}$ was $11 \%$, slightly above the acceptable range $(<10 \%)$, which may be attributed to the viscosity of saliva increasing pipetting error (Salimetrics, 2021).

Area under the curve (AUC) was used to obtain an aggregate index of cortisol exposure for the morning (including waking, 30 minutes after waking and 60 minutes after waking). AUC was calculated with respect to the ground $\left(\mathrm{AUC}_{\mathrm{G}}\right)$ and with respect to increase $\left(\mathrm{AUC}_{\mathrm{I}}\right)$ following guidelines of Pruessner et al. (2003). $\mathrm{AUC}_{\mathrm{G}}$ was calculated using the average value of two 
consecutive timepoints multiplied by the amount of time separating the two timepoints (i.e. average of cortisol at waking and cortisol at 30 minutes post-waking multiplied by thirty minutes). This was repeated for all intervals (this study had two time intervals: 1) waking to 30 minutes after waking and 2) 30 minutes after waking to 60 minutes after waking) and the values were summed. $\mathrm{AUC}_{\mathrm{I}}$ was calculated by subtracting the product of the first measurement (cortisol at waking) by the sum of the time intervals measured (60 minutes) from $\mathrm{AUC}_{\mathrm{G}} . \mathrm{AUC}_{\mathrm{G}}$ is considered an index of overall salivary cortisol output whereas $\mathrm{AUC}_{\mathrm{I}}$ is an index of intensity of the cortisol awakening response (Jens C. Pruessner et al., 2003).

Since the saliva samples were collected in the morning upon wakening, collection was not supervised by study staff and participants were required to obtain their own samples at home. Some participants had incomplete salivary cortisol samples either due to failing to provide samples for particular time points or provided samples having insufficient saliva for the assay. Participants missing cortisol data at all time points for a particular data collection day were excluded from the analysis $(\mathrm{n}=5)$.

\section{Statistical Analysis}

Statistical analysis was performed with SPSS Statistics version 26.0. Plasma CRP levels were not normally distributed (Kolmogorov-Smirnov test for normality statistic $=.20, \mathrm{df}=43$, $\mathrm{p}<.001)$. Therefore, they were log-transformed to obtain a more normal distribution for statistical analysis (Kolmogorov-Smirnov test for normality statistic $=.12, \mathrm{df}=43, \mathrm{p}=.10$ ). Multiple imputation (MI) was used to address the missing salivary cortisol data of the included participants (Graham, 2009). MI uses the available data to input plausible data values where they are missing. Sex, age, BMI, length of depressive episode, number of treatment failures, CRP and 
pre-treatment clinical variables (MADRS, MADRS-SI and QIDS-SR), change in CRP and clinical variables post-repeated ketamine infusions (MADRS, MADRS-SI and QIDS-SR), and the available salivary cortisol data were included in the model to input the missing data values. Additionally, MI adds random error variance to mimic real data which doesn't always lie exactly on a regression line. Following Walker et al. (2010), MI was conducted in SPSS, using fully conditional specification with five iterations. Therefore, a total of five complete data sets were obtained with different plausible inputed values. Salivary cortisol results presented are pooled from the five iterations of inputed data.

Bivariate correlations (Pearson's $r$ if parametric and Spearman's $\rho$ if nonparametric) were conducted to assess the relationships between pre-treatment biological variables (plasma CRP and salivary cortisol) and pre-treatment clinical variables (MADRS, MADRS-SI and QIDS-SR). A repeated measures analysis of variance (ANOVA) was used to determine whether peripheral biomarkers, plasma CRP and salivary cortisol, change with repeated ketamine infusions with sex (male or female) and response status (responder or nonresponder to ketamine) as betweensubjects factors. A second repeated measures ANOVA was used for responders with available data from all three timepoints (pre-treatment, post-repeated infusions and post-maintenance infusions) with sex as a between-subjects factor. Pre-treatment biomarker levels of ketamine responders and nonresponders were compared using two-tailed t-tests. A linear regression was used to evaluate whether pre-treatment biomarker levels predicted changes in the clinical variables with repeated ketamine infusions (MADRS, MADRS-SI and QIDS-SR). Results were considered significant at $\mathrm{p} \leq 0.05$. 


\section{RESULTS}

\section{Demographic and Clinical Characteristics at Baseline}

The baseline (pre-treatment) data for the 43 participants ( 24 females and 19 males) randomized in this study are summarized in Table 1. Participants ranged in age from 18 to 62 years old; the mean age was $41.7(\mathrm{SD}=12.3)$ years old. On average, females were significantly older than males (two tailed t-test stat $=3.25, \mathrm{df}=41, \mathrm{p}=.002$ ). The average Body Mass Index (BMI) was $26.6 \mathrm{~kg} / \mathrm{m}^{2}(\mathrm{SD}=4.6)$ which is considered overweight (range: $25 \mathrm{~kg} / \mathrm{m}^{2}-30 \mathrm{~kg} / \mathrm{m}^{2}$ ) based on CDC guidelines (Centers for Disease Control and Prevention, 2020).

The participant sample was highly treatment resistant with an average of $6.4(\mathrm{SD}=2.5)$ total failed treatment strategies during the current MDE. 7 participants (16\%) failed to respond to ECT in their current MDE. Participants' mean pre-treatment MADRS total score was 34.7 $(\mathrm{SD}=4.2)$, ranging from 27 (in the moderate depression range, scores from 20-34), to 43 (in the severe depression range >34; Müller et al., 2003). Participants' total scores on the QIDS-SR ranged from 9 to 26 with an average score of $17.9(\mathrm{SD}=4.8)$ which corresponds to severe depression. The mean score for Item 10 of the MADRS was $3.0(\mathrm{SD}=1.4) .38$ participants $(88 \%)$ presented with presence of suicidal ideation ( $\geq 2$ on MADRS-SI) at baseline and 18 participants (42\%) had marked suicidal ideation ( $\geq 4$ on MADRS-SI; suicidal thoughts are common and/or plans and preparations for suicide). 
Table 1: Demographic and clinical characteristics of study participants

\begin{tabular}{l|lll} 
& $\begin{array}{l}\text { Total Sample } \\
(\mathrm{n}=43)\end{array}$ & $\begin{array}{l}\text { Females } \\
(\mathrm{n}=24)\end{array}$ & $\begin{array}{l}\text { Males } \\
(\mathrm{n}=19)\end{array}$ \\
\hline Age, years, mean (SD) & $41.7(12.3)$ & $46.5(9.7)^{\mathrm{a}}$ & $35.5(12.7)^{\mathrm{a}}$ \\
Body mass index, $\mathrm{kg} / \mathrm{m}^{2}$, mean (SD) & $26.6(4.6)$ & $26.7(5.1)$ & $26.4(4.0)$ \\
Major depressive episode & & & \\
$\quad$ Single, $\mathrm{n}(\%)$ & $21(49)$ & $9(38)$ & $12(63)$ \\
$\quad$ Recurrent, $\mathrm{n}(\%)$ & $22(51)$ & $15(62)$ & $7(37)$ \\
Length of current episode, years, mean (SD) & $5.6(5.7)$ & $4.8(3.9)$ & $6.8(7.3)$ \\
Total failed treatment strategies ${ }^{\mathrm{b}}$, mean (SD) & $6.4(2.5)$ & $6.0(2.0)$ & $7.0(3.0)$ \\
$\quad$ Failed antidepressant trials, mean (SD) & $3.3(1.6)$ & $3.0(1.3)$ & $3.7(1.8)$ \\
Failed augmentations, mean (SD) & $2.9(1.2)$ & $2.8(1.1)$ & $3.0(1.5)$ \\
Baseline total MADRS Score, mean (SD) & $34.7(4.2)$ & $35.1(4.3)$ & $34.3(4.1)$ \\
Baseline total QIDS-SR Score, mean (SD) & $17.9(4.8)$ & $16.7(4.8)$ & $19.3(4.5)$ \\
Baseline MADRS-SI, mean (SD) & $3.0(1.4)$ & $2.9(1.5)$ & $3.1(1.3)$ \\
Lifetime history of suicide attempt n (\%) & $10(23)$ & $8(33)$ & $2(11)$ \\
Comorbid Psychiatric Disorders & & & \\
Generalized Anxiety Disorder, n (\%) & $10(23)$ & $6(25)$ & $4(21)$ \\
$\quad$ Social Phobia, $\mathrm{n}(\%)$ & $10(23)$ & $5(21)$ & $5(26)$ \\
Agoraphobia, $\mathrm{n}(\%)$ & $10(23)$ & $5(21)$ & $5(26)$ \\
Panic Disorder, n (\%) & $4(9)$ & $2(8)$ & $2(11)$ \\
Obsessive Compulsive Disorder, n (\%) & $2(5)$ & $2(8)$ & $0(0)$ \\
Alcohol Abuse, n (\%) & $1(2)$ & $0(0)$ & $1(5)$ \\
Bulimia Nervosa, n (\%) & $1(2)$ & $1(4)$ & $0(0)$ \\
\hline
\end{tabular}

${ }^{a}$ Females significantly older than males (two tailed t-test stat $=3.245, \mathrm{df}=41, \mathrm{p}=.002$ )

${ }^{b}$ Missing failed treatment strategies data for two participants $(n=41,23$ females and 18 males) 


\section{Clinical Results}

Clinical outcomes from the trial are summarized below for reference. For more information, please refer to published works: Phillips et al., (2019) and Phillips et al., (2020). The phase 1 randomized controlled crossover comparison of ketamine and midazolam revealed that a single ketamine infusion was superior to the active control, midazolam at reducing depressive symptoms (Phillips et al., 2019) and suicidal ideation (Phillips et al., 2020). On average, participants' MADRS total scores decreased by 10.9 points $(\mathrm{SD}=8.9)$ at the primary efficacy endpoint, 24 hours after the single ketamine infusion. In phase 2, with repeated ketamine infusions there was a cumulative reduction in depressive symptoms and suicidal ideation severity. At the end of phase 2, 59\% of participants met antidepressant response criteria $(\geq 50 \%$ decrease in MADRS) and 23\% achieved remission (MADRS total score $\leq 10)$. After repeated infusions, responders had a mean MADRS total score of $11.0(\mathrm{SD}=4.8)$ compared to a pre-treatment mean MADRS total score of $34.9(\mathrm{SD}=3.2)$. Lastly, the reduction in depressive symptoms and suicidal ideation severity was maintained in responders with once weekly maintenance infusions administered in phase 3 (Phillips et al., 2019; Phillips, Norris, et al., 2020). 


\section{Plasma C-Reactive Protein Results}

\section{Baseline Plasma C-Reactive Protein}

At baseline (pre-treatment), mean plasma CRP for all study participants was $3.95 \mathrm{mg} / \mathrm{L}$ $(\mathrm{SD}=3.76, \mathrm{n}=43)$ and $47 \%$ of the sample had elevated CRP levels ( $\geq 3 \mathrm{mg} / \mathrm{L}$; Table 2$)$. Males and females did not have significantly different mean $\log C R P$ values (two-tailed t-test stat $=-.98$, $\mathrm{df}=41, \mathrm{p}=.33$; Table 2). At baseline, $\log \mathrm{CRP}$ values were significantly positively correlated with participant BMI (Pearson's r=.51, p<.001; Figure 2), depression severity measured using both the MADRS total score (Pearson's r=.51, $\mathrm{p}=.001$; Figure 3), and the QIDS-SR total score (Pearson's r=.42, p=.006), and suicidal ideation severity measured by MADRS-SI (Spearman's rho $=.479, p=.001$; Table 3). When these correlations were stratified by sex, all correlations remained significant except for logCRP and QIDS-SR. Self-reported depression severity scores on the QIDS-SR were significantly correlated with logCRP values in females (Pearson's $\mathrm{r}=.52$, $p=.009$ ) but not in males (Pearson's $r=.44, p=.06$; Table 3). However, this non-significant result may be attributable to the lower sample size of males $(n=19)$ as the correlation is trending towards significance. The positive correlation between total number of treatment failures and $\log \mathrm{CRP}$ also trends towards significance (Spearman's rho=.27 $\mathrm{p}=.07$ ). Neither participant age nor length of current MDE were significantly correlated with $\log C R P$ values (Table 3). 
Table 2: Plasma C-Reactive Protein (CRP) at baseline (pre-treatment)

Total sample $(\mathrm{N}=43) \quad$ Females $(\mathrm{n}=24) \quad$ Males $(\mathrm{n}=19)$

Plasma CRP mg/L, mean, (SD)

$3.95(3.76)$

$20(47)$

$4.38(3.83)$

$12(50)$

$3.40(3.69)$

Number of participants with

elevated CRP: >3mg/L (\%) 
Table 3: Correlations between pre-treatment demographic and clinical characteristics and $\log$ CRP

\begin{tabular}{|c|c|c|c|}
\hline & $\begin{array}{l}\text { Total Sample } \\
(\mathrm{n}=43)\end{array}$ & $\begin{array}{l}\text { Females } \\
(n=24)\end{array}$ & Males $(n=19)$ \\
\hline Age, Pearson's r (p) & $.001(.97)$ & $-.28(.19)$ & $.10(.68)$ \\
\hline BMI, Pearson's r (p) & $.51(<.001)$ & $.54(.006)$ & $.49(.033)$ \\
\hline $\begin{array}{l}\text { Length of current episode }{ }^{a} \text {, } \\
\text { Spearman's rho (p) }\end{array}$ & $-.22(.15)$ & $-.19(.37)$ & $-.22(.36)$ \\
\hline $\begin{array}{l}\text { Total failed treatment } \\
\text { strategies }^{\text {ab }} \text {, Spearman's rho (p) }\end{array}$ & $.29(.069)$ & $.40(.062)$ & $.23(.367)$ \\
\hline $\begin{array}{l}\text { Baseline total MADRS Score, } \\
\text { Pearson's } r(p)\end{array}$ & $.51(.001)$ & $.53(.008)$ & $.47(.044)$ \\
\hline $\begin{array}{l}\text { Baseline total QIDS-SR Score, } \\
\text { Pearson's } r(p)\end{array}$ & $.42(.006)$ & $.52(.009)$ & $.44(.061)$ \\
\hline $\begin{array}{l}\text { Baseline MADRS-SI', } \\
\text { Spearman's rho }(\mathrm{p})\end{array}$ & $.48(.001)$ & $.47(.022)$ & $.59(.008)$ \\
\hline
\end{tabular}




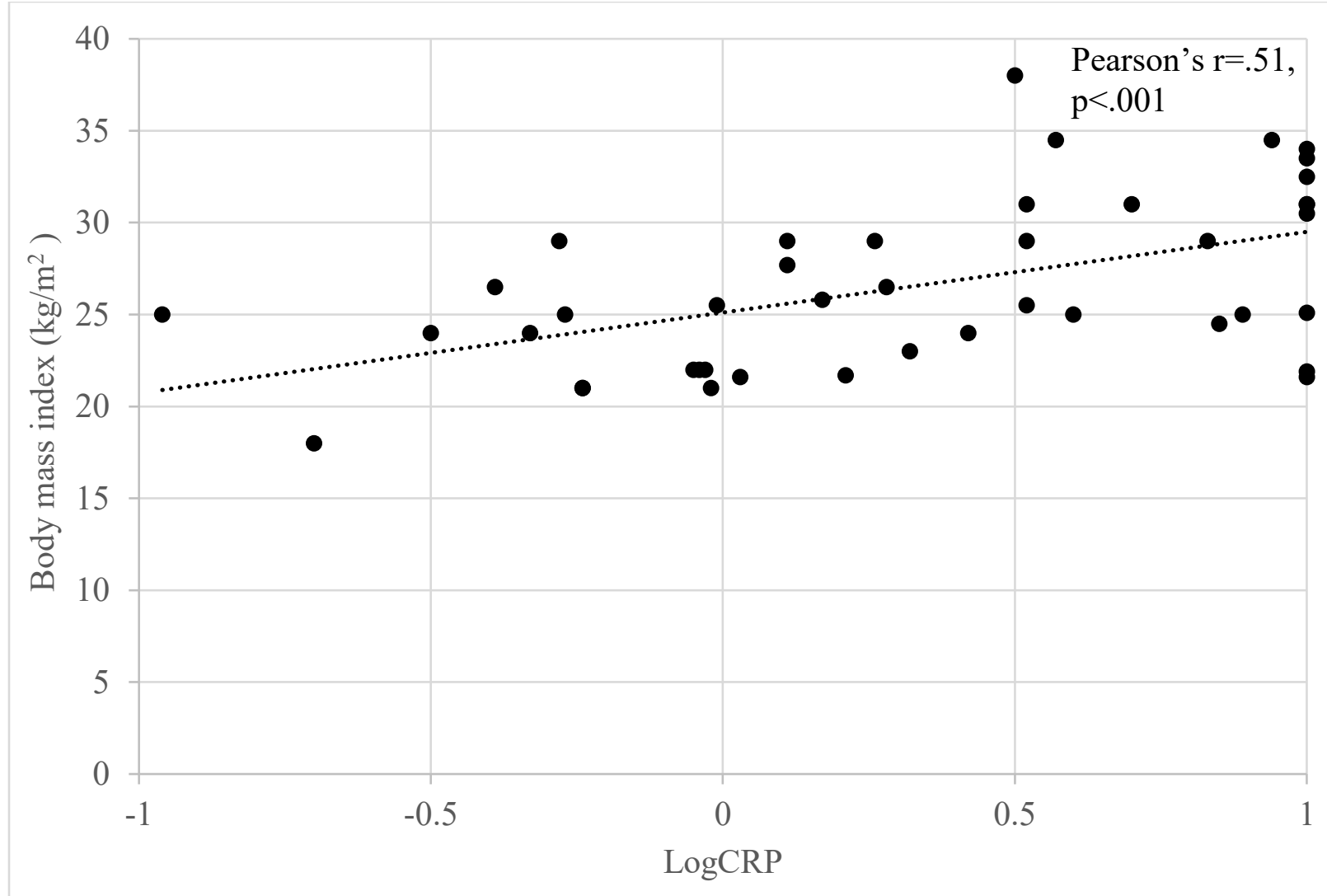

Figure 2: Correlation between body mass index $(\mathrm{kg} / \mathrm{m} 2)$ and pre-treatment $\log C R P$ values $(n=43)$ 


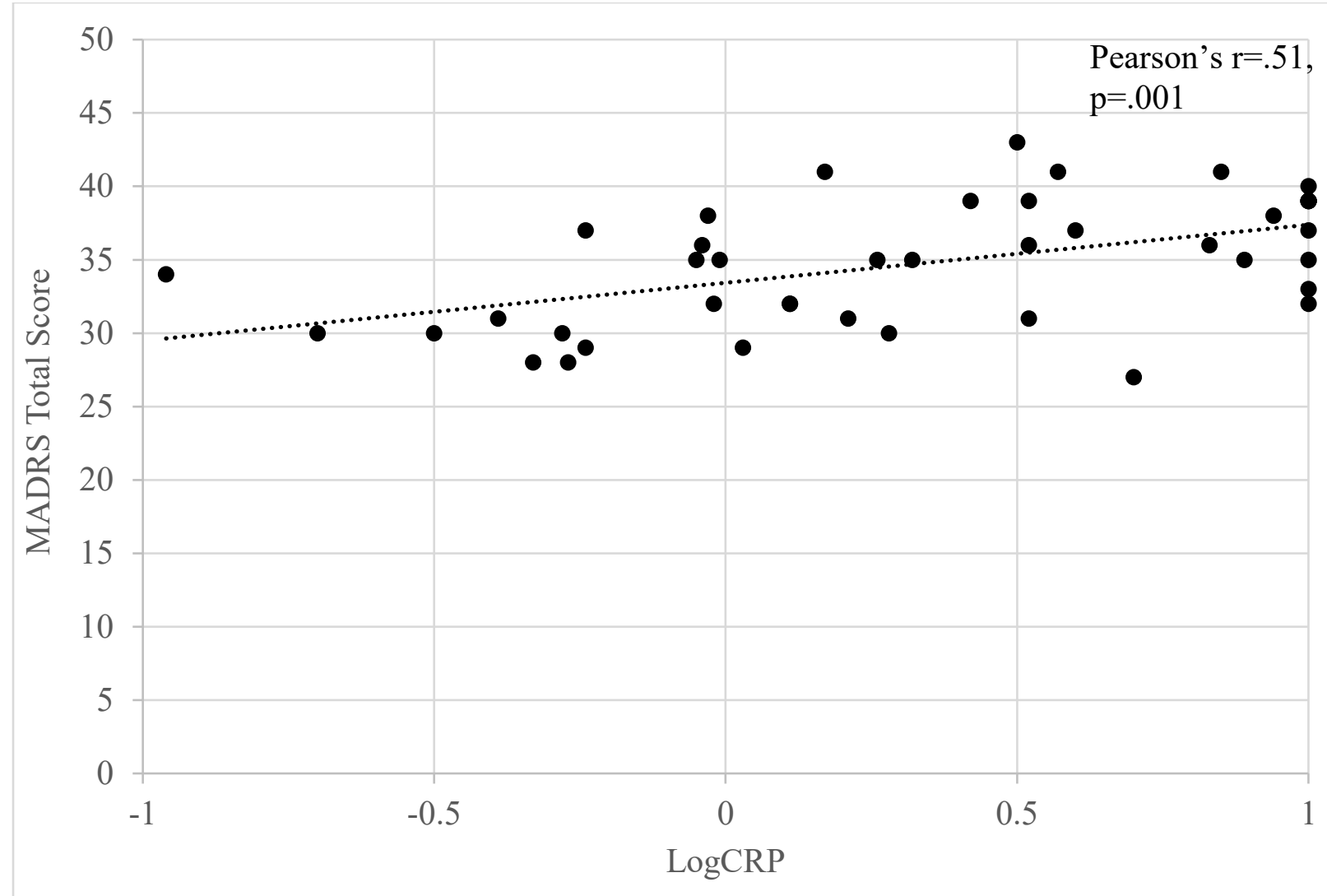

Figure 3: Correlation between baseline total MADRS score and pre-treatment $\log C R P$ values $(n=43)$ 
Plasma C-Reactive Protein with Repeated Ketamine Infusions Treatment

38 participants (23 responders and 15 nonresponders) had CRP data for the second timepoint, post-repeated ketamine infusions (39 participants completed phase 2 of clinical trial but a blood sample was not collected from 1 nonresponder). The mean plasma CRP level after repeated ketamine infusions was $4.13 \mathrm{mg} / \mathrm{L}(\mathrm{SD}=3.67$; Figure 4). CRP data was available for 21 ketamine responders for the third timepoint, post-maintenance infusions (blood samples were not collected from 2 participants). Responders' mean plasma CRP after maintenance ketamine infusions was $3.42 \mathrm{mg} / \mathrm{L}(\mathrm{SD}=3.56$; Figure 4).

In the full sample, $\log C R P$ values did not significantly change with repeated ketamine infusions (from pre-treatment through end of repeated ketamine infusions [end of phase 2], $F[1,34]=.02, p=.90 ;$ Figure 5). There were no significant main effects of $\operatorname{sex}(F[1,34]=.74$, $\mathrm{p}=.40)$ or response status $(\mathrm{F}[1,34]=.53, \mathrm{p}=.47)$ and no significant interactions between time, sex and response status on change in $\log C R P$ values $(p>.50)$.

A repeated measures ANOVA for responders that had CRP data for all three timepoints $(n=21)$, revealed no significant main effect of time on change in $\log C R P$ with repeated and maintenance infusions $(\mathrm{F}[1,19]=1.28, \mathrm{p}=.27$; Figure 5). There was also no significant main effect of sex on change in $\log C R P$ values $(F[1,19]=.49, \mathrm{p}=.49)$ and no significant interaction between time and $\operatorname{sex}(\mathrm{F}[1,19]=.90, \mathrm{p}=.36)$. 


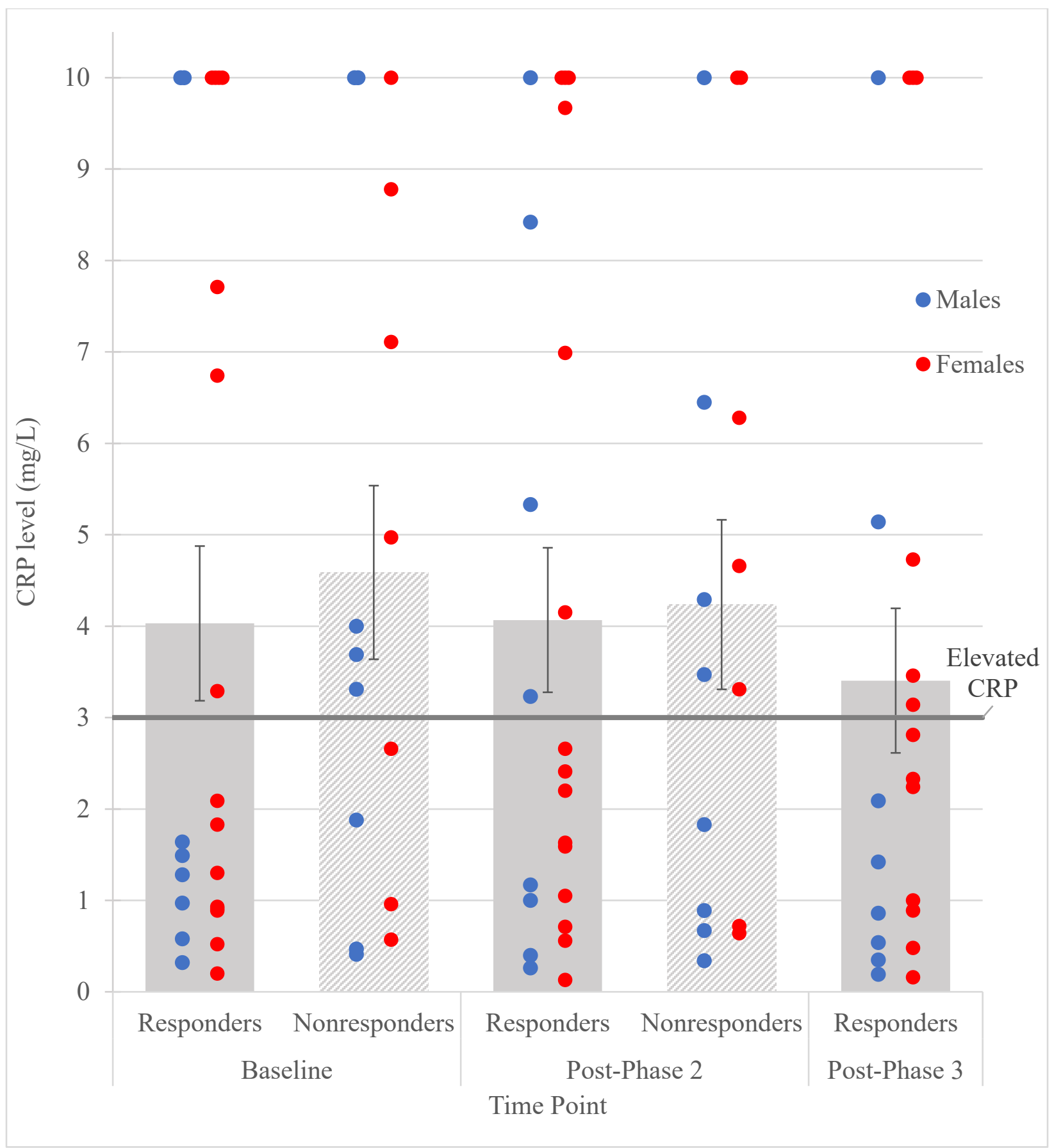

Figure 4: Change in plasma CRP values with repeated and maintenance infusions (mean $\pm \mathrm{SEM}$ ) 


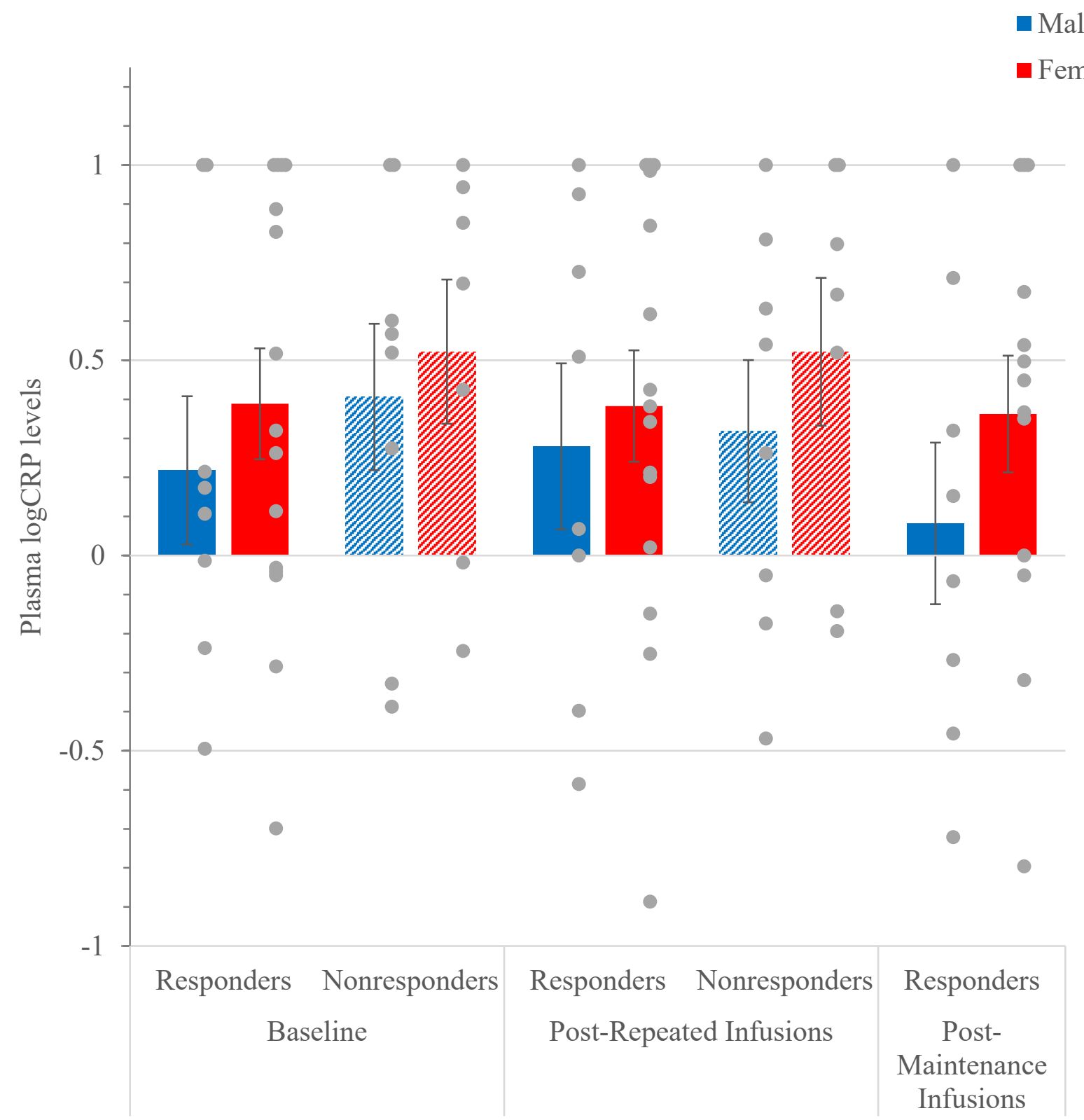

Figure 5: Change in plasma $\log C R P$ values with repeated and maintenance infusions (mean \pm SEM) 


\section{Salivary Cortisol Results}

\section{Baseline Salivary Cortisol}

From collected salivary cortisol samples, useable data from 29 participants were included in this analysis (19 responders and 10 nonresponders). 21 participants had complete salivary cortisol data for all time points while 8 participants were missing at least one data point. In total, 14 missing data points were inputed using multiple imputations $(6.1 \%$ of the salivary cortisol data set). Participants included in the salivary cortisol analysis did not significantly differ from the full trial sample by sex (Pearson Chi-Square $=.29, \mathrm{p}=.59$ ) or response status (Pearson ChiSquare $=2.77, p=.10$ ). Furthermore, representation of males and females did not significantly differ between responders and nonresponders included in the salivary cortisol analysis (Pearson Chi-Square $=.01, \mathrm{p}=.91)$.

At baseline, salivary cortisol $\mathrm{AUC}_{\mathrm{G}}$ did not significantly differ between males and females $\left(\mathrm{t}=-1.26, \mathrm{p}=.21\right.$, Table 4). However, salivary cortisol $\mathrm{AUC}_{\mathrm{I}}$ was significantly greater in females than in males ( $\mathbf{t = 2 . 2 5}, \mathbf{p}=\mathbf{. 0 2 4}$; Table 4). Therefore, while overall pre-treatment morning salivary cortisol output did not differ between the sexes, the sex difference in $\mathrm{AUC}_{\mathrm{I}}$ indicates females had a stronger intensity of cortisol awakening response (Figure 6). At baseline, salivary cortisol measures $\left(\mathrm{AUC}_{\mathrm{G}}\right.$ and $\left.\mathrm{AUC}_{\mathrm{I}}\right)$ were not significantly correlated with depressive symptom severity measured with MADRS or QIDS-SR total scores (Table 5). There was a negative correlation between salivary cortisol $\mathrm{AUC}_{\mathrm{G}}$ and suicidal ideation severity (MADRS-SI) that trended toward significance (Spearman's rho=-.35, p=.07). Salivary cortisol $\mathrm{AUC}_{\mathrm{I}}$ was not correlated with suicidal ideation (MADRS-SI; Spearman's rho=.07, $\mathrm{p}=.74$ ). Salivary cortisol $\mathrm{AUC}_{\mathrm{I}}$ was positively correlated with age (Pearson's $\mathrm{r}=.39, \mathrm{p}=.04$; Table 5) yet this correlation did not remain significant when stratified by sex (males: Pearson's $r=.34, p=.30$; females: 
Pearson's $\mathrm{r}=.18, \mathrm{p}=.49$ ). Finally, there was a negative correlation between salivary cortisol $\mathrm{AUC}_{\mathrm{G}}$ and failed treatment strategies that trended towards significance (Spearman's rho=-.35, $\mathrm{p}=.07$; Table 5). 


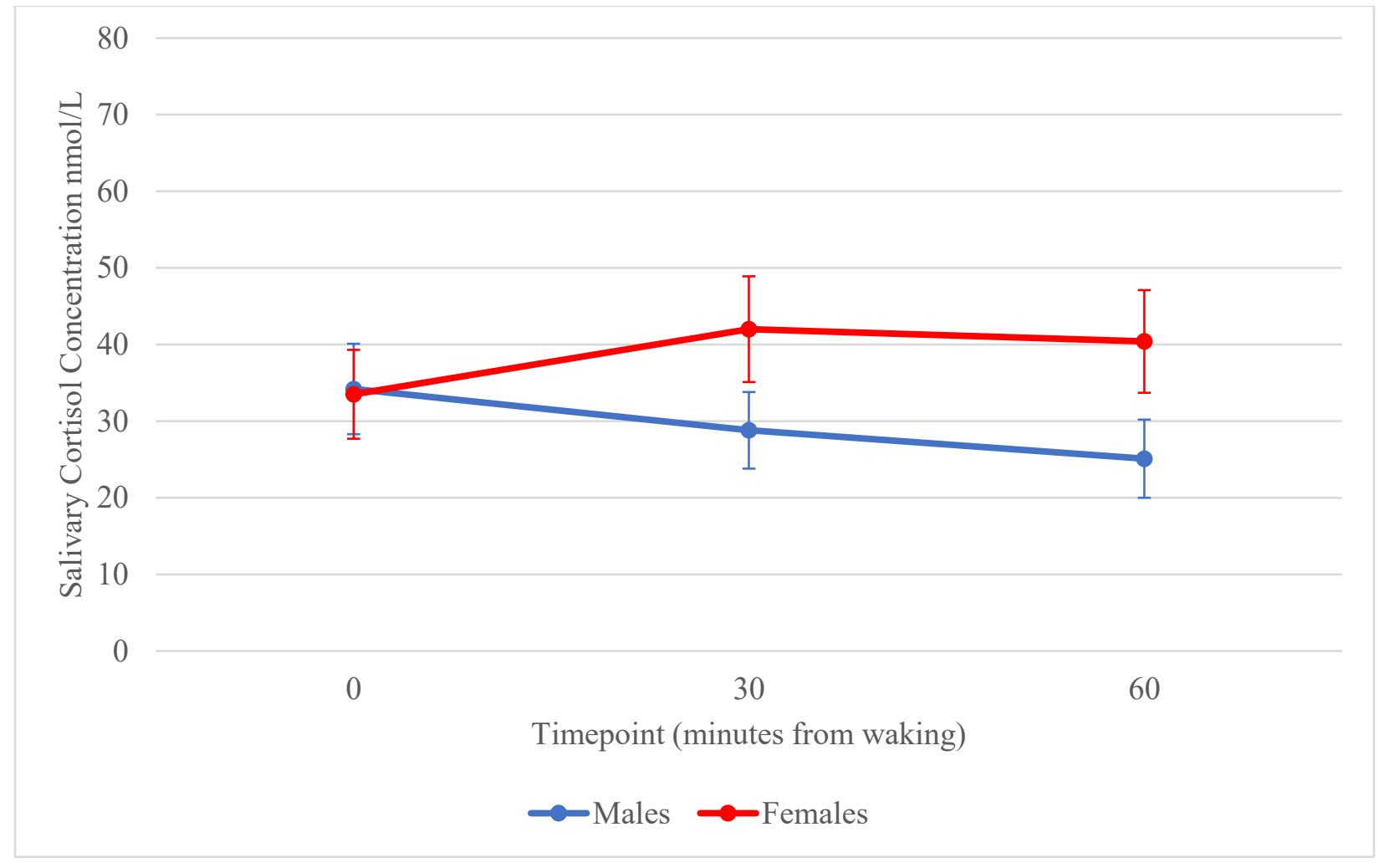

Figure 6: Baseline salivary cortisol awakening response in males $(\mathrm{n}=12)$ and females $(\mathrm{n}=17)$ (mean \pm SEM)

Table 4: Salivary cortisol awakening response at baseline

\begin{tabular}{l|lll} 
& Total sample $(\mathrm{N}=29)$ & Females $(\mathrm{n}=17)$ & Males $(\mathrm{n}=12)$ \\
\hline $\boldsymbol{A} \boldsymbol{U C}_{\boldsymbol{G}}$, mean $(\mathrm{SEM})$ & $2115.7(244.3)$ & $2371.2(360.5)$ & $1753.8(281.1)$ \\
$\boldsymbol{A U} \boldsymbol{C}_{\boldsymbol{I}}$, mean (SEM) & $87.5(153.1)$ & $358.3(199.0)^{*}$ & $-296.1(199.2)^{*}$
\end{tabular}

*Females had significantly higher salivary cortisol $\mathrm{AUC}_{\mathrm{I}}(\mathrm{t}=2.25, \mathrm{p}=.024)$ 
Table 5: Correlations between pre-treatment demographic and clinical characteristics and salivary cortisol awakening response

Age, Pearson's r (p)

BMI, Pearson's $r(p)$

Total sample $(n=29)$

$A U C_{G} \quad A U C_{I}$
$.10(.61) \quad \mathbf{3 9}(\mathbf{0 4})$

Length of current episode ${ }^{a}$, Spearman's rho (p)

Total failed treatment strategies ${ }^{\mathrm{ab}}$, Spearman's rho (p)

$-.29(.13) \quad-.27(.15)$

$-.16(.40) \quad .07(.72)$

$-.35(.07) \quad-.26(.19)$

Baseline total MADRS Score, Pearson's $r(p)$

$-.16(.24) \quad .28(.14)$

Baseline total QIDS-SR Score, Pearson's $r(p)$

$.02(.91) \quad .07(.72)$

Baseline MADRS-SI ${ }^{\mathrm{a}}$, Spearman's rho (p)

$-.35(.07) \quad .07(.74)$

${ }^{a}$ Variable not normally distributed (Kolmogorov-Smirnof test of normality significant at $p<.05$ ), therefore Spearman's rho was used

${ }^{b}$ Missing failed treatment strategies data for one participant ( $\mathrm{n}=28,17$ females and 11 males) 


\section{Salivary Cortisol with Repeated Ketamine Infusions Treatment}

29 participants (19 responders and 10 nonresponders) had salivary cortisol data at the baseline and post-repeated infusions timepoints. Additionally, 18 responders had salivary cortisol data at the post-maintenance infusions timepoint (one responder failed to provide saliva samples after maintenance infusions).

In the full sample, salivary cortisol $\mathrm{AUC}_{\mathrm{G}}$ did not significantly change from baseline to post-repeated infusions (baseline mean $=2115.7, \mathrm{SEM}=244.3$; post-repeated infusions mean=1812.2, SEM=256.3; F[1,25]<.15, p >.71; Figure 7). For antidepressant responders with available data for all three timepoints, there was a significant main effect of time on salivary cortisol $\mathrm{AUC}_{\mathrm{G}}$ values $(\mathrm{F}[1,16]>5.57, \mathrm{p}<.032$; Figure 7). Post-hoc pairwise comparisons found that post-maintenance infusions cortisol $\mathrm{AUC}_{\mathrm{G}}$ was significantly greater than post-repeated infusions cortisol $\mathrm{AUC}_{\mathrm{G}}$ (mean difference=725.72, $\mathrm{p}=.028$ ).

From baseline to post-repeated infusions, there was an increase in salivary cortisol $\mathrm{AUC}_{\mathrm{I}}$ that trended towards significance (baseline mean=87.5, SEM=153.1; post-repeated infusions mean $=347.5, \mathrm{SEM}=137.6 ; \mathrm{F}[1,25]>3.44, \mathrm{p}<.08)$. However, this increase was greater in nonresponders than responders (Figure 8). Therefore, in the second repeated measures ANOVA examining responders with data from all three timepoints $(n=18)$, the change in salivary cortisol $\mathrm{AUC}_{\mathrm{I}}$ throughout the clinical trial was not statistically significant $(\mathrm{F}[1,16]<1.73, \mathrm{p}>.20$; Figure 8).

In the repeated measures ANOVAs, sex and response status (where applicable) were examined as between-subjects factors. Salivary cortisol awakening response by sex and response status at each time point throughout the clinical trial are presented in Figure 9. There were no significant main effects of sex or response status on change in cortisol ( $\mathrm{p}>.05)$; however, there 
were significant sex by time interactions. There was a significant sex by time interaction for cortisol $\mathrm{AUC}_{\mathrm{G}}$ from baseline to post-repeated infusions $(\mathrm{F}[1,25]>5.97, \mathrm{p}<.03$; Figure 10). Such that, males' cortisol $\mathrm{AUC}_{\mathrm{G}}$ increased by $23 \%$ after repeated infusions (baseline mean=1754, $\mathrm{SEM}=281$; post-repeated infusions mean=2166, $\mathrm{SEM}=529$ ) and females' cortisol $\mathrm{AUC}_{\mathrm{G}}$ decreased by $34 \%$ (baseline mean $=2371, \mathrm{SEM}=360$; post-repeated infusions mean $=1562$, SEM=225). In responders with all three timepoints, the sex by time interaction trended towards significance $(F[1,16]>3.8, p<.07$; Figure 10).

Additionally, there was a sex by time interaction for cortisol $\mathrm{AUC}_{\mathrm{I}}$ trending towards significance from baseline to post-repeated infusions $(\mathrm{F}[1,25]>3.37, \mathrm{p}<.08)$. In responders with all three time points, the sex by time interaction was significant $(\mathrm{F}[1,16]>5.82, \mathrm{p}<.03)$. Salivary cortisol $\mathrm{AUC}_{\mathrm{I}}$ increased in males and decreased in females (Figure 11). In males, baseline CAR salivary cortisol concentration decreased by $16 \%$ (mean difference $=-5.3 \mathrm{nmol} / \mathrm{L}$, $\mathrm{SEM}=5.1 \mathrm{nmol} / \mathrm{L}$ ) from waking to 30 minutes post-waking. After repeated infusions, they had an increase of $42 \%$ (mean difference $=12.4 \mathrm{nmol} / \mathrm{L}, \mathrm{SEM}=6.4 \mathrm{nmol} / \mathrm{L}$ ) from waking to 30 minutes post-waking and after maintenance infusions, salivary cortisol concentrations increased $111 \%$ (mean difference $=32.3 \mathrm{nmol} / \mathrm{L}, \mathrm{SEM}=13.1 \mathrm{nmol} / \mathrm{L}$ ) from waking to 30 minutes post-waking (Figure 9B). Overall, these data suggest a strengthening of the cortisol awakening response with ketamine treatment. In females, the difference in salivary cortisol concentration from waking to 30 minutes decreased by a smaller magnitude than the increase observed in the males, increasing by $25 \%$ (mean difference $=8.5 \mathrm{nmol} / \mathrm{L}, \mathrm{SEM}=4.2 \mathrm{nmol} / \mathrm{L}$ ), $25 \%$ (mean difference $=5.2 \mathrm{nmol} / \mathrm{L}$, $\mathrm{SEM}=3.2)$ and $18 \%$ (mean difference $=6.0 \mathrm{nmol} / \mathrm{L}, \mathrm{SEM}=7.1)$ at baseline, post-repeated infusions and post-maintenance infusions respectively (Figure 9C). There were no significant interactions with response status $(\mathrm{p}>.05)$. 


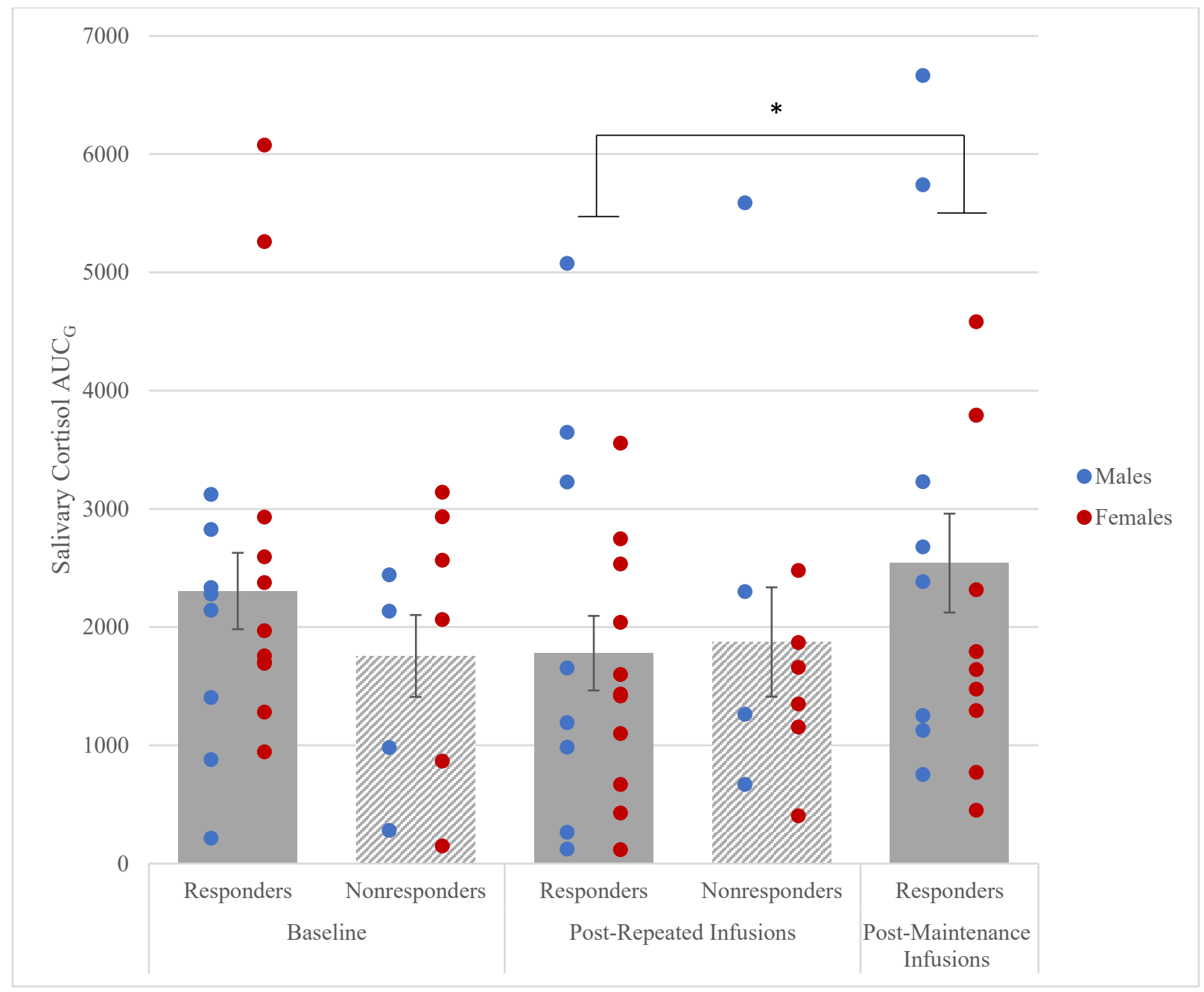

Figure 7: Salivary cortisol area under the curve with respect to the ground $\left(\mathrm{AUC}_{\mathrm{G}}\right)$ throughout the clinical trial (mean \pm SEM) *Significant at $\mathrm{p}<.0 .05$ 


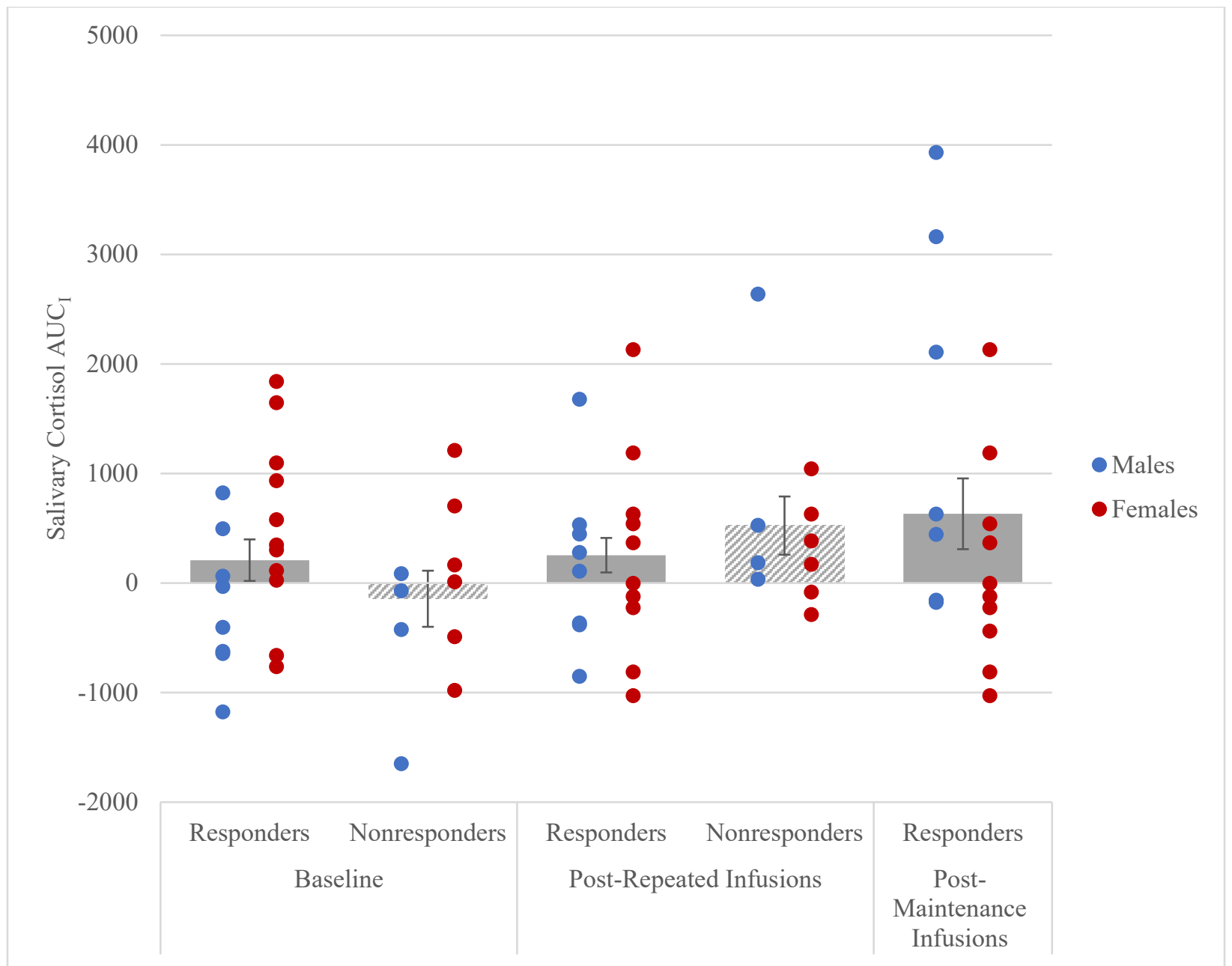

Figure 8: Salivary cortisol area under the curve with respect to increase $\left(\mathrm{AUC}_{\mathrm{I}}\right)$ throughout the clinical trial (mean \pm SEM) 


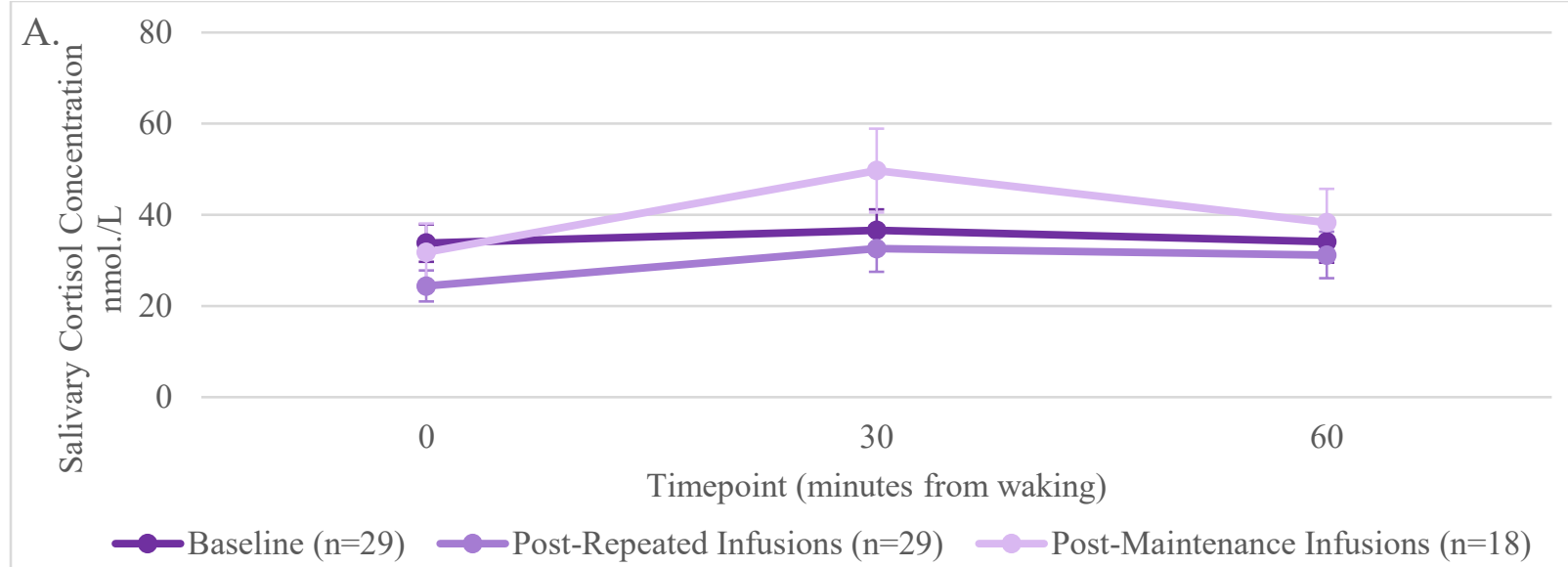

B. Males

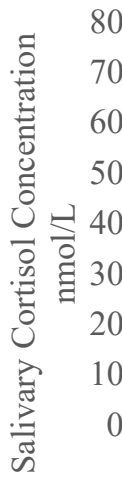
0
Timepoint (minutes from waking)
-Baseline ( $\mathrm{n}=12)$
-Post-Repeated Infusions $(\mathrm{n}=12)$
- Post-Maintenance Infusions $(n=8)$

D. Responders

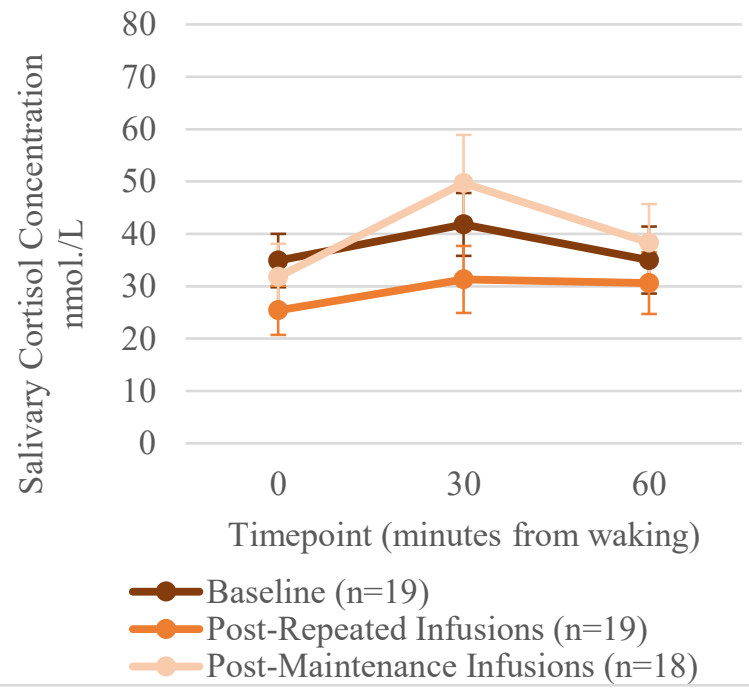

C. Females

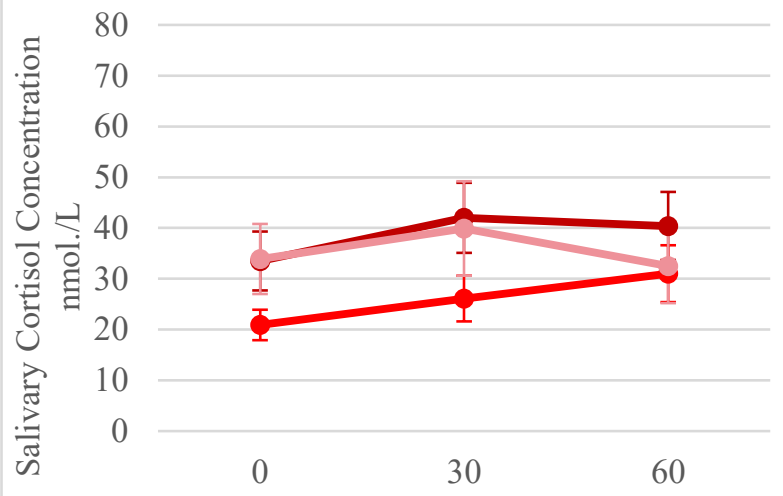

Timepoint (minutes from waking) -Baseline $(\mathrm{n}=17)$

-Post-Repeated Infusions $(\mathrm{n}=17)$

- Post-Maintenance Infusions $(\mathrm{n}=10)$

E. Nonresponders

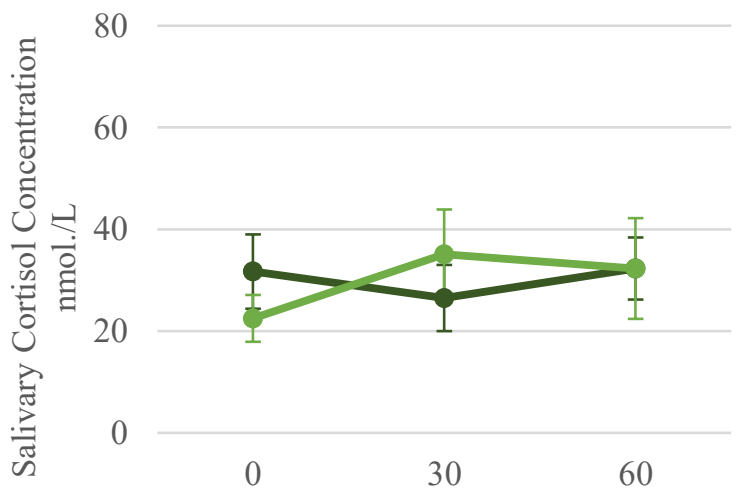

Timepoint (minutes from waking)

$\longrightarrow$ Baseline $(\mathrm{n}=10)$

-Post-Repeated Infusions $(\mathrm{n}=10)$

Figure 9: Change in salivary cortisol awakening response throughout clinical trial (mean $\pm \mathrm{SEM}$ ) 


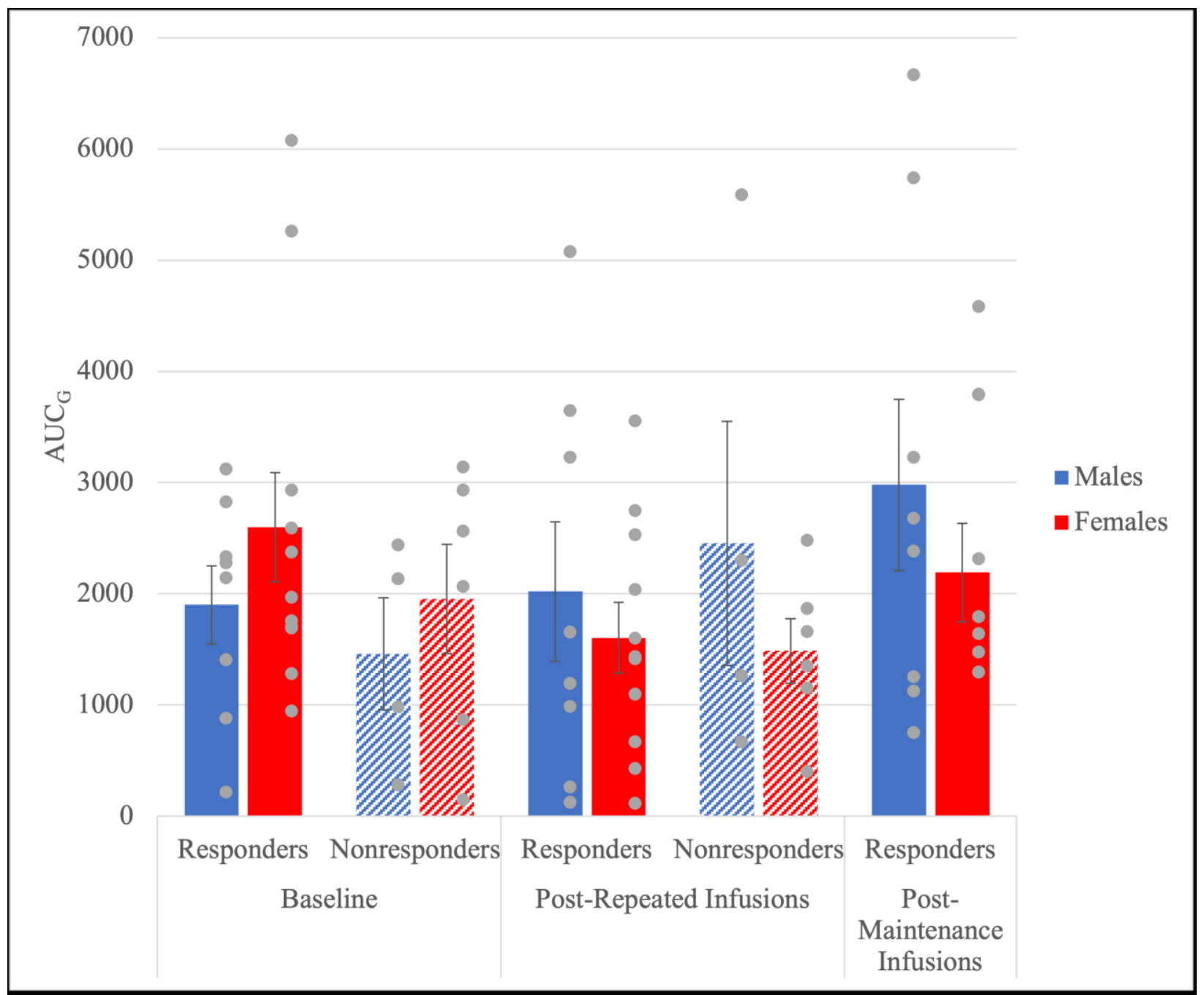

Figure 10: Changes in salivary cortisol area under the curve with respect to ground $\left(\mathrm{AUC}_{\mathrm{G}}\right)$ by sex throughout the clinical trial (mean \pm SEM) 


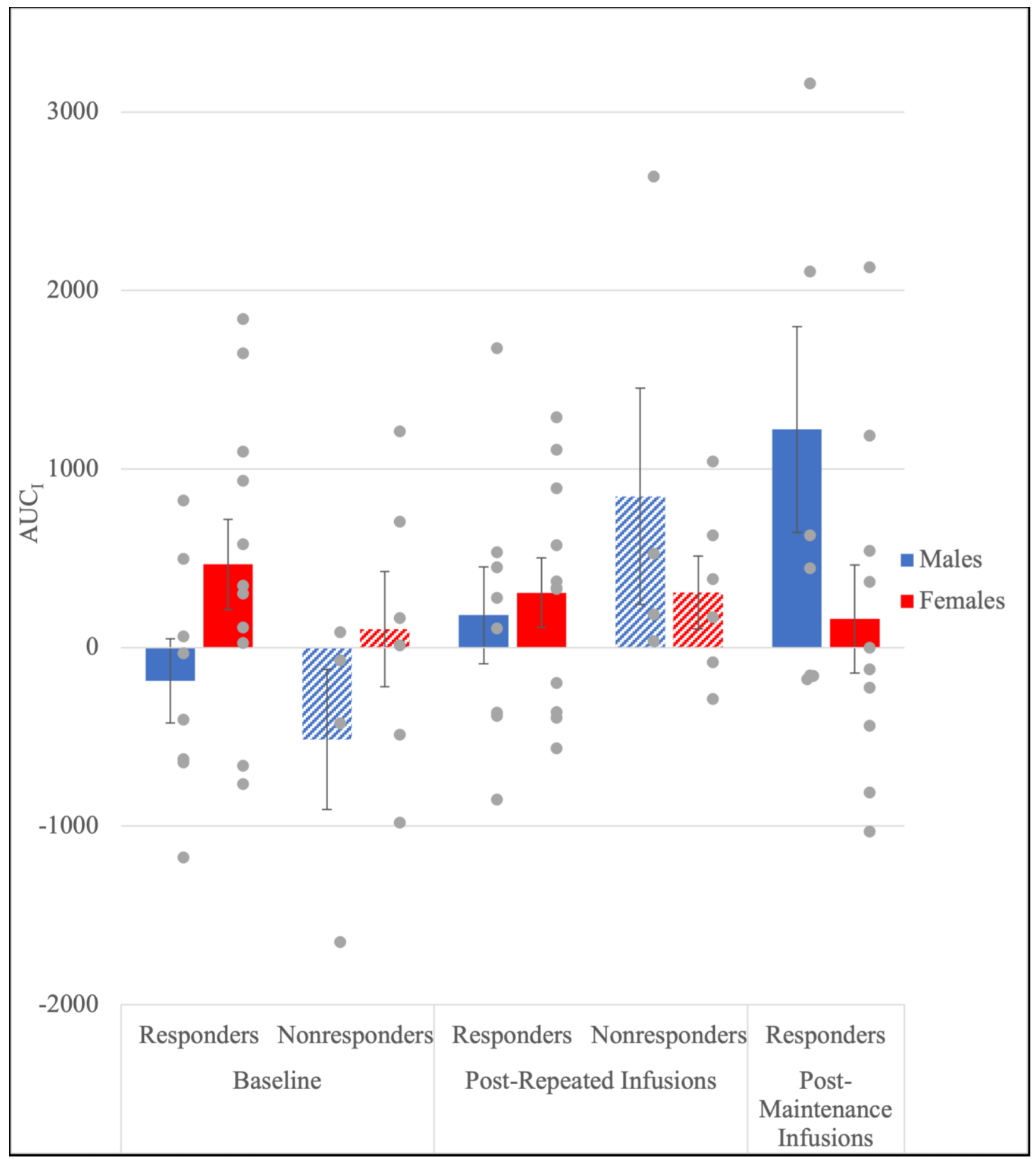

Figure 11: Changes in salivary cortisol area under the curve with respect to increase $\left(\mathrm{AUC}_{\mathrm{I}}\right)$ by sex throughout the clinical trial (mean \pm SEM). 


\section{Biological Variables and Treatment Response}

Pre-treatment $\log C R P$ did not differ between responders $(4.03 \pm 4.06, n=23)$ and nonresponders $(4.25 \pm 3.62, \mathrm{n}=17 ; \mathrm{t}=.29, \mathrm{p}=.78)$ to repeated ketamine infusions (Figure 12A). Similarly, there were no statistically significant differences between responders $(n=19)$ and nonresponders $(\mathrm{n}=10)$ in pre-treatment salivary cortisol $\mathrm{AUC}_{\mathrm{G}}(\mathrm{t}=-1.07, \mathrm{p}=.28)$ or $\mathrm{AUC}_{\mathrm{I}}(\mathrm{t}=-1.10$, $\mathrm{p}=.27$; Figure 12B). Pre-treatment biological variables $\left(\log C R P, A_{G} C_{G}\right.$ and $\left.A U C_{I}\right)$ did not predict change in depression severity measured by the change in MADRS total score $\left(\mathrm{R}^{2}<.17\right.$, $\mathrm{p}>.64)$ or the QIDS-SR $\left(\mathrm{R}^{2}<.15, \mathrm{p}>.70\right)$ and did not predict change in suicidal ideation severity on the MADRS-SI $\left(\mathrm{R}^{2}<.24, \mathrm{p}>.39\right.$; Table 6). Age, sex and BMI were also included in the above models as they were correlated with the biological variables at baseline (Table 6). 

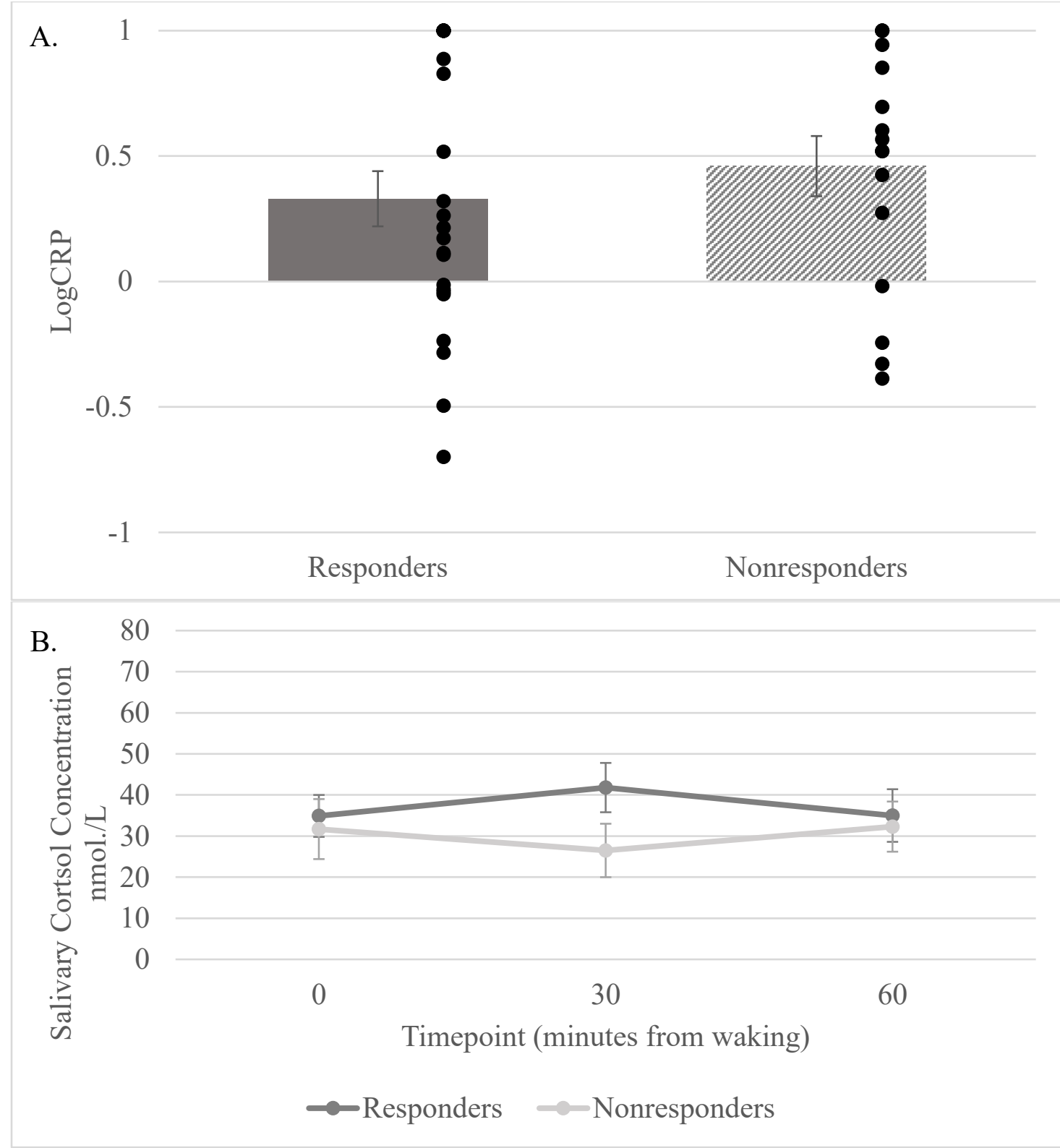

Figure 12: Panel A. Pre-treatment $\log C R P$ values by response status (mean $\pm S E M)$. Panel B. Pre-treatment salivary cortisol awakening response in responders $(\mathrm{n}=19)$ and nonresponders $(\mathrm{n}=10 ;$ mean \pm SEM $)$ 
Table 6: Regression coefficients ( $($ ) for baseline biological measures predicting change in clinical variables $(n=29)$

Change in: MADRS Total Score QIDS-SR Total Score MADRS-SI

\begin{tabular}{|c|c|c|c|}
\hline $\log C R P, B(p)$ & $8.77(.13)$ & $1.79(.61)$ & $-.09(.88)$ \\
\hline $\mathrm{AUC}_{\mathrm{G}}, \beta(\mathrm{p})$ & $.00(.82)$ & $-.001(.37)$ & $-9.76 \times 10^{-5}(.60)$ \\
\hline $\mathrm{AUC}_{\mathrm{I}}, \beta(\mathrm{p})$ & $-.01(.12)$ & $-.002(.38)$ & $.00(.27)$ \\
\hline Age, $B(p)$ & $.181(.37)$ & $-.01(.97)$ & $.04(.08)$ \\
\hline Sex, $\beta(p)$ & $1.94(.69)$ & $4.55(.13)$ & $.43(.40)$ \\
\hline BMI, $ß$ (p) & $-1.03(.14)$ & $-.40(.35)$ & $-.02(.78)$ \\
\hline
\end{tabular}




\section{DISCUSSION}

\section{Summary of findings}

The primary aim of this project was to determine whether treatment with repeated ketamine infusions was associated with changes in the peripheral biomarkers plasma CRP and salivary cortisol. While there was no significant effect of ketamine treatment on CRP levels over time, salivary cortisol did change with ketamine treatment in a sex-dependent manner. Male participants had a blunted CAR at baseline however it was reversed after treatment demonstrated by increases in both $\mathrm{AUC}_{\mathrm{G}}$ and $\mathrm{AUC}_{\mathrm{I}}$. In contrast, females' morning salivary cortisol decreased after repeated ketamine infusions demonstrated by decreases in $\mathrm{AUC}_{\mathrm{G}}$ and $\mathrm{AUC}_{\mathrm{I}}$.

The second aim was to test whether baseline levels of CRP and salivary cortisol would predict response to repeated ketamine treatment. At baseline, there were no differences between ketamine responders' and nonresponders' pre-treatment plasma CRP or salivary cortisol. Furthermore, pre-treatment levels of plasma CRP and salivary cortisol did not predict change in depressive symptoms or change in suicidal ideation with repeated infusions (both of which were decreased with ketamine treatment).

Lastly, as hypothesized for the third aim, pre-treatment plasma CRP was elevated and positively correlated with depressive symptom and suicidal ideation severity. While salivary cortisol appeared elevated relative to reported normative data (Pruessner et al., 1997) prior to treatment initiation, it was not significantly correlated with baseline depressive symptoms or suicidal ideation severity. 


\section{C-reactive Protein}

Almost half of the participants in the present study had elevated pre-treatment plasma CRP ( $>3 \mathrm{mg} / \mathrm{L})$ indicating the presence of low-grade inflammation. This prevalence of elevated CRP among study participants appears higher than previous reports especially as compared to a meta-analysis by Osimo et al. (2019) that found that approximately $27 \%$ of people with depression have low-grade inflammation (CRP levels $>3 \mathrm{mg} / \mathrm{L})$. The higher prevalence of lowgrade inflammation may be attributed to the increased severity of depressive illness and treatment resistance in this sample.

More than half of the participants $(58 \%)$ had severe depression at baseline based on their score on the MADRS. Previous literature has shown an association between elevated plasma CRP and depressive symptom severity (Valkanova et al., 2013). This relationship was replicated in the present study; plasma CRP was positively correlated with scores on the MADRS at baseline. Interestingly, some studies have reported gender differences in the relationship between CRP and depression symptom severity, however reports have been conflicting. Köhler-Forsberg et al. (2017) found that higher CRP was only associated with increased depressive symptoms severity in women but not among men. Contrarily, others have reported that the relationship between CRP and depressive symptom severity was only significant in men (Song et al., 2015; Vetter et al., 2013). In the present study, we found that there was a significant positive correlation between plasma CRP and depressive symptoms severity on the MADRS in both men and women. However, the positive correlation between CRP and self-reported depressive symptoms on the QIDS-SR reached significance only in females but not in males. The correlation between men and depressive symptoms has been reported within a more specific sample population including an elderly sample (Song et al., 2015) and an obese sample (Vetter et 
al., 2013). Given these findings, biological factors including age and obesity may mediate the gender differences observed in the relationship between CRP and depressive symptoms.

We did not find statistically significant differences in plasma CRP levels between males and females at baseline and throughout the trial. Some studies have reported gender differences in CRP with women having higher levels of CRP than their male counterparts (Everett, Rosario, McLaughlin, \& Austin, 2014; Khera et al., 2005). However, both studies had thousands of participants. Our lower sample size may have been underpowered to detect sex differences explaining the non-significant findings. Despite the differences not being statistically significant, mean CRP levels in females were consistently higher than males in all groups (responders and nonresponders) and time points (baseline, post-phase 2 and post-phase 3).

Another factor that may contribute to the elevated prevalence of low-grade inflammation in this sample is their treatment-resistance. To be included in this trial, participants had to meet criteria for TRD (failure to respond to at least two mechanistically distinct medications for depression plus two augmentation strategies). Consequently, this sample was very treatmentresistant with an average of 6 failed treatment strategies in the current major depressive episode. A positive correlation between number of failed treatment strategies and plasma CRP trended towards significance. This is in accordance with the literature that has found that, generally, higher inflammation has been associated with treatment-resistance in depression (Chamberlain et al., 2019; Strawbridge et al., 2015).

In this study plasma CRP did not significantly change with repeated infusions throughout the clinical trial and higher pre-treatment CRP did not predict change in depressive symptoms with ketamine treatment. While this is the first study investigating the effect of repeated ketamine infusions on CRP, two studies have measured CRP before and after a single 
subanesthetic ketamine infusion and found no significant change (Chen et al., 2018b; Kruse et al., 2021). Thus, there is no current evidence that single or repeated ketamine infusions are associated with changes in CRP levels despite reported effects of ketamine treatment on other immune factors including IL-6 (Chen et al., 2018b; Yang et al., 2015), IL-1ß (Yang et al., 2015), IL-8 (Kruse et al., 2021) and TNF- $\alpha$ (Yang et al., 2015). As previously mentioned however, these findings have not been consistently replicated and thus, the relationship between ketamine treatment and inflammation still remains unclear (Cui et al., 2019).

\section{Cortisol}

Participants' mean pre-treatment salivary cortisol awakening response (CAR) levels were elevated compared to the levels reported for healthy participants in the literature (Ambroziak, Kondracka, Bartoszewicz, Krasnodębska-Kiljańska, \& Bednarczuk, 2015; Pruessner et al., 1997; Shin et al., 2011). While these results are similar to some studies that have reported elevations in CAR in patients with depression compared to controls (Bhagwagar, Hafizi, \& Cowen, 2005; Vreeburg et al., 2009), overall, the literature is inconsistent. Both Strickland et al. (2002) and Izakova et al. (2020) found that individuals with depression presented with lower morning cortisol compared to controls. It is hypothesized that the heterogeneity in cortisol levels may be attributed to the heterogeneity within major depressive disorder itself whereby both elevated CAR and a blunted CAR are related to depressive pathology (Dedovic \& Ngiam, 2015).

Both measures of CAR $\left(\mathrm{AUC}_{\mathrm{G}}\right.$ and $\left.\mathrm{AUC}_{\mathrm{I}}\right)$ were not significantly correlated with depressive symptom severity in this sample which corroborates what has been found in the literature (Bhagwagar et al., 2005; Suijk et al., 2019; Vammen et al., 2014). While there is no evidence of a linear correlation between depressive symptom severity and CAR, one study with over 1000 
participants reported a nonlinear inverted U relationship (Wardenaar et al., 2011), leading to the hypothesis that persistent elevated CAR eventually becomes blunted explaining how both elevated and blunted CAR have been reported in depression (Dedovic \& Ngiam, 2015). This hypothesis could explain the negative correlations trending towards significance of CAR with suicidal ideation severity and treatment resistance whereby the participants that were more treatment resistant and had greater suicidal ideation exhibited more blunted CAR. Additionally, there was a significant positive correlation between age and $\mathrm{AUC}_{\mathrm{I}}$. While this relationship has not been reported in healthy controls (Pruessner et al., 1997; Shin et al., 2011), in studies investigating depressive symptoms, a modest positive correlation between morning cortisol secretion and age has been reported (Asnis et al., 1981; Stetler \& Miller, 2011; Zhang, Liu, Liu, $\mathrm{Lu}, \& \mathrm{Hou}, 2020)$.

At baseline, male participants presented with a blunted cortisol awakening response indicated by a significantly lower $\mathrm{AUC}_{\mathrm{I}}$ compared to females. In healthy participants, males show a more rapid decrease after the peak in comparison to women (Pruessner et al., 1997; Wüst et al., 2000). Generally, in studies with depressed individuals no gender differences are reported (Bhagwagar et al., 2005; Stetler \& Miller, 2011). Although a recent study conducted by Vargas et al. (2017) reported similar findings to the present study, males with depression exhibiting a blunted CAR compared to females with depression.

There was no significant main effect of repeated ketamine infusions on either measure of the CAR $\left(\mathrm{AUC}_{\mathrm{G}}\right.$ and $\left.\mathrm{AUC}_{\mathrm{I}}\right)$. There was a significant increase in responders' salivary cortisol $\mathrm{AUC}_{\mathrm{G}}$ from post-repeated infusions to post-maintenance infusions. This indicates that responders had greater cortisol output the morning after their final maintenance infusion in phase 3 than the morning after their final repeated infusion in phase 2. It is important to note that post- 
maintenance infusions, $\mathrm{AUC}_{\mathrm{G}}$ did not significantly differ with baseline $\mathrm{AUC}_{\mathrm{G}}$. One possible explanation is ketamine's effects on CAR change the longer a participant is undergoing treatment. In the short-term from baseline to post-repeated infusions, responders' average $\mathrm{AUC}_{\mathrm{G}}$ decreased (although this difference was not significant) suggesting a decrease in morning cortisol output. In contrast, in treatment responders with longer-term ketamine treatment (4 additional weekly maintenance infusions) there was increased cortisol output.

One potential alternative explanation for this finding is that participants could have been experiencing increased stress the day after their final ketamine infusion. In the present study, some participants reported negative emotions following the cessation of ketamine treatment after completion of the clinical trial (Talbot, Phillips, \& Blier, 2019). Even in healthy individuals the CAR becomes elevated in times of stress and it is hypothesized that this aids with coping with the stressful situation (Dedovic \& Ngiam, 2015; Powell \& Schlotz, 2012). Therefore, it may be hypothesized that the pending completion of the trial and cessation of ketamine treatment could have been associated with an increase in their CAR.

Given the sex differences in HPA regulation and the interaction between the HPA axis and hypothalamic-pituitary-gonadal (HPG) axis (reviewed here: Goel et al., 2014; Oyola and Handa, 2017; Heck and Handa, 2019), sex was examined as a factor in the analyses. This study found that there were sex-specific effects on change in CAR with ketamine treatment. Salivary cortisol $\mathrm{AUC}_{\mathrm{G}}$, an index of total hormonal output, increased in males and decreased in females post-repeated infusions (both increased after maintenance infusions addressed above). Females' cortisol output decreased 34\% after repeated ketamine infusions which may indicate a normalization of the elevated salivary cortisol levels observed at baseline. However, females salivary cortisol concentrations after repeated ketamine infusions still remained elevated 
compared to what has been reported for healthy controls (Clow, Thorn, Evans, \& Hucklebridge, 2004). In males, the increased cortisol output can be attributed to the strengthening of CAR which was blunted at baseline. This is evidenced by the increase in males' salivary cortisol AUC throughout the clinical trial. After repeated ketamine infusions, males' mean difference from waking to 30 minutes was $12.4 \mathrm{nmol} / 1$ which is within the range reported in healthy controls (range $=4-15 \mathrm{nmol} / \mathrm{L}$; Clow et al., 2004). Although, males' mean difference from waking to 30 minutes after maintenance infusions was greater than reported range in healthy controls, it was within the range by percentage (range: $50-160 \%$; Clow et al., 2004). This discrepancy may be attributed to the generally elevated levels of salivary cortisol reported in this sample. Overall, these findings indicate that the effect of ketamine treatment on the HPA axis is sex-specific such that females had decreased awakening cortisol output after repeated infusions and males exhibited strengthening of their previously blunted CAR.

Proposed mechanism for sex-specific changes in cortisol after ketamine treatment

There is evidence implicating glutamate and the NMDA receptor in HPA axis regulation (Evanson \& Herman, 2015; Herman, Mueller, \& Figueiredo, 2004). Chronic stress has widespread effects on NMDA receptor subunits expression including the frontal cortex (Lee \& Goto, 2011), the hippocampus (Calabrese et al., 2012) and the hypothalamus (Ziegler, Cullinan, $\&$ Herman, 2005). Two key brain regions have emerged in studies using NMDA receptor antagonists to examine the role of the NMDA receptor in regulation of HPA axis and glucocorticoid output. Firstly, Zhou et al., (2018) found that administration of the NMDA antagonist, 2-amino-5-phosphonopentanoic acid (AP5) reversed elevated firing of CRHexpressing neurons of the paraventricular nucleus of the hypothalamus (PVN) in chronically 
stressed rats (Zhou et al., 2018). Furthermore, they found that administration of the NMDA antagonist, memantine, directly into the PVN reduced elevations in corticosterone (Zhou et al., 2018). Secondly, Wang et al., (2019) found that administration of a single subanesthetic dose of ketamine increased glucocorticoid receptor (GR) expression in the hippocampus and decreased plasma corticosterone. This suggests that NMDA receptor antagonism may be able to reverse the atrophy of the glucocorticoid-mediated feedback from the hippocampus that is observed in depression (Pariante \& Lightman, 2008). In addition to increasing GR expression, studies have reported that NMDA antagonists prevent mitochondrial oxidative stress and dysfunction in the hippocampus (Mishra, Hidau, \& Rai, 2021) and increase hippocampal neurogenesis (Clarke et al., 2017) in chronic stress animal models. Furthermore, in humans receiving corticosteroid therapy, the administration of the NMDA receptor antagonist, memantine, attenuated hippocampal volume loss (Brown et al., 2019). Thus, these studies have elucidated two potential mechanisms for ketamine to effect cortisol secretion: 1) antagonizing the NMDA receptor on the CRH-producing neurons in the PVN (Zhou et al., 2018) and 2) increasing GR expression in the hippocampus (Wang et al., 2019) and thus potentially increasing GR-mediated feedback.

Sex differences have been reported in both the key brain regions proposed to be involved in NMDA receptors effects on glucocorticoids. First, the number of CRH-producing neurons in the PVN differs between the men and women (Bao \& Swaab, 2007). Additionally, the CRHproducing neurons of the PVN are affected by sex hormones. These neurons possess receptors for both estrogens (Bao, Hestiantoro, Van Someren, Swaab, \& Zhou, 2005) and androgens (Bao et al., 2006) and changes in circulating sex hormones in humans (i.e. from castration, ovariectomy or sex-hormone producing tumour) have been shown to affect the amount of CRHproducing neurons in the PVN (Bao \& Swaab, 2007). Similarly, preclinical studies have shown 
the hippocampus is also influenced by sex hormones and expresses both estrogen and androgen receptors (Isgor \& Watson, 2005; Lathe, 2001; Moghadami, Jahanshahi, Sepehri, \& Amini, 2016; Ooishi et al., 2012). Furthermore, experimental manipulation of sex hormones have been shown to affect GR expression in the hippocampus of rodents (Kerr, Beck, \& Handa, 1996; Sheng et al., 2003). Unfortunately, female animals were not included in the preclinical studies investigating NMDA antagonists modulation on glucocorticoids (Wang et al., 2019; Zhou et al., 2018). Given the sex differences in the key regions they investigated, there remains a need to examine whether their reported effects of NMDA antagonists also occur in females.

Sex differences have been reported with ketamine treatment including differences in behavioural and biological correlates in animal models and differences in ketamine pharmacokinetics in humans (Saland, Duclot, \& Kabbaj, 2017). While sex differences have been reported in the antidepressant effects of ketamine in preclinical models (Saland et al., 2017), both the present randomized controlled trial (Farah, Norris, Talbot, Blier, \& Phillips, 2019) and Freeman et al. (2019) found no differences in efficacy or tolerability to repeated ketamine infusions between male and female participants. However, a meta-analysis found a positive correlation between the percentage of participants that were male and antidepressant effect 7 days after a single infusion of ketamine (Coyle \& Laws, 2015). Although, it remains unclear whether sex differences exist in treatment response to ketamine, there is evidence supporting its sex-specific effects on biological correlates. Of particular interest, multiple preclinical studies have reported sex differences in the hippocampus after ketamine treatment including differences in BDNF (Saland, Schoepfer, \& Kabbaj, 2016), spine density (Thelen et al., 2019), glutamate receptor 1 (GluR1; Thelen et al., 2019) and astrocyte morphology (Ardalan et al., 2020). 
Therefore, if ketamine exerts effects on cortisol through acting on the CRH-producing neurons in the PVN and influencing GR expression in the hippocampus, and sex hormones affect CRH-producing neurons in the PVN and GR expression in the hippocampus, it is plausible that ketamine's effect on cortisol would differ between the sexes. While this is the first study to report sex-specific effects of repeated ketamine treatment on cortisol, there is evidence of sex differences in other biological correlates after ketamine treatment (including pharmacokinetics and metabolism, see Saland et al., 2017) which warrant further study in humans. Given the preclinical sex differences reported in the hippocampus after ketamine treatment, it is a promising target to investigate ketamine's effect on glucocorticoids in clinical populations and how this may differ between the sexes.

\section{Strengths and Limitations}

Strengths

To date, this is the first study to investigate CRP after repeated ketamine infusions treatment and the first study to report sex-specific effects of repeated ketamine infusions on cortisol. However, this is the second study to investigate the effect of repeated ketamine infusions on cortisol. Allen et al., (2018) was the first published study that investigated repeated ketamine treatment on CAR and reported no significant effect. However, they did not examine sex as a factor. This highlights another strength of the present study; examination of sex differences in the analysis. Given the sex differences in depression prevalence among patients (Ferrari et al., 2013), in pre-clinical biological correlates after ketamine treatment (Saland et al., 2017), HPA axis functioning (Goel et al., 2014) and immune profile (Rizzetto, Fava, Tuohy, \& Selmi, 2018), including sex as a factor strengthened the analysis of the present study. 
Another strength of the present study is the participant sample. Participants underwent extensive screening including physical examination, ECG, blood test, urinalysis, measurement of vital signs and they were excluded if any unstable medical condition was detected. The participants in the sample had moderate to severe treatment-resistant depression. Relationships previously reported in the literature were replicated including elevated levels of pre-treatment CRP and cortisol; correlation between CRP and depressive symptom severity; correlation between CRP and BMI; and the correlation between cortisol and age. In the present study, participants' pre-treatment salivary cortisol appeared elevated compared to reported values (Pruessner et al., 1997) which may have allowed the detection of changes associated with ketamine treatment since preclinical data suggests that ketamine only effects glucocorticoids if levels differ from controls prior to treatment (Wang et al., 2019; Zhou et al., 2018). This may be another explanation for the null finding reported by Allen et al. (2018); as their participants exhibited similar levels of cortisol to the healthy control group prior to repeated ketamine infusion treatment.

\section{Limitations}

One limitation of this study was the relatively small sample size. While 43 participants were included in the randomized controlled clinical trial, all participants were included in the CRP analyses and 29 participants were included in the cortisol analyses. While these sample sizes are comparable to other studies investigating biological correlates with ketamine treatment (Allen et al., 2018; Chen et al., 2018b; Kruse et al., 2021), there is a need for larger studies that may be more sensitive to detecting changes and to confirm current findings, given the current inconsistencies in some of the smaller studies (Cui et al., 2019). Such work is ongoing at the 
IMHR including a multi-site trial aimed to recruit a larger sample size to investigate biological correlates in patients undergoing treatment with ketamine and ECT (Phillips, Jaworska, et al., 2020). Another limitation of the present study was the lack of healthy control group. Instead, levels of biological correlates were compared to pre-treatment values and compared to reported values in the literature.

The range of CRP that could be detected was also limited by the standard curve of the ELISA. While two dilutions were done, the maximum detectable value was $10 \mathrm{mg} / \mathrm{L}$ and approximately $20 \%$ of the participant samples were above this value. Therefore, any changes that occurred above $10 \mathrm{mg} / \mathrm{L}$ could not be detected. Another limitation of the present study is lack of menstrual cycle data for the female participants. Both the CAR and CRP have been reported to be affected by the change in circulating sex hormones during the menstrual cycle (Gursoy et al., 2015; Ozgocer, Ucar, \& Yildiz, 2017) which may have contributed to the variation in our present

analyses. Lastly, participants remained on concomitant medication throughout the trial. Thus, these conclusions may be limited to the use of ketamine as an adjunct therapy instead of a monotherapy. However, our baseline findings of elevations in CRP and CAR have been reported in unmedicated individuals with TRD (Bhagwagar et al., 2005; Haapakoski et al., 2015).

\section{Clinical Implications and Future Directions}

While there is evidence that ketamine has anti-inflammatory effects in pre-clinical studies and clinical studies using anesthetic doses (De Kock et al., 2013; Loix et al., 2011), studies investigating inflammatory markers after subanaesthetic ketamine infusions have failed to report consistent anti-inflammatory effects associated with treatment (Chen et al., 2018b; Kiraly et al., 2017; Kruse et al., 2021; Park et al., 2017; Yang et al., 2015). In the present study, a large 
proportion of patients had elevated pre-treatment CRP and their levels were not significantly reduced with ketamine treatment. Given the hypothesized impact of inflammatory processes in promoting depressive symptoms (Anisman, 2009), this may illuminate a deficiency of ketamine treatment for depression, specifically inflammation-driven depression. However, ketamine treatment decreased depressive symptoms in a large proportion of participants in the present study (Phillips et al., 2019) despite participants commencing treatment with elevated inflammation. Given the bidirectional interaction between the immune system and the glutamatergic system (Cui et al., 2019), further investigation of potential explanations for inconsistent findings relating subanaesthetic ketamine treatment and immune factors in the literature on clinical populations is warranted.

Since both blunted and elevated CAR are implicated in depressive pathology (Dedovic \& Ngiam, 2015; Wardenaar et al., 2011), it can be hypothesized that pharmacotherapies for depression may "normalize" the CAR by reversing both blunting and elevations. Results from the present study indicate that ketamine may normalize the CAR in a sex-specific way. In females, cortisol hormonal output was reduced after repeated infusions potentially demonstrating reversal of the elevated levels at baseline. In contrast, cortisol hormonal output in males increased with ketamine treatment. However, the increase may have been primarily due to the reversal of their blunted pre-treatment CAR. This would be consistent with preclinical findings that NMDA antagonism normalized levels of the specified biomarker only in animals that exhibited abnormal levels at baseline but had no effect on animals that exhibited a normal phenotype at baseline (Zhou et al., 2018; Wang et al., 2019). It is important to note that despite these significant effects, the CAR of both male and female participants remained elevated after 
repeated ketamine treatment in comparison to values reported for healthy controls (Pruessner et al., 1997). Given the small sample size, further larger studies confirming this finding are needed.

This study found that plasma CRP and salivary cortisol did not predict change in clinical symptoms with ketamine treatment and neither biomarker differed prior to treatment in ketamine responders and nonresponders. Thus, there remains an unmet need for identification of a peripheral biomarker that predicts antidepressant response to ketamine to more efficiently select treatment strategies for patients with TRD who have not responded to other approaches. In addition to immune factors, neuroimaging correlates, sleep markers, growth factors, metabolic factors, genetic markers, clinical characteristics and neurocognitive measures are all currently being investigated as potential biomarkers for response to ketamine treatment (Duman \& Krystal, 2020). While examination of these biomarkers is promising, there still remains a need for larger replication studies before translation into clinical use (Duman \& Krystal, 2020).

\section{CONCLUSION}

This is the first study to report sex-specific effects of repeated ketamine infusions treatment on cortisol. Further sex-specific investigation into ketamine's effect on glucocorticoids is needed with particular attention to key brain regions: the paraventricular nucleus of the hypothalamus and the hippocampus. This study highlights the importance of considering sex in future preclinical and clinical studies investigating biological correlates in ketamine treatment for depression. Overall, understanding the biological underpinnings of the antidepressant effects of novel treatment strategies, such as ketamine, can guide physicians in effectively treating patients with depression. 


\section{REFERENCES}

Aan Het Rot, M., Collins, K. A., Murrough, J. W., Perez, A. M., Reich, D. L., Charney, D. S., \& Mathew, S. J. (2010). Safety and Efficacy of Repeated-Dose Intravenous Ketamine for Treatment-Resistant Depression. https://doi.org/10.1016/j.biopsych.2009.08.038

Aguiar, F. J. B., Ferreira-Júnior, M., Sales, M. M., Cruz-Neto, L. M., Fonseca, L. A. M., Sumita, N. M., ... Duarte, A. J. S. (2013). C-reactive protein: clinical applications and proposals for a rational use. Revista Da Associação Médica Brasileira (English Edition), 59(1), 85-92. https://doi.org/10.1016/s2255-4823(13)70434-x

Aguilar-Valles, A., De Gregorio, D., Matta-Camacho, E., Eslamizade, M. J., Khlaifia, A., Skaleka, A., ... Sonenberg, N. (2021). Antidepressant actions of ketamine engage cellspecific translation via eIF4E. Nature, 590(7845), 315-319. https://doi.org/10.1038/s41586020-03047-0

Ahmed, S. N., \& Petchkovsky, L. (1980). Abuse of ketamine. The British Journal of Psychiatry: The Journal of Mental Science. Cambridge University Press. https://doi.org/10.1192/bjp.137.3.303b

Albert, P. R. (2015). Why is depression more prevalent in women? J Psychiatry Neurosci, 40(4), 219. https://doi.org/10.1503/jpn.150205

Aleksandrova, L. R., Phillips, A. G., \& Wang, Y. T. (2017). Antidepressant effects of ketamine and the roles of AMPA glutamate receptors and other mechanisms beyond NMDA receptor antagonism. Journal of Psychiatry and Neuroscience. Canadian Medical Association. https://doi.org/10.1503/jpn.160175

Allen, A. P., Naughton, M., Dowling, J., Walsh, A., O’Shea, R., Shorten, G., ... Dinan, T. G. (2018). Kynurenine pathway metabolism and the neurobiology of treatment-resistant depression: Comparison of multiple ketamine infusions and electroconvulsive therapy. Journal of Psychiatric Research, 100, 24-32.

https://doi.org/10.1016/j.jpsychires.2018.02.011

Ambroziak, U., Kondracka, A., Bartoszewicz, Z., Krasnodębska-Kiljańska, M., \& Bednarczuk, T. (2015). The morning and late-night salivary cortisol ranges for healthy women may be used in pregnancy. Clinical Endocrinology, 83(6), 774-778.

https://doi.org/10.1111/cen.12853

American Psychiatric Association. (2000). Diagnostic and statistical manual of mental disorders (4th ed.). Washington, DC: Author.

American Psychiatric Association. (2013). Diagnostic and statistical manual of mental health disorders (5th ed.). Arlington, VA: Author.

Andrade, C. (2017). Ketamine for depression, 4: In what dose, at what rate, by what route, for how long, and at what frequency? Journal of Clinical Psychiatry, 78(7), e852-e857. https://doi.org/10.4088/JCP.17f11738

Anisman, H. (2009). Cascading effects of stressors and inflammatory immune system activation: implications for major depressive disorder. Rev Psychiatr Neurosci (Vol. 34).

Antoniuk, S., Bijata, M., Ponimaskin, E., \& Wlodarczyk, J. (2019, April 1). Chronic unpredictable mild stress for modeling depression in rodents: Meta-analysis of model reliability. Neuroscience and Biobehavioral Reviews. Elsevier Ltd. https://doi.org/10.1016/j.neubiorev.2018.12.002

Anttila, S. A. K., \& Leinonen, E. V. J. (2001). A review of the pharmacological and clinical profile of mirtazapine. CNS Drug Reviews. Neva Press Inc. https://doi.org/10.1111/j.1527- 
3458.2001.tb00198.x

Ardalan, M., Elfving, B., Rafati, A. H., Mansouri, M., Zarate, C. A., Mathe, A. A., \& Wegener, G. (2020). Rapid effects of S-ketamine on the morphology of hippocampal astrocytes and BDNF serum levels in a sex-dependent manner. European Neuropsychopharmacology, 32, 94-103. https://doi.org/10.1016/j.euroneuro.2020.01.001

Arsenault-Lapierre, G., Kim, C., \& Turecki, G. (2004, November 4). Psychiatric diagnoses in 3275 suicides: A meta-analysis. BMC Psychiatry. BioMed Central. https://doi.org/10.1186/1471-244X-4-37

Asnis, G. M., Sachar, E. J., Halbreich, U., Nathan, R. S., Novacenko, H., \& Ostrow, L. C. (1981). Cortisol secretion in relation to age in major depression. Psychosomatic Medicine, 43(3), 235-242. https://doi.org/10.1097/00006842-198106000-00005

Audet, M. C., \& Anisman, H. (2013, April 22). Interplay between pro-inflammatory cytokines and growth factors in depressive illnesses. Frontiers in Cellular Neuroscience. Frontiers. https://doi.org/10.3389/fncel.2013.00068

Autry, A. E., Adachi, M., Nosyreva, E., Na, E. S., Los, M. F., Cheng, P. F., ... Monteggia, L. M. (2011). NMDA receptor blockade at rest triggers rapid behavioural antidepressant responses. Nature, 475(7354), 91-96. https://doi.org/10.1038/nature10130

Bang-Andersen, B., Ruhland, T., Jørgensen, M., Smith, G., Frederiksen, K., Jensen, K. G., ... Stensbøl, T. B. (2011). Discovery of 1-[2-(2,4-Dimethylphenylsulfanyl)phenyl]piperazine (Lu AA21004): A Novel Multimodal Compound for the Treatment of Major Depressive Disorder. Journal of Medicinal Chemistry, 54(9), 3206-3221. https://doi.org/10.1021/jm101459g

Bao, A. M., \& Swaab, D. F. (2007). Gender Difference in Age-Related Number of CorticotropinReleasing Hormone-Expressing Neurons in the Human Hypothalamic Paraventricular Nucleus and the Role of Sex Hormones. Neuroendocrinology, 85(1), 27-36. https://doi.org/10.1159/000099832

Bao, A. M., Fischer, D. F., Wu, Y. H., Hol, E. M., Balesar, R., Unmehopa, U. A., ... Swaab, D. F. (2006). A direct androgenic involvement in the expression of human corticotropinreleasing hormone. Molecular Psychiatry, 11(6), 567-576. https://doi.org/10.1038/sj.mp.4001800

Bao, Ai Min, Hestiantoro, A., Van Someren, E. J. W., Swaab, D. F., \& Zhou, J. N. (2005). Colocalization of corticotropin-releasing hormone and oestrogen receptor- $\alpha$ in the paraventricular nucleus of the hypothalamus in mood disorders. Brain, 128(6), 1301-1313. https://doi.org/10.1093/brain/awh448

Basso, L., Bönke, L., Aust, S., Gärtner, M., Heuser-Collier, I., Otte, C., .. Grimm, S. (2020). Antidepressant and neurocognitive effects of serial ketamine administration versus ECT in depressed patients. Journal of Psychiatric Research, 123, 1-8. https://doi.org/10.1016/j.jpsychires.2020.01.002

Bellavance, M. A., \& Rivest, S. (2014). The HPA - immune axis and the immunomodulatory actions of glucocorticoids in the brain. Frontiers in Immunology. Frontiers Media S.A. https://doi.org/10.3389/fimmu.2014.00136

Berlim, M. T., Van Den Eynde, F., Tovar-Perdomo, S., \& Daskalakis, Z. J. (2014). Response, remission and drop-out rates following high-frequency repetitive transcranial magnetic stimulation (rTMS) for treating major depression: A systematic review and meta-analysis of randomized, double-blind and sham-controlled trials. Psychological Medicine, 44(2), 225239. https://doi.org/10.1017/S0033291713000512 
Berlim, Marcelo T., McGirr, A., Van Den Eynde, F., Fleck, M. P. A., \& Giacobbe, P. (2014). Effectiveness and acceptability of deep brain stimulation (DBS) of the subgenual cingulate cortex for treatment-resistant depression: A systematic review and exploratory metaanalysis. Journal of Affective Disorders. Elsevier. https://doi.org/10.1016/j.jad.2014.02.016

Berman, R. M., Cappiello, A., Anand, A., Oren, D. A., Heninger, G. R., Charney, D. S., \& Krystal, J. H. (2000). Antidepressant effects of ketamine in depressed patients. Biological Psychiatry, 47(4), 351-354. https://doi.org/10.1016/S0006-3223(99)00230-9

Bernal, M., Haro, J. M., Bernert, S., Brugha, T., de Graaf, R., Bruffaerts, R., ... Alonso, J. (2007). Risk factors for suicidality in Europe: Results from the ESEMED study. Journal of Affective Disorders, 101(1-3), 27-34. https://doi.org/10.1016/j.jad.2006.09.018

Berry, S. M., Broglio, K., Bunker, M., Jayewardene, A., Olin, B., \& Rush, A. J. (2013, February 28). A patient-level meta-analysis of studies evaluating vagus nerve stimulation therapy for treatment-resistant depression. Medical Devices: Evidence and Research. Med Devices (Auckl). https://doi.org/10.2147/MDER.S41017

Bhagwagar, Z., Hafizi, S., \& Cowen, P. J. (2005). Increased salivary cortisol after waking in depression. Psychopharmacology, 182(1), 54-57. https://doi.org/10.1007/s00213-005-0062$\mathrm{Z}$

Björkholm, C., Jardemark, K., Schilström, B., \& Svensson, T. H. (2015). Ketamine-like effects of a combination of olanzapine and fluoxetine on AMPA and NMDA receptor-mediated transmission in the medial prefrontal cortex of the rat. European Neuropsychopharmacology, 25(10), 1842-1847. https://doi.org/10.1016/j.euroneuro.2015.07.002

Black, M., Lanthorn, T., Small, D., Mealing, G., Lam, V., \& Morley, P. (1996). Study of potency, kinetics of block and toxicity of NMDA receptor antagonists using fura-2. European Journal of Pharmacology, 317(2-3), 377-381. https://doi.org/10.1016/S00142999(96)00730-3

Blakemore, C., \& Jennett, S. (2001). The Oxford Companion to the Body. Oxford University Press. https://doi.org/10.1093/acref/9780198524038.001.0001

Bokor, G., \& Anderson, P. D. (2014). Ketamine: an update on its abuse. Journal of Pharmacy Practice, 27(6), 582-586. https://doi.org/10.1177/0897190014525754

Bonaccorso, S., Marino, V., Puzella, A., Pasquini, M., Biondi, M., Artini, M., ... Maes, M. (2002). Increased Depressive Ratings in Patients With Hepatitis C Receiving Interferon- $\alpha-$ Based Immunotherapy Are Related to Interferon- $\alpha$-Induced Changes in the Serotonergic System. Journal of Clinical Psychopharmacology, 22(1).

Bonnet, U. (2015). Long-Term Ketamine Self-Injections in Major Depressive Disorder: Focus on Tolerance in Ketamine's Antidepressant Response and the Development of Ketamine Addiction. Journal of Psychoactive Drugs, 47(4), 276-285. https://doi.org/10.1080/02791072.2015.1072653

Bostwick, J. M., \& Pankratz, V. S. (2000, December 1). Affective disorders and suicide risk: A reexamination. American Journal of Psychiatry. American Psychiatric Publishing. https://doi.org/10.1176/appi.ajp.157.12.1925

Brown, E. S., Kulikova, A., Van Enkevort, E., Nakamura, A., Ivleva, E. I., Tustison, N. J., ... Malone, K. (2019). A randomized trial of an NMDA receptor antagonist for reversing corticosteroid effects on the human hippocampus. Neuropsychopharmacology, 44(13), 2263-2267. https://doi.org/10.1038/s41386-019-0430-8

Calabrese, F., Guidotti, G., Molteni, R., Racagni, G., Mancini, M., \& Riva, M. A. (2012). Stress- 
induced changes of hippocampal NMDA receptors: Modulation by duloxetine treatment. PLoS ONE, 7(5). https://doi.org/10.1371/journal.pone.0037916

Calvey, T. N. (1995). Isomerism and anaesthetic drugs. Acta Anaesthesiologica Scandinavica, 39, 83-90. https://doi.org/10.1111/j.1399-6576.1995.tb04316.x

Capuron, L., Gumnick, J. F., Musselman, D. L., Lawson, D. H., Reemsnyder, A., Nemeroff, C. B., \& Miller, A. H. (2002). Neurobehavioral effects of interferon- $\alpha$ in cancer patients: Phenomenology and paroxetine responsiveness of symptom dimensions. Neuropsychopharmacology, 26(5), 643-652. https://doi.org/10.1016/S0893133X(01)00407-9

Carson, S. W., Halbreich, U., Yeh, C. M., Asnis, G., \& Goldstein, S. (1988). Cortisol suppression per nanogram per milliliter of plasma dexamethasone in depressive and normal subjects. Biological Psychiatry, 24(5), 569-577. https://doi.org/10.1016/00063223(88)90167-9

Centers for Disease Control and Prevention. (2020). About Adult BMI | Healthy Weight, Nutrition, and Physical Activity | CDC. Retrieved March 16, 2021, from https://www.cdc.gov/healthyweight/assessing/bmi/adult_bmi/index.html\#InterpretedAdults

Chamberlain, S. R., Cavanagh, J., De Boer, P., Mondelli, V., Jones, D. N. C., Drevets, W. C., ... Bullmore, E. T. (2019). Treatment-resistant depression and peripheral C-reactive protein. British Journal of Psychiatry, 214(1), 11-19. https://doi.org/10.1192/bjp.2018.66

Chan, L. F., Eu, C. L., Soh, S. Y., Maniam, T., Shahidii Kadir, Z., Chong, B. T. W., ... Kahn, D. A. (2018). Is Ketamine the Future Clozapine for Depression? A Case Series and Literature Review on Maintenance Ketamine in Treatment-resistant Depression With Suicidal Behavior. Journal of Psychiatric Practice, 24(4), 279-291. https://doi.org/10.1097/PRA.0000000000000316

Chen, J. jun, Zhao, L. bo, Liu, Y. yun, Fan, S. hua, \& Xie, P. (2017). Comparative efficacy and acceptability of electroconvulsive therapy versus repetitive transcranial magnetic stimulation for major depression: A systematic review and multiple-treatments metaanalysis. Behavioural Brain Research, 320, 30-36. https://doi.org/10.1016/j.bbr.2016.11.028

Chen, M. H., Li, C. T., Lin, W. C., Hong, C. J., Tu, P. C., Bai, Y. M., ... Su, T. P. (2018a). Cognitive function of patients with treatment-resistant depression after a single low dose of ketamine infusion. Journal of Affective Disorders, 241, 1-7. https://doi.org/10.1016/j.jad.2018.07.033

Chen, M. H., Li, C. T., Lin, W. C., Hong, C. J., Tu, P. C., Bai, Y. M., ... Su, T. P. (2018b). Rapid inflammation modulation and antidepressant efficacy of a low-dose ketamine infusion in treatment-resistant depression: A randomized, double-blind control study. Psychiatry Research, 269, 207-211. https://doi.org/10.1016/j.psychres.2018.08.078

Chilukuri, H., Reddy, N., Pathapati, R., Manu, A., Jollu, S., \& Shaik, A. (2014). Acute antidepressant effects of intramuscular versus intravenous ketamine. Indian Journal of Psychological Medicine, 36(1), 71-76. https://doi.org/10.4103/0253-7176.127258

Clarke, M., Razmjou, S., Prowse, N., Dwyer, Z., Litteljohn, D., Pentz, R., ... Hayley, S. (2017). Ketamine modulates hippocampal neurogenesis and pro-inflammatory cytokines but not stressor induced neurochemical changes. Neuropharmacology, 112(Pt A), 210-220. https://doi.org/10.1016/j.neuropharm.2016.04.021

Clow, A., Thorn, L., Evans, P., \& Hucklebridge, \& F. (2004). Stress The International Journal on the Biology of Stress The Awakening Cortisol Response: Methodological Issues and 
Significance The Awakening Cortisol Response: Methodological Issues and Significance. The Awakening Cortisol Response: Methodological Issues and Significance, 7(1), 29-37. https://doi.org/10.1080/10253890410001667205

Coates, K. M., \& Flood, P. (2001). Ketamine and its preservative, benzethonium chloride, both inhibit human recombinant $\alpha 7$ and $\alpha 4 \beta 2$ neuronal nicotinic acetylcholine receptors in Xenopus oocytes. British Journal of Pharmacology, 134(4), 871-879. https://doi.org/10.1038/sj.bjp.0704315

Conwell, Y., Duberstein, P. R., Cox, C., Herrmann, J. H., Forbes, N. T., \& Caine, E. D. (1996). Relationships of age and axis I diagnoses in victims of completed suicide: A psychological autopsy study. American Journal of Psychiatry, 153(8), 1001-1008. https://doi.org/10.1176/ajp.153.8.1001

Coyle, C. M., \& Laws, K. R. (2015, May 1). The use of ketamine as an antidepressant: A systematic review and meta-analysis. Human Psychopharmacology. John Wiley and Sons Ltd. https://doi.org/10.1002/hup.2475

Cruz-Topete, D., \& Cidlowski, J. A. (2014). One hormone, two actions: Anti- And proinflammatory effects of glucocorticoids. NeuroImmunoModulation, 22(1-2), 20-32. https://doi.org/10.1159/000362724

Cui, W., Ning, Y., Hong, W., Wang, J., Liu, Z., \& Li, M. D. (2019). Crosstalk Between Inflammation and Glutamate System in Depression: Signaling Pathway and Molecular Biomarkers for Ketamine's Antidepressant Effect. Molecular Neurobiology, 56(5), 34843500. https://doi.org/10.1007/s12035-018-1306-3

Cusin, C., Ionescu, D. F., Pavone, K. J., Akeju, O., Cassano, P., Taylor, N., ... Fava, M. (2017). Ketamine augmentation for outpatients with treatment-resistant depression: Preliminary evidence for two-step intravenous dose escalation. Australian and New Zealand Journal of Psychiatry, 51(1), 55-64. https://doi.org/10.1177/0004867416631828

Cyranowski, J. M., Frank, E., Young, E., \& Shear, M. K. (2000, January 1). Adolescent onset of the gender difference in lifetime rates of major depression. A theoretical model. Archives of General Psychiatry. American Medical Association.

https://doi.org/10.1001/archpsyc.57.1.21

Daly, E. J., Trivedi, M. H., Janik, A., Li, H., Zhang, Y., Li, X., ... Singh, J. B. (2019). Efficacy of Esketamine Nasal Spray Plus Oral Antidepressant Treatment for Relapse Prevention in Patients with Treatment-Resistant Depression: A Randomized Clinical Trial. JAMA Psychiatry, 76(9), 893-903. https://doi.org/10.1001/jamapsychiatry.2019.1189

Dantzer, R. (2018, January 1). Neuroimmune interactions: From the brain to the immune system and vice versa. Physiological Reviews. American Physiological Society. https://doi.org/10.1152/physrev.00039.2016

De Kock, M., Loix, S., \& Lavand'homme, P. (2013). Ketamine and Peripheral Inflammation. CNS Neuroscience \& Therapeutics, 19(6), 403-410. https://doi.org/10.1111/cns.12104

Dedovic, K., \& Ngiam, J. (2015, May 14). The cortisol awakening response and major depression: Examining the evidence. Neuropsychiatric Disease and Treatment. Dove Medical Press Ltd. https://doi.org/10.2147/NDT.S62289

Diamond, P. R., Farmery, A. D., Atkinson, S., Haldar, J., Williams, N., Cowen, P. J., ... McShane, R. (2014). Ketamine infusions for treatment resistant depression: A series of 28 patients treated weekly or twice weekly in an ECT clinic. Journal of Psychopharmacology, 28(6), 536-544. https://doi.org/10.1177/0269881114527361

Domino, E. F. (2010). Taming the ketamine tiger. Anesthesiology, 113(3), 678-684. 
https://doi.org/10.1097/ALN.0b013e3181ed09a2

Domino, E. F., Chodoff, P., \& Corssen, G. (1965). Pharmacologic effects of CI-581, a new dissociative anesthetic, in man. Clin Pharmacol Ther., 6, 279-291.

Dong, M., Zeng, L. N., Lu, L., Li, X. H., Ungvari, G. S., Ng, C. H., ... Xiang, Y. T. (2019). Prevalence of suicide attempt in individuals with major depressive disorder: A metaanalysis of observational surveys. Psychological Medicine, 49(10), 1691-1704. https://doi.org/10.1017/S0033291718002301

Drug Enforcement Agency. (1999). Schedules of Controlled Substances: Placement of Ketamine into Schedule III. Federal Register. Retrieved from https://www.federalregister.gov/documents/1999/07/13/99-17803/schedules-of-controlledsubstances-placement-of-ketamine-into-schedule-iii

Duman, R. S., \& Aghajanian, G. K. (2012). Synaptic Dysfunction in Depression: Potential Therapeutic Targets on JSTOR. Science, 338(6103), 68-72. Retrieved from https://wwwjstor-org.proxy.library.carleton.ca/stable/41704032?pqorigsite $\% 3$ Dsummon $=\&$ seq $=2 \#$ metadata_info_tab_contents

Duman, R. S., \& Krystal, J. H. (2020). Rapid Acting Antidepressants. (S. J. Enna, Ed.) (1st ed.). Cambridge MA: Elsevier Inc. Retrieved from https://books.google.ca/books?id=M33nDwAAQBAJ\&printsec=frontcover\&source=gbs_ge _summary_r\&cad $=0 \# \mathrm{v}=$ onepage $\& \mathrm{q} \& \mathrm{f}=$ false

Duman, R. S., Li, N., Liu, R. J., Duric, V., \& Aghajanian, G. (2012). Signaling pathways underlying the rapid antidepressant actions of ketamine. In Neuropharmacology (Vol. 62, pp. 35-41). Pergamon. https://doi.org/10.1016/j.neuropharm.2011.08.044

Eisenberger, N. I., Inagaki, T. K., Mashal, N. M., \& Irwin, M. R. (2010). Inflammation and social experience: An inflammatory challenge induces feelings of social disconnection in addition to depressed mood. Brain, Behavior, and Immunity, 24(4), 558-563. https://doi.org/10.1016/j.bbi.2009.12.009

Evanson, N. K., \& Herman, J. P. (2015). Metabotropic glutamate receptor-mediated signaling dampens the HPA axis response to restraint stress. Physiology and Behavior, 150, 2-7. https://doi.org/10.1016/j.physbeh.2015.02.027

Everett, B. G., Rosario, M., McLaughlin, K. A., \& Austin, S. B. (2014). Sexual orientation and gender differences in markers of inflammation and immune functioning. Annals of Behavioral Medicine, 47(1), 57-70. https://doi.org/10.1007/s12160-013-9567-6

Farah, A., Norris, S., Talbot, J., Blier, P., \& Phillips, J. L. (2019). Effect of prior treatment history and sex on antidepressant response to subanesthetic ketamine infusions. J Psychiatry Neurosci, 44(5 Suppl 1), S2. https://doi.org/10.1503/jpn.190127

Felger, J. C., Haroon, E., Patel, T. A., Goldsmith, D. R., Wommack, E. C., Woolwine, B. J., ... Miller, A. H. (2020). What does plasma CRP tell us about peripheral and central inflammation in depression? Molecular Psychiatry, 25(6), 1301-1311. https://doi.org/10.1038/s41380-018-0096-3

Ferrari, A. J., Somerville, A. J., Baxter, A. J., Norman, R., Patten, S. B., Vos, T., \& Whiteford, H. A. (2013). Global variation in the prevalence and incidence of major depressive disorder: A systematic review of the epidemiological literature. Psychological Medicine, 43(3), 471481. https://doi.org/10.1017/S0033291712001511

Fischer, S., Strawbridge, R., Vives, A. H., \& Cleare, A. J. (2017, February 1). Cortisol as a predictor of psychological therapy response in depressive disorders: Systematic review and meta-analysis. British Journal of Psychiatry. Royal College of Psychiatrists. 
https://doi.org/10.1192/bjp.bp.115.180653

Fond, G., Loundou, A., Rabu, C., Macgregor, A., Lançon, C., Brittner, M., ... Boyer, L. (2014, September 15). Ketamine administration in depressive disorders: A systematic review and meta-analysis. Psychopharmacology. Springer Verlag. https://doi.org/10.1007/s00213-0143664-5

Freeman, M. P., Papakostas, G. I., Hoeppner, B., Mazzone, E., Judge, H., Cusin, C., ... Fava, M. (2019). Sex differences in response to ketamine as a rapidly acting intervention for treatment resistant depression. Journal of Psychiatric Research, 110, 166-171. https://doi.org/10.1016/j.jpsychires.2019.01.010

Fried, E. I., \& Nesse, R. M. (2015). Depression is not a consistent syndrome: An investigation of unique symptom patterns in the STAR*D study. Journal of Affective Disorders, 172, 96102. https://doi.org/10.1016/j.jad.2014.10.010

Gaynes, B. N., Lux, L., Gartlehner, G., Asher, G., Forman-Hoffman, V., Green, J., ... Lohr, K. N. (2020, February 1). Defining treatment-resistant depression. Depression and Anxiety. Blackwell Publishing Inc. https://doi.org/10.1002/da.22968

Geddes, J., Carney, S., Cowen, P., Goodwin, G., Rogers, R., Dearness, K., ... Scott, A. (2003). Efficacy and safety of electroconvulsive therapy in depressive disorders: A systematic review and meta-analysis. Lancet, 361(9360), 799-808. https://doi.org/10.1016/S01406736(03) $12705-5$

Gelenberg, A. J., Marlene Freeman, C. P., Markowitz, J. C., Rosenbaum, J. F., Thase, M. E., Trivedi, M. H., ... Silbersweig, D. A. (2010). Practice Guideline For The Treatment of Patients With Major Depressive Disorder (3rd ed.). American Psychiatric Association. Retrieved from http://www.psychiatryonline.com/pracGuide/pracGuideTopic_7.aspx.

Goel, N., Workman, J. L., Lee, T. T., Innala, L., \& Viau, V. (2014). Sex Differences in the HPA Axis. In Comprehensive Physiology (pp. 1121-1155). Wiley.

https://doi.org/10.1002/cphy.c130054

Government of Canada. (2019, September 19). Controlled Drugs and Substances Act. Retrieved July 29, 2020, from https://laws-lois.justice.gc.ca/eng/acts/c-38.8/fulltext.html

Government of Canada. (2020, March 4). Suicide in Canada: Key Statistics (infographic) Canada.ca. Retrieved July 23, 2020, from https://www.canada.ca/en/publichealth/services/publications/healthy-living/suicide-canada-key-statistics-infographic.html

Graham, J. W. (2009, January 26). Missing data analysis: Making it work in the real world. Annual Review of Psychology. Annual Reviews . https://doi.org/10.1146/annurev.psych.58.110405.085530

Green, S. M., Roback, M. G., Kennedy, R. M., \& Krauss, B. (2011). Clinical practice guideline for emergency department ketamine dissociative sedation: 2011 update. Annals of Emergency Medicine, 57(5), 449-461. https://doi.org/10.1016/j.annemergmed.2010.11.030

Gursoy, A. Y., Caglar, G. S., Kiseli, M., Pabuccu, E., Candar, T., \& Demirtas, S. (2015). CRP at early follicular phase of menstrual cycle can cause misinterpretation for cardiovascular risk assessment. Interventional Medicine and Applied Science, 7(4), 143-146. https://doi.org/10.1556/1646.7.2015.4.2

Haapakoski, R., Mathieu, J., Ebmeier, K. P., Alenius, H., \& Kivimäki, M. (2015). Cumulative meta-analysis of interleukins 6 and $1 \beta$, tumour necrosis factor $\alpha$ and C-reactive protein in patients with major depressive disorder. Brain, Behavior, and Immunity, 49, 206-215. https://doi.org/10.1016/j.bbi.2015.06.001

Hantouche, E., Angst, J., \& Azorin, J.-M. (2010). Explained factors of suicide attempts in major 
depression. Journal of Affective Disorders, 127, 305-308.

https://doi.org/10.1016/j.jad.2010.04.032

Harrison, N. A., Brydon, L., Walker, C., Gray, M. A., Steptoe, A., \& Critchley, H. D. (2009).

Inflammation Causes Mood Changes Through Alterations in Subgenual Cingulate Activity and Mesolimbic Connectivity. Biological Psychiatry, 66(5), 407-414.

https://doi.org/10.1016/j.biopsych.2009.03.015

Harwood, D., Hawton, K., Hope, T., \& Jacoby, R. (2001). Psychiatric disorder and personality factors associated with suicide in older people: a descriptive and case-control study. International Journal of Geriatric Psychiatry, 16(2), 155-165. https://doi.org/10.1002/1099-1166(200102)16:2<155::AID-GPS289>3.0.CO;2-0

Hashimoto, K. (2015). Inflammatory Biomarkers as Differential Predictors of Antidepressant Response. International Journal of Molecular Sciences, 16(12), 7796-7801. https://doi.org/10.3390/ijms16047796

Hashimoto, K. (2019). Rapid-acting antidepressant ketamine, its metabolites and other candidates: A historical overview and future perspective. Psychiatry and Clinical Neurosciences, 73(10), 613-627. https://doi.org/10.1111/pcn.12902

Health Canada. (2020). Spravato: Notice of Compliance (NOC) .

Heck, A. L., \& Handa, R. J. (2019). Sex differences in the hypothalamic-pituitary-adrenal axis' response to stress: an important role for gonadal hormones. Neuropsychopharmacology: Official Publication of the American College of Neuropsychopharmacology, 44(1), 45-58. https://doi.org/10.1038/s41386-018-0167-9

Henriksson, M. M., Aro, H. M., Marttunen, M. J., Heikkinen, M. E., Isometsa, E. T., Kuoppasalmi, K. I., \& Lonnqvist, J. K. (1993). Mental Disorders and Comorbidity in Suicide. American Journal of Psychiatry, 150(6), 935-940. https://doi.org/10.1176/ajp.150.6.935

Herman, J. P., Mueller, N. K., \& Figueiredo, H. (2004). Role of GABA and glutamate circuitry in hypothalamo-pituitary- adrenocortical stress integration. In Annals of the New York Academy of Sciences (Vol. 1018, pp. 35-45). New York Academy of Sciences. https://doi.org/10.1196/annals.1296.004

Hermes, G., \& Sanacora, G. (2016). Ketamine for Treatment-Resistant Depression The First Decade of Progress. (S. J. Mathew \& C. A. Zarate, Eds.). Switzerland: Springer International Publishing.

Hillhouse, T. M., \& Porter, J. H. (2015). A Brief History of the Development of Antidepressant Drugs: From Monoamines to Glutamate. https://doi.org/10.1037/a0038550

Hirota, K., Hashimoto, Y., \& Lambert, and D. G. (2002). Interaction of Intravenous Anesthetics with Recombinant Human M1-M3 Muscarinic Receptors Expressed in Chinese Hamster Ovary Cells. Anesthesia \& Analgesia, 95(6), 1607-1610. https://doi.org/10.1097/00000539200212000-00025

Hirschfeld, R. M. A. (2000). History and Evolution of the Monoamine Hypothesis of Depression. The Journal of Clinical Psychiatry, 61(suppl 6), 4-6.

Howren, M. B., Lamkin, D. M., \& Suls, J. (2009). Associations of Depression With C-Reactive Protein, IL-1, and IL-6: A Meta-Analysis. Psychosomatic Medicine, 71(2), 171-186. https://doi.org/10.1097/PSY.0b013e3181907c1b

Hudetz, J. A., Iqbal, Z., Gandhi, S. D., Patterson, K. M., Byrne, A. J., Hudetz, A. G., ... Warltier, D. C. (2009). Ketamine attenuates post-operative cognitive dysfunction after cardiac surgery. Acta Anaesthesiologica Scandinavica, 53(7), 864-872. 
https://doi.org/10.1111/j.1399-6576.2009.01978.x

Hustveit, O., Maurset, A., \& Øye, I. (1995). Interaction of the Chiral Forms of Ketamine with Opioid, Phencyclidine, $\sigma$ and Muscarinic Receptors. Pharmacology \& Toxicology, 77(6), 355-359. https://doi.org/10.1111/j.1600-0773.1995.tb01041.x

invitrogen. (2019). Human C-Reactive Protein ELISA Kit: Product Information Kit. invitrogen.

Irwin, S. A., \& Iglewicz, A. (2010). Oral ketamine for the rapid treatment of depression and anxiety in patients receiving hospice care. Journal of Palliative Medicine, 13(7), 903-908. https://doi.org/10.1089/jpm.2010.9808

Isgor, C., \& Watson, S. J. (2005). Estrogen receptor $\alpha$ and $\beta$ mRNA expressions by proliferating and differentiating cells in the adult rat dentate gyrus and subventricular zone. Neuroscience, 134(3), 847-856. https://doi.org/10.1016/j.neuroscience.2005.05.008

Ivanova, J. I., Birnbaum, H. G., Kidolezi, Y., Subramanian, G., Khan, S. A., \& Stensland, M. D. (2010). Direct and indirect costs of employees with treatment-resistant and non-treatmentresistant major depressive disorder. Current Medical Research and Opinion, 26(10), 24752484. https://doi.org/10.1185/03007995.2010.517716

Izakova, L., Hlavacova, N., Segeda, V., Kapsdorfer, D., Morovicsova, E., \& Jezova, D. (2020). Salivary Aldosterone, Cortisol, and Their Morning to Evening Slopes in Patients with Depressive Disorder and Healthy Subjects: Acute Episode and Follow-Up 6 Months after Reaching Remission. Neuroendocrinology, 110(11-12), 1001-1009. https://doi.org/10.1159/000505921

James, S. L., Abate, D., Abate, K. H., Abay, S. M., Abbafati, C., Abbasi, N., ... Murray, C. J. L. (2018). Global, regional, and national incidence, prevalence, and years lived with disability for 354 Diseases and Injuries for 195 countries and territories, 1990-2017: A systematic analysis for the Global Burden of Disease Study 2017. The Lancet, 392(10159), 1789-1858. https://doi.org/10.1016/S0140-6736(18)32279-7

Janssen. (2020). SPRAVATO ${ }^{\circledR}$ (esketamine)* Nasal Spray is Available for Canadian Patients: A New Antidepressant with a Novel Mechanism of Action to Treat Major Depressive Disorder in Adults. Toronto.

Jaya, A. G. P. S., Widnyana, I. M. G., Wiryana, M., Aribawa, I. G. N. M., Aryabiantara, I. W., Hartawan, I. G. A. G. U., ... Senapathi, T. (2016). Effectiveness of low-dose intravenous ketamine to attenuate stress response in patients undergoing emergency cesarean section with spinal anesthesia. Journal of Pain Research, Volume 9, 689-692. https://doi.org/10.2147/JPR.S109616

JHP Pharmaceuticals LLC. (2012). KETALAR-ketamine hydrochloride injection . Rochester. Retrieved from http://www.fda.gov/medwatch/.

Johnston, K. M., Powell, L. C., Anderson, I. M., Szabo, S., \& Cline, S. (2019). The burden of treatment-resistant depression: A systematic review of the economic and quality of life literature. Journal of Affective Disorders, 242, 195-210. https://doi.org/10.1016/j.jad.2018.06.045

Juruena, M. F., Bocharova, M., Agustini, B., \& Young, A. H. (2018, June 1). Atypical depression and non-atypical depression: Is HPA axis function a biomarker? A systematic review. Journal of Affective Disorders. Elsevier B.V. https://doi.org/10.1016/j.jad.2017.09.052

Kalsbeek, A., van der Spek, R., Lei, J., Endert, E., Buijs, R. M., \& Fliers, E. (2012, February 5). Circadian rhythms in the hypothalamo-pituitary-adrenal (HPA) axis. Molecular and Cellular Endocrinology. Elsevier. https://doi.org/10.1016/j.mce.2011.06.042 
Kapur, S., \& Seeman, P. (2002). NMDA receptor antagonists ketamine and PCP have direct effects on the dopamine D2 and serotonin 5-HT2 receptors - Implications for models of schizophrenia. Molecular Psychiatry, 7(8), 837-844. https://doi.org/10.1038/sj.mp.4001093

Karlović, D., Serretti, A., Vrkić, N., Martinac, M., \& Marčinko, D. (2012). Serum concentrations of CRP, IL-6, TNF- $\alpha$ and cortisol in major depressive disorder with melancholic or atypical features. Psychiatry Research, 198(1), 74-80.

https://doi.org/10.1016/j.psychres.2011.12.007

Kayser, S., Bewernick, B. H., Matusch, A., Hurlemann, R., Soehle, M., \& Schlaepfer, T. E. (2015). Magnetic seizure therapy in treatment-resistant depression: Clinical, neuropsychological and metabolic effects. Psychological Medicine, 45(5), 1073-1092. https://doi.org/10.1017/S0033291714002244

Kellner, C. H., Knapp, R., Husain, M. M., Rasmussen, K., Sampson, S., Cullum, M., ... Petrides, G. (2010). Bifrontal, bitemporal and right unilateral electrode placement in ECT:

Randomised trial. British Journal of Psychiatry, 196(3), 226-234. https://doi.org/10.1192/bjp.bp.109.066183

Kennedy, S. H., Lam, R. W., Mcintyre, R. S., Valé Rie Tourjman, S., Bhat, V., Blier, P., ... Uher, R. (2016). Canadian Network for Mood and Anxiety Treatments (CANMAT) 2016 Clinical Guidelines for the Management of Adults with Major Depressive Disorder: Section 3. Pharmacological Treatments. The Canadian Journal of Psychiatry, 61(9), 540-560. https://doi.org/10.1177/0706743716659417

Kerr, J. E., Beck, S. G., \& Handa, R. J. (1996). Androgens modulate glucocorticoid receptor mRNA, but not mineralocorticoid receptor mRNA levels, in the rat hippocampus. Journal of Neuroendocrinology, 8(6), 439-447. https://doi.org/10.1046/j.1365-2826.1996.04735.x

Khalili-Mahani, N., Martini, C. H., Olofsen, E., Dahan, A., \& Niesters, M. (2015). Effect of subanaesthetic ketamine on plasma and saliva cortisol secretion. British Journal of Anaesthesia, 115(1), 68-75. https://doi.org/10.1093/bja/aev135

Khera, A., McGuire, D. K., Murphy, S. A., Stanek, H. G., Das, S. R., Vongpatanasin, W., ... De Lemos, J. A. (2005). Race and gender differences in C-reactive protein levels. Journal of the American College of Cardiology, 46(3), 464-469. https://doi.org/10.1016/j.jacc.2005.04.051

Kiraly, D. D., Horn, S. R., Van Dam, N. T., Costi, S., Schwartz, J., Kim-Schulze, S., ... Murrough, J. W. (2017). Altered peripheral immune profiles in treatment-resistant depression: response to ketamine and prediction of treatment outcome. Translational Psychiatry, 7(3), e1065-e1065. https://doi.org/10.1038/tp.2017.31

Kishimoto, T., Chawla, J. M., Hagi, K., Zarate, C. A., Kane, J. M., Bauer, M., \& Correll, C. U. (2016). Single-dose infusion ketamine and non-ketamine N-methyl-d-aspartate receptor antagonists for unipolar and bipolar depression: A meta-analysis of efficacy, safety and time trajectories. Psychological Medicine, 46(7), 1459-1472. https://doi.org/10.1017/S0033291716000064

Köhler-Forsberg, O., Buttenschøn, H. N., Tansey, K. E., Maier, W., Hauser, J., Dernovsek, M. Z., ... Mors, O. (2017). Association between C-reactive protein (CRP) with depression symptom severity and specific depressive symptoms in major depression. Brain, Behavior, and Immunity, 62, 344-350. https://doi.org/10.1016/j.bbi.2017.02.020

Köhler, O., E. Benros, M., Nordentoft, M., Farkouh, M. E., Iyengar, R. L., Mors, O., \& Krogh, J. (2014, December 1). Effect of anti-inflammatory treatment on depression, depressive symptoms, and adverse effects a systematic review and meta-analysis of randomized 
clinical trials. JAMA Psychiatry. American Medical Association. https://doi.org/10.1001/jamapsychiatry.2014.1611

Kruse, J. L., Congdon, E., Olmstead, R., Njau, S., Breen, E. C., Narr, K. L., ... Irwin, M. R. (2018). Inflammation and Improvement of Depression Following Electroconvulsive Therapy in Treatment-Resistant Depression. The Journal of Clinical Psychiatry, 79(2), 17m11597. https://doi.org/10.4088/JCP.17m11597

Kruse, J. L., Vasavada, M. M., Olmstead, R., Hellemann, G., Wade, B., Breen, E. C., ... Irwin, M. R. (2021). Depression treatment response to ketamine: sex-specific role of interleukin-8, but not other inflammatory markers. Translational Psychiatry, 11(1), 1-9. https://doi.org/10.1038/s41398-021-01268-z

Kryst, J., Kawalec, P., Mitoraj, A. M., Pilc, A., Lasoń, W., \& Brzostek, T. (2020). Efficacy of single and repeated administration of ketamine in unipolar and bipolar depression: a metaanalysis of randomized clinical trials. Pharmacological Reports, 72(3), 543-562. https://doi.org/10.1007/s43440-020-00097-z

Krystal, J. H., Karper, L. P., Seibyl, J. P., Freeman, G. K., Delaney, R., Bremner, J. D., ... Charney, D. S. (1994). Subanesthetic Effects of the Noncompetitive NMDA Antagonist, Ketamine, in Humans: Psychotomimetic, Perceptual, Cognitive, and Neuroendocrine Responses. Archives of General Psychiatry, 51(3), 199-214. https://doi.org/10.1001/archpsyc.1994.03950030035004

Kubitz, N., Mehra, M., Potluri, R. C., Garg, N., \& Cossrow, N. (2013). Characterization of Treatment Resistant Depression Episodes in a Cohort of Patients from a US Commercial Claims Database. PLoS ONE, 8(10), e76882. https://doi.org/10.1371/journal.pone.0076882

Lackie, J. (2019). A Dictionary of Biomedicine. A Dictionary of Biomedicine. Oxford University Press. https://doi.org/10.1093/acref/9780191829116.001.0001

Lai, R., Katalinic, N., Glue, P., Somogyi, A. A., Mitchell, P. B., Leyden, J., ... Loo, C. K. (2014). Pilot dose-response trial of I.V. ketamine in treatment-resistant depression. World Journal of Biological Psychiatry, 15(7), 579-584. https://doi.org/10.3109/15622975.2014.922697

Lanning, C. F., \& Harmel, M. H. (1975, February). Ketamine anesthesia. Annual Review of Medicine. https://doi.org/10.1146/annurev.me.26.020175.001033

Lanquillon, S., Krieg, J. C., Bening-Abu-Shach, U., \& Vedder, H. (2000). Cytokine production and treatment response in major depressive disorder. Neuropsychopharmacology, 22(4), 370-379. https://doi.org/10.1016/S0893-133X(99)00134-7

Lapidus, K. A. B., Levitch, C. F., Perez, A. M., Brallier, J. W., Parides, M. K., Soleimani, L., ... Murrough, J. W. (2014). A randomized controlled trial of intranasal ketamine in major depressive disorder. Biological Psychiatry, 76(12), 970-976. https://doi.org/10.1016/j.biopsych.2014.03.026

Lara, D. R., Bisol, L. W., \& Munari, L. R. (2013). Antidepressant, mood stabilizing and procognitive effects of very low dose sublingual ketamine in refractory unipolar and bipolar depression. International Journal of Neuropsychopharmacology, 16(9), 2111-2117. https://doi.org/10.1017/S1461145713000485

Lathe, R. (2001). Hormones and the hippocampus. Journal of Endocrinology. J Endocrinol. https://doi.org/10.1677/joe.0.1690205

Lee, Y. A., \& Goto, Y. (2011). Chronic stress modulation of prefrontal cortical NMDA receptor expression disrupts limbic structure-prefrontal cortex interaction. European Journal of Neuroscience, 34(3), 426-436. https://doi.org/10.1111/j.1460-9568.2011.07750.x 
Lenze, E. J., Farber, N. B., Kharasch, E., Schweiger, J., Yingling, M., Olney, J., \& Newcomer, J. W. (2016). Ninety-six hour ketamine infusion with co-administered clonidine for treatmentresistant depression: A pilot randomised controlled trial. World Journal of Biological Psychiatry, 17(3), 230-238. https://doi.org/10.3109/15622975.2016.1142607

Li, C.-T., Chen, M.-H., Lin, W.-C., Hong, C.-J., Yang, B.-H., Liu, R.-S., ... Su, T.-P. (2016). The effects of low-dose ketamine on the prefrontal cortex and amygdala in treatmentresistant depression: A randomized controlled study. Human Brain Mapping, 37(3), 10801090. https://doi.org/10.1002/hbm.23085

Li, N., Lee, B., Liu, R. J., Banasr, M., Dwyer, J. M., Iwata, M., ... Duman, R. S. (2010). mTORdependent synapse formation underlies the rapid antidepressant effects of NMDA antagonists. Science, 329(5994), 959-964. https://doi.org/10.1126/science.1190287

Loix, S., De Kock, M., \& Henin, P. (2011, January 1). The anti-inflammatory effects of ketamine: State of the art. Acta Anaesthesiologica Belgica. Retrieved from http://europepmc.org/article/med/21612145

Lombardo, G., Enache, D., Gianotti, L., Schatzberg, A. F., Young, A. H., Pariante, C. M., \& Mondelli, V. (2019). Baseline cortisol and the efficacy of antiglucocorticoid treatment in mood disorders: A meta-analysis. Psychoneuroendocrinology, 110. https://doi.org/10.1016/j.psyneuen.2019.104420

Loo, C. K., Gálvez, V., O’Keefe, E., Mitchell, P. B., Hadzi-Pavlovic, D., Leyden, J., ... Glue, P. (2016). Placebo-controlled pilot trial testing dose titration and intravenous, intramuscular and subcutaneous routes for ketamine in depression. Acta Psychiatrica Scandinavica, 134(1), 48-56. https://doi.org/10.1111/acps.12572

Lopresti, A. L., Maker, G. L., Hood, S. D., \& Drummond, P. D. (2014, January 3). A review of peripheral biomarkers in major depression: The potential of inflammatory and oxidative stress biomarkers. Progress in Neuro-Psychopharmacology and Biological Psychiatry. Elsevier. https://doi.org/10.1016/j.pnpbp.2013.09.017

Maeng, S., Zarate, C. A., Du, J., Schloesser, R. J., McCammon, J., Chen, G., \& Manji, H. K. (2008). Cellular Mechanisms Underlying the Antidepressant Effects of Ketamine: Role of $\alpha$-Amino-3-Hydroxy-5-Methylisoxazole-4-Propionic Acid Receptors. Biological Psychiatry, 63(4), 349-352. https://doi.org/10.1016/j.biopsych.2007.05.028

McGonagle, K. A., \& Kessler, R. C. (1990). Chronic stress, acute stress, and depressive symptoms. American Journal of Community Psychology, 18(5), 681-706. https://doi.org/10.1007/BF00931237

McKay, M. S., \& Zakzanis, K. K. (2010, February 1). The impact of treatment on HPA axis activity in unipolar major depression. Journal of Psychiatric Research. Pergamon. https://doi.org/10.1016/j.jpsychires.2009.07.012

Milev, R. V., Giacobbe, P., Kennedy, S. H., Blumberger, D. M., Daskalakis, Z. J., Downar, J., ... Ravindran, A. V. (2016). Canadian Network for Mood and Anxiety Treatments (CANMAT) 2016 clinical guidelines for the management of adults with major depressive disorder: Section 4. Neurostimulation treatments. Canadian Journal of Psychiatry. SAGE Publications Inc. https://doi.org/10.1177/0706743716660033

Millan, M. J., Gobert, A., Lejeune, F., Dekeyne, A., Newman-Tancredi, A., Pasteau, V., ... Cussac, D. (2003). The novel melatonin agonist agomelatine (S20098) is an antagonist at 5hydroxytryptamine $2 \mathrm{C}$ receptors, blockade of which enhances the activity of frontocortical dopaminergic and adrenergic pathways. Journal of Pharmacology and Experimental Therapeutics, 306(3), 954-964. https://doi.org/10.1124/jpet.103.051797 
Miller, A. H., Maletic, V., \& Raison, C. L. (2009, May 1). Inflammation and Its Discontents: The Role of Cytokines in the Pathophysiology of Major Depression. Biological Psychiatry. Elsevier. https://doi.org/10.1016/j.biopsych.2008.11.029

Miller, A. H., \& Raison, C. L. (2016, January 1). The role of inflammation in depression: From evolutionary imperative to modern treatment target. Nature Reviews Immunology. Nature Publishing Group. https://doi.org/10.1038/nri.2015.5

Mishra, S. K., Hidau, M. K., \& Rai, S. (2021). Memantine treatment exerts an antidepressantlike effect by preventing hippocampal mitochondrial dysfunction and memory impairment via upregulation of CREB/BDNF signaling in the rat model of chronic unpredictable stressinduced depression. Neurochemistry International, 142, 104932. https://doi.org/10.1016/j.neuint.2020.104932

Mitchell, N. D., \& Baker, G. B. (2010). An update on the role of glutamate in the pathophysiology of depression. Acta Psychiatrica Scandinavica, 122(3), 192-210. https://doi.org/10.1111/j.1600-0447.2009.01529.x

Moghadami, S., Jahanshahi, M., Sepehri, H., \& Amini, H. (2016). Gonadectomy reduces the density of androgen receptor-immunoreactive neurons in male rat's hippocampus: Testosterone replacement compensates it. Behavioral and Brain Functions, 12(1), 1-10. https://doi.org/10.1186/s12993-016-0089-9

Moghaddam, B., Adams, B., Verma, A., \& Daly, D. (1997). Activation of glutamatergic neurotransmission by ketamine: A novel step in the pathway from NMDA receptor blockade to dopaminergic and cognitive disruptions associated with the prefrontal cortex. Journal of Neuroscience, 17(8), 2921-2927. https://doi.org/10.1523/jneurosci.17-0802921.1997

Monastero, R. N., \& Pentyala, S. (2017). Cytokines as Biomarkers and Their Respective Clinical Cutoff Levels. International Journal of Inflammation. Hindawi Limited. https://doi.org/10.1155/2017/4309485

Monteggia, L. M., Gideons, E., \& Kavalali, E. T. (2013, June 15). The role of eukaryotic elongation factor 2 kinase in rapid antidepressant action of ketamine. Biological Psychiatry. NIH Public Access. https://doi.org/10.1016/j.biopsych.2012.09.006

Montgomery, S. A., \& Asberg, M. (1979). A new depression scale designed to be sensitive to change. British Journal of Psychiatry, 134(4), 382-389.

https://doi.org/10.1192/bjp.134.4.382

Morgan, C. J. A., Muetzelfeldt, L., \& Curran, H. V. (2010). Consequences of chronic ketamine self-administration upon neurocognitive function and psychological wellbeing: A 1-year longitudinal study. Addiction, 105(1), 121-133. https://doi.org/10.1111/j.13600443.2009.02761.x

MP Biomedicals. (n.d.). Suggested Salivary Procedure For Use with the MP Biomedicals Coated Tube 125I Cortisol Kit. Solon, OH: MP Biomedicals.

Mrazek, D. A., Hornberger, J. C., Altar, C. A., \& Degtiar, I. (2014, August 1). A review of the clinical, economic, and societal burden of treatment-resistant depression: 1996-2013. Psychiatric Services. American Psychiatric AssociationArlington, VA. https://doi.org/10.1176/appi.ps.201300059

Muller, J., Pentyala, S., Dilger, J., \& Pentyala, S. (2016). Ketamine enantiomers in the rapid and sustained antidepressant effects. Therapeutic Advances in Psychopharmacology, 6(3), 185192. https://doi.org/10.1177/2045125316631267

Müller, M. J., Himmerich, H., Kienzle, B., \& Szegedi, A. (2003). Differentiating moderate and 
severe depression using the Montgomery-Åsberg depression rating scale (MADRS).

Journal of Affective Disorders, 77(3), 255-260. https://doi.org/10.1016/S0165-

0327(02)00120-9

Murrough, J. W., Iosifescu, D. V., Chang, L. C., Al Jurdi, R. K., Green, C. E., Perez, A. M., ... Mathew, S. J. (2013). Antidepressant efficacy of ketamine in treatment-resistant major depression: A two-site randomized controlled trial. American Journal of Psychiatry, 170(10), 1134-1142. https://doi.org/10.1176/appi.ajp.2013.13030392

Murrough, J. W., Perez, A. M., Pillemer, S., Stern, J., Parides, M. K., Aan Het Rot, M., ... Iosifescu, D. V. (2013). Rapid and longer-term antidepressant effects of repeated ketamine infusions in treatment-resistant major depression. Biological Psychiatry, 74(4), 250-256. https://doi.org/10.1016/j.biopsych.2012.06.022

Nagasawa, S. (2008). C-Reactive Protein : New Research. New York, UNITED STATES: Nova Science Publishers, Incorporated. Retrieved from http://ebookcentral.proquest.com/lib/oculcarleton-ebooks/detail.action?docID=3018750

Naughton, M., Clarke, G., Oleary, O. F., Cryan, J. F., \& Dinan, T. G. (2014, March). A review of ketamine in affective disorders: Current evidence of clinical efficacy, limitations of use and pre-clinical evidence on proposed mechanisms of action. Journal of Affective Disorders. https://doi.org/10.1016/j.jad.2013.11.014

Navaneelan, T. (2017). Suicide rates: An overview. Statistics Canada. Retrieved from https://www150.statcan.gc.ca/n1/pub/82-624-x/2012001/article/11696-eng.htm

Nelsen, M. R., \& Dunner, D. L. (1995). Clinical and differential diagnostic aspects of treatmentresistant depression. J. Psychiat. Res, 29(1), 43-50.

Newport, D. J., Carpenter, L. L., McDonald, W. M., Potash, J. B., Tohen, M., \& Nemeroff, C. B. (2015). Ketamine and other NMDA antagonists: Early clinical trials and possible mechanisms in depression. American Journal of Psychiatry, 172(10), 950-966. https://doi.org/10.1176/appi.ajp.2015.15040465

Nickel, T., Sonntag, A., Schill, J., Zobel, A. W., Ackl, N., Brunnauer, A., ... Holsboer, F. (2003). Clinical and Neurobiological Effects of Tianeptine and Paroxetine in Major Depression. Journal of Clinical Psychopharmacology, 23(2). Retrieved from https://journals.lww.com/psychopharmacology/Fulltext/2003/04000/Clinical_and_Neurobio logical_Effects_of_Tianeptine.8.aspx

Nikisch, G., Mathé, A. A., Czernik, A., Thiele, J., Bohner, J., Eap, C. B., ... Baumann, P. (2005). Long-term citalopram administration reduces responsiveness of HPA axis in patients with major depression: Relationship with S-citalopram concentrations in plasma and cerebrospinal fluid (CSF) and clinical response. Psychopharmacology, 181(4), 751-760. https://doi.org/10.1007/s00213-005-0034-3

Nishimura, M., Sato, K., Okada, T., Yoshiya, I., Schloss, P., Shimada, S., \& Tohyama, M. (1998). Ketamine inhibits monoamine transporters expressed in human embryonic kidney 293 cells. Anesthesiology, 88(3), 768-774. https://doi.org/10.1097/00000542-19980300000029

Nock, M. K., Hwang, I., Sampson, N. A., \& Kessler, R. C. (2010). Mental disorders, comorbidity and suicidal behavior: Results from the national comorbidity survey replication. Molecular Psychiatry, 15(8), 868-876. https://doi.org/10.1038/mp.2009.29

Nock, Matthew K., Borges, G., Bromet, E. J., Alonso, J., Angermeyer, M., Beautrais, A., ... Williams, D. (2008). Cross-national prevalence and risk factors for suicidal ideation, plans and attempts. British Journal of Psychiatry, 192(2), 98-105. 
https://doi.org/10.1192/bjp.bp.107.040113

Nock, Matthew K., Borges, G., Bromet, E. J., Cha, C. B., Kessler, R. C., \& Lee, S. (2008).

Suicide and Suicidal Behaviour. Epidemiologic Reviews, 30(1), 133-154.

https://doi.org/10.1093/EPIREV

Nolen-Hoeksema, S., \& Girgus, J. S. (1994). The emergence of gender differences in depression during adolescence. Psychological Bulletin, 115(3), 424-443. https://doi.org/10.1037/00332909.115.3.424

Ooishi, Y., Kawato, S., Hojo, Y., Hatanaka, Y., Higo, S., Murakami, G., ... Mukai, H. (2012, August). Modulation of synaptic plasticity in the hippocampus by hippocampus-derived estrogen and androgen. Journal of Steroid Biochemistry and Molecular Biology. J Steroid Biochem Mol Biol. https://doi.org/10.1016/j.jsbmb.2011.10.004

Osimo, E. F., Baxter, L. J., Lewis, G., Jones, P. B., \& Khandaker, G. M. (2019). Prevalence of low-grade inflammation in depression: a systematic review and meta-analysis of CRP levels. https://doi.org/10.1017/S0033291719001454

Ostroff, R., \& Kothari, J. S. (2015). Reversal of Non-Suppression of Cortisol Levels in a Patient With Refractory Depression Receiving Ketamine. American Journal of Psychiatry, 172(1), 95-96. https://doi.org/10.1176/appi.ajp.2014.14060776

Owens, M. J., Morgan, W. N., Plott, S. J., \& Nemeroff, C. B. (1997). Neurotransmitter Receptor and Transporter Binding Profile of Antidepressants and Their Metabolites . Journal of Pharmacology and Experimental Therapeutics, 283(3), 1305-1322. Retrieved from http://jpet.aspetjournals.org/content/283/3/1305.long

Oyola, M. G., \& Handa, R. J. (2017). Hypothalamic-pituitary-adrenal and hypothalamicpituitary-gonadal axes: sex differences in regulation of stress responsivity. Stress (Amsterdam, Netherlands), 20(5), 476-494. https://doi.org/10.1080/10253890.2017.1369523

Ozgocer, T., Ucar, C., \& Yildiz, S. (2017). Cortisol awakening response is blunted and pain perception is increased during menses in cyclic women. Psychoneuroendocrinology, 77, 158-164. https://doi.org/10.1016/j.psyneuen.2016.12.011

Papakostas, G. I. (2020, April 1). Maintaining rapid antidepressant effects following ketamine infusion: A major unmet need. Journal of Clinical Psychiatry. Physicians Postgraduate Press Inc. https://doi.org/10.4088/JCP.19r12859

Papakostas, G. I., Shelton, R. C., Zajecka, J. M., Bottiglieri, T., Roffman, J., Cassiello, C., ... Fava, M. (2014). Effect of Adjunctive $<$ scp $>1</$ scp $>$-Methylfolate $15 \mathrm{mg}$ Among Inadequate Responders to SSRIs in Depressed Patients Who Were Stratified by Biomarker Levels and Genotype. The Journal of Clinical Psychiatry, 75(08), 855-863. https://doi.org/10.4088/JCP.13m08947

Pariante, C. M., \& Lightman, S. L. (2008, September 1). The HPA axis in major depression: classical theories and new developments. Trends in Neurosciences. Elsevier Current Trends. https://doi.org/10.1016/j.tins.2008.06.006

Parikh, S. V., Quilty, L. C., Ravitz, P., Rosenbluth, M., Pavlova, B., Grigoriadis, S., ... Uher, R. (2016). Canadian Network for Mood and Anxiety Treatments (CANMAT) 2016 clinical guidelines for the management of adults with major depressive disorder: Section 2. Psychological treatments. Canadian Journal of Psychiatry. SAGE Publications Inc. https://doi.org/10.1177/0706743716659418

Park, M., Newman, L. E., Gold, P. W., Luckenbaugh, D. A., Yuan, P., Machado-Vieira, R., \& Zarate, C. A. (2017). Change in cytokine levels is not associated with rapid antidepressant 
response to ketamine in treatment-resistant depression. Journal of Psychiatric Research, 84, 113-118. https://doi.org/10.1016/J.JPSYCHIRES.2016.09.025

Patten, S. B., Williams, J. V. A., Lavorato, D. H., Fiest, K. M., Bulloch, A. G. M., \& Wang, J. L. (2015). The prevalence of major depression is not changing. Canadian Journal of Psychiatry, 60(1), 31-34. https://doi.org/10.1177/070674371506000107

Patten, S. B., Williams, J. V. A., Lavorato, D. H., Wang, J. L., McDonald, K., \& Bulloch, A. G. M. (2015). Descriptive epidemiology of major depressive disorder in Canada in 2012. Canadian Journal of Psychiatry, 60(1), 23-30. https://doi.org/10.1177/070674371506000106

Paul, I. A., Nowak, G., Layer, R. T., Popik, P., \& Skolnick, P. (1994). Adaptation of the Nmethyl-D-aspartate receptor complex following chronic antidepressant treatments. Journal of Pharmacology and Experimental Therapeutics, 269(1).

Pearson, C., Janz, T., \& Ali, J. (2013). Mental and substance use disorders in Canada Health at a Glance. Retrieved from www.statcan.gc.ca,

Phillips, J. L., Jaworska, N., Kamler, E., Bhat, V., Blier, J., Foster, J. A., ... Blier, P. (2020). A randomized, crossover comparison of ketamine and electroconvulsive therapy for treatment of major depressive episodes: A Canadian biomarker integration network in depression (CAN-BIND) study protocol. BMC Psychiatry, 20(1). https://doi.org/10.1186/s12888-02002672-3

Phillips, J. L., Norris, S., Talbot, J., Birmingham, M., Hatchard, T., Ortiz, A., ... Blier, P. (2019). Single, repeated, and maintenance ketamine infusions for treatment-resistant depression: A randomized controlled trial. In American Journal of Psychiatry (Vol. 176, pp. 401-409). American Psychiatric Association. https://doi.org/10.1176/appi.ajp.2018.18070834

Phillips, J. L., Norris, S., Talbot, J., Hatchard, T., Ortiz, A., Birmingham, M., ... Blier, P. (2020). Single and repeated ketamine infusions for reduction of suicidal ideation in treatmentresistant depression. Neuropsychopharmacology, 45(4), 606-612. https://doi.org/10.1038/s41386-019-0570-x

Powell, D. J., \& Schlotz, W. (2012). Daily Life Stress and the Cortisol Awakening Response: Testing the Anticipation Hypothesis. PLoS ONE, 7(12), 52067. https://doi.org/10.1371/journal.pone.0052067

Pruessner, J. C., Wolf, O. T., Hellhammer, D. H., Buske-Kirschbaum, A., Von Auer, K., Jobst, S., ... Kirschbaum, C. (1997). Free cortisol levels after awakening: A reliable biological marker for the assessment of adrenocortical activity. Life Sciences, 61(26), 2539-2549. https://doi.org/10.1016/S0024-3205(97)01008-4

Pruessner, Jens C., Kirschbaum, C., Meinlschmid, G., \& Hellhammer, D. H. (2003). Two formulas for computation of the area under the curve represent measures of total hormone concentration versus time-dependent change. Psychoneuroendocrinology, 28(7), 916-931. https://doi.org/10.1016/S0306-4530(02)00108-7

Rai, D., Zitko, P., Jones, K., Lynch, J., \& Araya, R. (2013, March). Country- and individuallevel socioeconomic determinants of depression: Multilevel cross-national comparison. British Journal of Psychiatry. Cambridge University Press. https://doi.org/10.1192/bjp.bp.112.112482

Raison, C. L., Rutherford, R. E., Woolwine, B. J., Shuo, C., Schettler, P., Drake, D. F., ... Miller, A. H. (2013). A randomized controlled trial of the tumor necrosis factor antagonist infliximab for treatment-resistant depression: The role of baseline inflammatory biomarkers. Archives of General Psychiatry, 70(1), 31-41. 
https://doi.org/10.1001/2013.jamapsychiatry.4

Rasmussen, K. G., Lineberry, T. W., Galardy, C. W., Kung, S., Lapid, M. I., Palmer, B. A., ... Frye, M. A. (2013). Serial infusions of low-dose ketamine for major depression. Journal of Psychopharmacology, 27(5), 444-450. https://doi.org/10.1177/0269881113478283

Reichenberg, A., Yirmiya, R., Schuld, A., Kraus, T., Haack, M., Morag, A., \& Pollmächer, T. (2001). Cytokine-associated emotional and cognitive disturbances in humans. Archives of General Psychiatry, 58(5), 445-452. https://doi.org/10.1001/archpsyc.58.5.445

Rivest, S. (2010). Interactions between the immune and neuroendocrine systems. Progress in Brain Research, 181(C), 43-53. https://doi.org/10.1016/S0079-6123(08)81004-7

Rizvi, S. J., Grima, E., Tan, M., Rotzinger, S., Lin, P., McIntyre, R. S., \& Kennedy, S. H. (2014). Treatment-resistant depression in primary care across Canada. Canadian Journal of Psychiatry, 59(7), 349-357. https://doi.org/10.1177/070674371405900702

Rizzetto, L., Fava, F., Tuohy, K. M., \& Selmi, C. (2018, August 1). Connecting the immune system, systemic chronic inflammation and the gut microbiome: The role of sex. Journal of Autoimmunity. Academic Press. https://doi.org/10.1016/j.jaut.2018.05.008

Rota, E., Broda, R., Cangemi, L., Migliaretti, G., Paccotti, P., Rosso, C., ... Portaleone, P. (2005). Neuroendocrine (HPA axis) and clinical correlates during fluvoxamine and amitriptyline treatment. Psychiatry Research, 133(2-3), 281-284. https://doi.org/10.1016/j.psychres.2003.12.030

Rush, A. J., Trivedi, M. H., Ibrahim, H. M., Carmody, T. J., Arnow, B., Klein, D. N., ... Keller, M. B. (2003). The 16-item Quick Inventory of Depressive Symptomatology (QIDS), clinician rating (QIDS-C), and self-report (QIDS-SR): A psychometric evaluation in patients with chronic major depression. Biological Psychiatry, 54(5), 573-583. https://doi.org/10.1016/S0006-3223(02)01866-8

Rush, A. J., Trivedi, M. H., Wisniewski, S. R., Nierenberg, A. A., Stewart, J. W., Warden, D., ... Fava, M. (2006). Acute and longer-term outcomes in depressed outpatients requiring one or several treatment steps: A STAR*D report. American Journal of Psychiatry, 163(11), 19051917. https://doi.org/10.1176/ajp.2006.163.11.1905

Sackeim, H. A. (2001). The Definition and Meaning of Treatment-Resistant Depression. The Journal of Clinical Psychiatry, 62(suppl 16), 10-17.

Saland, S. K., Duclot, F., \& Kabbaj, M. (2017, April 1). Integrative analysis of sex differences in the rapid antidepressant effects of ketamine in preclinical models for individualized clinical outcomes. Current Opinion in Behavioral Sciences. Elsevier Ltd. https://doi.org/10.1016/j.cobeha.2016.11.002

Saland, S. K., Schoepfer, K. J., \& Kabbaj, M. (2016). Hedonic sensitivity to low-dose ketamine is modulated by gonadal hormones in a sex-dependent manner. Scientific Reports, 6(1), 21322. https://doi.org/10.1038/srep21322

Salimetrics. (2021). Calculating Inter- and Intra-Assay Coefficients of Variability - Salimetrics. Retrieved May 24, 2021, from https://salimetrics.com/calculating-inter-and-intra-assaycoefficients-of-variability/

Sanacora, G., \& Schatzberg, A. F. (2015). Ketamine: Promising Path or False Prophecy in the Development of Novel Therapeutics for Mood Disorders. Neuropsychopharmacology, 40(2), 259-267. https://doi.org/10.1038/npp.2014.261

Sanacora, G., Treccani, G., \& Popoli, M. (2012). Towards a glutamate hypothesis of depression: An emerging frontier of neuropsychopharmacology for mood disorders. In Neuropharmacology (Vol. 62, pp. 63-77). 
https://doi.org/10.1016/j.neuropharm.2011.07.036

Sanchez, C., Asin, K. E., \& Artigas, F. (2015, January 1). Vortioxetine, a novel antidepressant with multimodal activity: Review of preclinical and clinical data. Pharmacology and Therapeutics. Elsevier Inc. https://doi.org/10.1016/j.pharmthera.2014.07.001

Sassano-Higgins, S., Baron, D., Juarez, G., Esmaili, N., \& Gold, M. (2016). A Review of Ketamine Abuse and Diversion. Depression and Anxiety, 33(8), 718-727. https://doi.org/10.1002/da.22536

Schak, K. M., Vande Voort, J. L., Johnson, E. K., Kung, S., Leung, J. G., Rasmussen, K. G., ... Frye, M. A. (2016). Potential Risks of Poorly Monitored Ketamine Use in Depression Treatment. American Journal of Psychiatry, 173(3), 215-218. https://doi.org/10.1176/appi.ajp.2015.15081082

Schuh, F. T. (1975). Influence Of Ketamine On Human Plasma Cholinesterase. Br. J. Anaesth, 47, 1315. https://doi.org/10.1093/bja/47.12.1315

Schüle, C. (2007). Neuroendocrinological mechanisms of actions of antidepressant drugs. Journal of Neuroendocrinology, 19(3), 213-226. https://doi.org/10.1111/j.13652826.2006.01516.x

Schüle, C., Baghai, T. C., Eser, D., Schwarz, M., Bondy, B., \& Rupprecht, R. (2009). Effects of mirtazapine on dehydroepiandrosterone-sulfate and cortisol plasma concentrations in depressed patients. Journal of Psychiatric Research, 43(5), 538-545. https://doi.org/10.1016/j.jpsychires.2008.07.003

Serafini, G., Pompili, M., Belvederi Murri, M., Respino, M., Ghio, L., Girardi, P., ... Amore, M. (2015, June 1). The effects of repetitive transcranial magnetic stimulation on cognitive performance in treatment-resistant depression. A systematic review. Neuropsychobiology. S. Karger AG. https://doi.org/10.1159/000381351

Sharafi, E., Taghva, A., Arbabi, M., Dadarkhah, A., \& Ghaderi, J. (2019). Transcranial Direct Current Stimulation for Treatment-Resistant Major Depression: A Double-Blind Randomized Sham-Controlled Trial. Clinical EEG and Neuroscience, 50(6), 375-382. https://doi.org/10.1177/1550059419863209

Sheehan, D. V., Lecrubier, Y., Sheehan, K. H., Amorim, P., Janavs, J., Weiller, E., ... Dunbar, G. C. (1998). The Mini-International Neuropsychiatric Interview (M.I.N.I.): The Development and Validation of a Structured Diagnostic Psychiatric Interview for DSM-IV and ICD-10. The Journal of Clinical Psychiatry, 59(suppl 20), 22-33.

Sheng, Z., Yanai, A., Fujinaga, R., Kawano, J., Tanaka, M., Watanabe, Y., \& Shinoda, K. (2003). Gonadal and adrenal effects on the glucocorticoid receptor in the rat hippocampus, with special reference to regulation by estrogen from an immunohistochemical view-point. Neuroscience Research, 46(2), 205-218. https://doi.org/10.1016/S0168-0102(03)00056-7

Shin, I., Ahn, R. sup, Chun, S. il, Lee, Y. jin, Kim, M. soo, Lee, C. kwan, \& Sung, S. (2011). Cortisol awakening response and nighttime salivary cortisol levels in healthy working Korean subjects. Yonsei Medical Journal, 52(3), 435-444. https://doi.org/10.3349/ymj.2011.52.3.435

Shiroma, P. R., Johns, B., Kuskowski, M., Wels, J., Thuras, P., Albott, C. S., \& Lim, K. O. (2014). Augmentation of response and remission to serial intravenous subanesthetic ketamine in treatment resistant depression. Journal of Affective Disorders, 155(1), 123-129. https://doi.org/10.1016/j.jad.2013.10.036

Siegel, R. (1978). Phencyclidine and ketamine intoxication: a study of four populations of recreational users. NIDA Res Monogr, 21, 119-147. Retrieved from 
https://pubmed.ncbi.nlm.nih.gov/101865/

Singh, J. B., Fedgchin, M., Daly, E., Xi, L., Melman, C., De Bruecker, G., ... Van Nueten, L. (2016). Intravenous Esketamine in Adult Treatment-Resistant Depression: A Double-Blind, Double-Randomization, Placebo-Controlled Study. Biological Psychiatry, 80(6), 424-431. https://doi.org/10.1016/j.biopsych.2015.10.018

Sinyor, M., Schaffer, A., \& Levitt, A. (2010, March 1). The Sequenced Treatment Alternatives to Relieve Depression (STAR*D) trial: A review. Canadian Journal of Psychiatry. Canadian Psychiatric Association. https://doi.org/10.1177/070674371005500303

Skolnick, P., Layer, R. T., Popik, P., Nowak, G., Paul, I. A., \& Trullas, R. (1996). Adaptation of N-methyl-D-aspartate (NMDA) receptors following antidepressant treatment: Implications for the pharmacotherapy of depression. Pharmacopsychiatry, 29(1), 23-26. https://doi.org/10.1055/s-2007-979537

Skolnick, Phil. (1999, June 30). Antidepressants for the new millennium. European Journal of Pharmacology. Eur J Pharmacol. https://doi.org/10.1016/S0014-2999(99)00330-1

Song, B. M., Lee, J. M., Choi, W., Youm, Y., Chu, S. H., Park, Y. R., \& Kim, H. C. (2015). Association between $\mathrm{C}$ reactive protein level and depressive symptoms in an elderly Korean population: Korean Social Life, Health and Aging Project. BMJ Open. BMJ Publishing Group. https://doi.org/10.1136/bmjopen-2014-006429

Sos, P., Klirova, M., Novak, T., Kohutova, B., Horacek, J., \& Palenicek, T. (2013). Relationship of ketamine's antidepressant and psychotomimetic effects in unipolar depression. Neuroendocrinology Letters, 34(4), 287-293. Retrieved from www.nel.edu

Souery, D., Amsterdam, J., De Montigny, C., Lecrubier, Y., Montgomery, S., Lipp, O., ... Mendlewicz, J. (1999). Treatment resistant depression: Methodological overview and operational criteria. European Neuropsychopharmacology, 9(1-2), 83-91. https://doi.org/10.1016/S0924-977X(98)00004-2

Souery, Daniel, Oswald, P., Massat, I., Bailer, U., Bollen, J., Demyttenaere, K., ... Mendlewicz, J. (2007). Clinical factors associated with treatment resistance in major depressive disorder: Results from a European multicenter study. Journal of Clinical Psychiatry, 68(7), 10621070. https://doi.org/10.4088/jcp.v68n0713

Stahl, S. M., Pradko, J. F., Haight, B. R., Modell, J. G., Rockett, C. B., \& Learned-Coughlin, S. (2004). A Review of the Neuropharmacology of Bupropion, a Dual Norepinephrine and Dopamine Reuptake Inhibitor. The Primary Care Companion to The Journal of Clinical Psychiatry, 06(04), 159-166. https://doi.org/10.4088/pcc.v06n0403

Stetler, C., \& Miller, G. E. (2011). Depression and Hypothalamic-Pituitary-Adrenal Activation: A Quantitative Summary of Four Decades of Research. Psychosomatic Medicine, 73(2), 114-126. https://doi.org/10.1097/PSY.0b013e31820ad12b

Strawbridge, R., Arnone, D., Danese, A., Papadopoulos, A., Herane Vives, A., \& Cleare, A. J. (2015, October 1). Inflammation and clinical response to treatment in depression: A metaanalysis. European Neuropsychopharmacology. Elsevier. https://doi.org/10.1016/j.euroneuro.2015.06.007

Strickland, P. L., Deakin, J. F. W., Percival, C., Dixon, J., Gater, R. A., \& Goldberg, D. P. (2002). Bio-social origins of depression in the community: Interactions between social adversity, cortisol and serotonin neurotransmission. British Journal of Psychiatry, 180(FEB.), 168-173. https://doi.org/10.1192/bjp.180.2.168

Strong, C. E., \& Kabbaj, M. (2018, November 1). On the safety of repeated ketamine infusions for the treatment of depression: Effects of sex and developmental periods. Neurobiology of 
Stress. Elsevier Inc. https://doi.org/10.1016/j.ynstr.2018.09.001

Suijk, D. L. S., Dols, A., van Exel, E., Stek, M. L., Veltman, E., Bouckaert, F., ... Rhebergen, D. (2019). Salivary cortisol as predictor for depression characteristics and remission in electroconvulsive therapy in older persons. World Journal of Biological Psychiatry, 20(9), 683-690. https://doi.org/10.1080/15622975.2018.1433326

Talbot, J., Phillips, J. L., \& Blier, P. (2019, November 1). Ketamine for chronic depression: Two cautionary tales. Journal of Psychiatry and Neuroscience. Canadian Medical Association. https://doi.org/10.1503/jpn.190073

Thelen, C., Flaherty, E., Saurine, J., Sens, J., Mohamed, S., \& Pitychoutis, P. M. (2019). Sex Differences in the Temporal Neuromolecular and Synaptogenic Effects of the Rapid-acting Antidepressant Drug Ketamine in the Mouse Brain. Neuroscience, 398, 182-192. https://doi.org/10.1016/j.neuroscience.2018.11.053

Trivedi, M. H., Rush, A. J., Wisniewski, S. R., Nierenberg, A. A., Warden, D., Ritz, L., ... Fava, M. (2006). Evaluation of outcomes with citalopram for depression using measurementbased care in STAR*D: Implications for clinical practice. American Journal of Psychiatry, 163(1), 28-40. https://doi.org/10.1176/appi.ajp.163.1.28

Troubat, R., Barone, P., Leman, S., Desmidt, T., Cressant, A., Atanasova, B., ... Camus, V. (2021). Neuroinflammation and depression: A review. European Journal of Neuroscience, 53(1), 151-171. https://doi.org/10.1111/ejn.14720

Trullas, R., \& Skolnick, P. (1990). Functional antagonists at the NMDA receptor complex exhibit antidepressant actions. European Journal of Pharmacology, 185(1), 1-10. https://doi.org/10.1016/0014-2999(90)90204-J

U.S. Food \& Drug Administration. (1970, February 19). FDA-Approved Drugs. Retrieved July 28,2020 , from

https://www.accessdata.fda.gov/scripts/cder/daf/index.cfm?event=overview.process\&Appl $\mathrm{No}=016812$

U.S. Food \& Drug Administration. (2019, March 5). FDA approves new nasal spray medication for treatment-resistant depression; available only at a certified doctor's office or clinic | FDA. Retrieved July 30, 2020, from https://www.fda.gov/news-events/pressannouncements/fda-approves-new-nasal-spray-medication-treatment-resistant-depressionavailable-only-certified

Ulrich-Lai, Y. M., \& Herman, J. P. (2009, June 13). Neural regulation of endocrine and autonomic stress responses. Nature Reviews Neuroscience. Nature Publishing Group. https://doi.org/10.1038/nrn2647

Valkanova, V., Ebmeier, K. P., \& Allan, C. L. (2013, September 25). CRP, IL-6 and depression: A systematic review and meta-analysis of longitudinal studies. Journal of Affective Disorders. Elsevier B.V. https://doi.org/10.1016/j.jad.2013.06.004

Vammen, M. A., Mikkelsen, S., Hansen, Å. M., Grynderup, M. B., Andersen, J. H., Bonde, J. P., ... Thomsen, J. F. (2014). Salivary cortisol and depression in public sector employees: Cross-sectional and short term follow-up findings. Psychoneuroendocrinology, 41, 63-74. https://doi.org/10.1016/j.psyneuen.2013.12.006

Vande Voort, J. L., Morgan, R. J., Kung, S., Rasmussen, K. G., Rico, J., Palmer, B. A., ... Bobo, W. V. (2016). Continuation phase intravenous ketamine in adults with treatment-resistant depression. Journal of Affective Disorders, 206, 300-304.

https://doi.org/10.1016/j.jad.2016.09.008

Vargas, I., Mayer, S., \& Lopez-Duran, N. (2017). The Cortisol Awakening Response and 
Depressive Symptomatology: The Moderating Role of Sleep and Gender. Stress and Health, 33(3), 199-210. https://doi.org/10.1002/smi.2691

Vetter, M. L., Wadden, T. A., Vinnard, C., Moore, R. H., Khan, Z., Volger, S., ...

Faulconbridge, L. F. (2013). Gender differences in the relationship between symptoms of depression and high-sensitivity CRP. International Journal of Obesity, 37(0 1), S38-S43. https://doi.org/10.1038/ijo.2013.95

Vincent, J. P., Kartalovski, B., Geneste, P., Kamenka, J. M., \& Lazdunski, M. (1979). Interaction of phencyclidine ('angel dust') with a specific receptor in rat brain membranes. Proceedings of the National Academy of Sciences of the United States of America, 76(9), 4678-4682. https://doi.org/10.1073/pnas.76.9.4678

Vollenweider, F. X., Leenders, K. L., Øye, I., Hell, D., \& Angst, J. (1997). Differential psychopathology and patterns of cerebral glucose utilisation produced by (S)- and (R)ketamine in healthy volunteers using positron emission tomography (PET). European Neuropsychopharmacology, 7(1), 25-38. https://doi.org/10.1016/S0924-977X(96)00042-9

Vreeburg, S. A., Hoogendijk, W. J. G., Van Pelt, J., DeRijk, R. H., Verhagen, J. C. M., Van Dyck, R., ... Penninx, B. W. J. H. (2009). Major depressive disorder and hypothalamicpituitary-adrenal axis activity: Results from a large cohort study. Archives of General Psychiatry, 66(6), 617-626. https://doi.org/10.1001/archgenpsychiatry.2009.50

Walker, E. F., Brennan, P. A., Esterberg, M., Brasfield, J., Pearce, B., \& Compton, M. T. (2010). Longitudinal changes in cortisol secretion and conversion to psychosis in at-risk youth. Journal of Abnormal Psychology, 119(2), 401-408. https://doi.org/10.1037/a0018399

Wan, L.-B., Levitch, C. F., Perez, A. M., Brallier, J. W., Iosifescu, D. V., Chang, L. C., ... Murrough, J. W. (2015). Ketamine Safety and Tolerability in Clinical Trials for TreatmentResistant Depression. The Journal of Clinical Psychiatry, 76(03), 247-252. https://doi.org/10.4088/JCP.13m08852

Wang, W., Liu, L., Yang, X., Gao, H., Tang, Q. K., Yin, L. Y., ... Gao, C. (2019). Ketamine improved depressive-like behaviors via hippocampal glucocorticoid receptor in chronic stress induced- susceptible mice. Behavioural Brain Research, 364, 75-84. https://doi.org/10.1016/j.bbr.2019.01.057

Warden, D., Rush, A. J., Trivedi, M. H., Fava, M., \& Wisniewski, S. R. (2007). The STAR*D Project Results: A Comprehensive Review of Findings. Retrieved from http://www.stard.org

Wardenaar, K. J., Vreeburg, S. A., Van Veen, T., Giltay, E. J., Veen, G., Penninx, B. W. J. H., \& Zitman, F. G. (2011). Dimensions of depression and anxiety and the hypothalamo-pituitaryadrenal axis. Biological Psychiatry, 69(4), 366-373. https://doi.org/10.1016/j.biopsych.2010.09.005

Weiner, A. L., Vieira, L., McKay, C. A., \& Bayer, M. J. (2000). Ketamine abusers presenting to the Emergency Department: A case series. Journal of Emergency Medicine, 18(4), 447451. https://doi.org/10.1016/S0736-4679(00)00162-1

Więdłocha, M., Marcinowicz, P., Krupa, R., Janoska-Jaździk, M., Janus, M., Dębowska, W., ... Szulc, A. (2018, January 3). Effect of antidepressant treatment on peripheral inflammation markers - A meta-analysis. Progress in Neuro-Psychopharmacology and Biological Psychiatry. Elsevier Inc. https://doi.org/10.1016/j.pnpbp.2017.04.026

Wilkinson, S. T., Ballard, E. D., Bloch, M. H., Mathew, S. J., Murrough, J. W., Feder, A., ... Sanacora, G. (2018). The effect of a single dose of intravenous ketamine on suicidal ideation: A systematic review and individual participant data meta-analysis. In American 
Journal of Psychiatry (Vol. 175, pp. 150-158). American Psychiatric Association. https://doi.org/10.1176/appi.ajp.2017.17040472

Wilkinson, S. T., Katz, R. B., Toprak, M., Webler, R., Ostroff, R. B., \& Sanacora, G. (2018). Acute and longer-term outcomes using ketamine as a clinical treatment at the yale psychiatric hospital. Journal of Clinical Psychiatry, 79(4). https://doi.org/10.4088/JCP.17m11731

Wong, D. T., Horng, J. S., Bymaster, F. P., Hauser, K. L., \& Molloy, B. B. (1974). A selective inhibitor of serotonin uptake: Lilly 110140, 3-(p-Trifluoromethylphenoxy)-n-methyl-3phenylpropylamine. Life Sciences, 15(3), 471-479. https://doi.org/10.1016/00243205(74)90345-2

Wong, M. L., Kling, M. A., Munson, P. J., Listwak, S., Licinio, J., Prolo, P., ... Gold, P. W. (2000). Pronounced and sustained central hypernoradrenergic function in major depression with melancholic features: Relation to hypercortisolism and corticotropin-releasing hormone. Proceedings of the National Academy of Sciences of the United States of America, 97(1), 325-330. https://doi.org/10.1073/pnas.97.1.325

World Health Organization. (2004). ICD-10 : international statistical classification of diseases and related health problems (2nd ed., Vol. 10). Geneva. Retrieved from https://catalogue.nla.gov.au/Record/3454953

World Health Organization. (2019, September 2). Suicide. Retrieved July 22, 2020, from https://www.who.int/news-room/fact-sheets/detail/suicide

World Health Organization. (2020, January 30). Depression. Retrieved July 21, 2020, from https://www.who.int/news-room/fact-sheets/detail/depression

Wüst, S., Wolf, J., Hellhammer, D. H., Federenko, I., Schommer, N., \& Kirschbaum, C. (2000). The cortisol awakening response - normal values and confounds. Noise \& Health, 2(7), 7988. Retrieved from http://www.ncbi.nlm.nih.gov/pubmed/12689474

Yang, C., Wardenaar, K. J., Bosker, F. J., Li, J., \& Schoevers, R. A. (2019, October 1). Inflammatory markers and treatment outcome in treatment resistant depression: A systematic review. Journal of Affective Disorders. Elsevier B.V. https://doi.org/10.1016/j.jad.2019.07.045

Yang, J., Wang, N., Yang, C., Shi, J., Yu, H., \& Hashimoto, K. (2015). Serum Interleukin-6 Is a Predictive Biomarker for Ketamine's Antidepressant Effect in Treatment-Resistant Patients With Major Depression. Biological Psychiatry, 77(3), e19-e20. https://doi.org/10.1016/j.biopsych.2014.06.021

Zarate, C. A., Brutsche, N., Laje, G., Luckenbaugh, D. A., Venkata, S. L. V., Ramamoorthy, A., ... Wainer, I. W. (2012). Relationship of ketamine's plasma metabolites with response, diagnosis, and side effects in major depression. Biological Psychiatry, 72(4), 331-338. https://doi.org/10.1016/j.biopsych.2012.03.004

Zarate, C. A., Singh, J. B., Carlson, P. J., Brutsche, N. E., Ameli, R., Luckenbaugh, D. A., ... Manji, H. K. (2006). A randomized trial of an N-methyl-D-aspartate antagonist in treatment-resistant major depression. Archives of General Psychiatry, 63(8), 856-864. https://doi.org/10.1001/archpsyc.63.8.856

Zhan, Y., Zhou, Y., Zheng, W., Liu, W., Wang, C., Lan, X., ... Ning, Y. (2020). Alterations of multiple peripheral inflammatory cytokine levels after repeated ketamine infusions in major depressive disorder. Translational Psychiatry, 10(1), 1-9. https://doi.org/10.1038/s41398020-00933-Z

Zhang, Y., Liu, J., Liu, Y., Lu, W., \& Hou, A. (2020). Salivary cortisol concentrations in police 
officers - A cross-sectional study in Beijing, China. Bioscience Reports, 40(4). https://doi.org/10.1042/BSR20193406

Zheng, W., Zhou, Y. L., Liu, W. J., Wang, C. Y., Zhan, Y. N., Li, H. Q., .. Ning, Y. P. (2018). Rapid and longer-term antidepressant effects of repeated-dose intravenous ketamine for patients with unipolar and bipolar depression. Journal of Psychiatric Research, 106, 61-68. https://doi.org/10.1016/j.jpsychires.2018.09.013

Zheng, W., Zhou, Y. L., Liu, W. J., Wang, C. Y., Zhan, Y. N., Li, H. Q., .. Ning, Y. P. (2019). Neurocognitive performance and repeated-dose intravenous ketamine in major depressive disorder. Journal of Affective Disorders, 246, 241-247. https://doi.org/10.1016/j.jad.2018.12.005

Zhou, J.-J., Gao, Y., Zhang, X., Kosten, T. A., \& Li, D.-P. (2018). Enhanced Hypothalamic NMDA Receptor Activity Contributes to Hyperactivity of HPA Axis in Chronic Stress in Male Rats. Endocrinology, 159(3), 1537-1546. https://doi.org/10.1210/en.2017-03176

Ziegler, D. R., Cullinan, W. E., \& Herman, J. P. (2005). Organization and regulation of paraventricular nucleus glutamate signaling systems: N-methyl-D-aspartate receptors. Journal of Comparative Neurology, 484(1), 43-56. https://doi.org/10.1002/cne.20445

Zukin, S. R., \& Zukin, R. S. (1979). Specific [3H]phencyclidine binding in rat central nervous system. Proceedings of the National Academy of Sciences of the United States of America, 76(10), 5372-5376. https://doi.org/10.1073/pnas.76.10.5372 